\title{
Regional integration processes: Four studies about convergence, growth and monitoring tools
}

\section{Dissertation}

zur Erlangung des wirtschaftswissenschaftlichen Doktorgrades der Wirtschaftswissenschaftlichen Fakultät der Universität Göttingen

\author{
vorgelegt von \\ Yvonne Sperlich, geb. Treichel \\ aus Chemnitz, \\ Göttingen Juni 2010
}


Erstgutachter: Prof. Dr. Michael Grimm, Erasmus University Rotterdam

Zweitgutachter: Prof. Dr. Walter Zucchini, Universität Göttingen

Tag der mündlichen Prüfung: 17.06.2010 


\section{Acknowledgement}

I am grateful to my supervisor, Michael Grimm, for his important comments and supporting as well as friendly cooperation. My special thanks go to Walter Zucchini and to Inmaculada Martinez-Zarzoso for their valuable help and encouragement as well as their patience. I thank very much my co-author Stefan Sperlich for all his invaluable ideas and his motivation. I thank Stephan Klasen, which offers me to work on his chair almost the whole $\mathrm{PhD}$ period and gives me equipment for work on my dissertation. Besides I thank all my colleagues for the friendly cooperation and practical help. I thank Geraldine Krause for proof-reading; Ricardo Mora for his valuable comments and my office mates for good talks.

Lastly, I would like to thank my family and my close friends for their loving supporting and patience; without them I had never finish this work. 


\section{Contents}

List of Figures

List of Tables

Introduction and Overview

1. The regional integration process in South-South agreement areas: Growth and convergence........................................................ 12

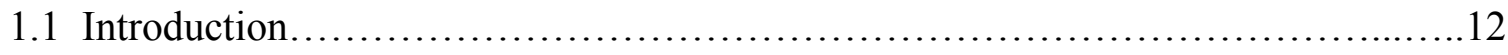

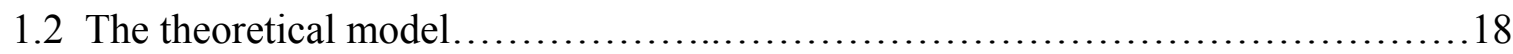

1.3 The South-South Integration areas, data and estimation issues....................24

1.4 The empirical analysis................................................... 31

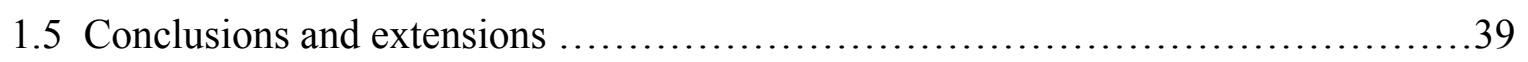

2. Income dispersion and sigma convergence in South-South agreement areas...........41

2.1 Introduction................................................................ 41

2.2 Methodology and data................................................... 45

2.3 Discussion of per capita growth.......................................... 48

2.4 Empirical results of sigma convergence....................................53

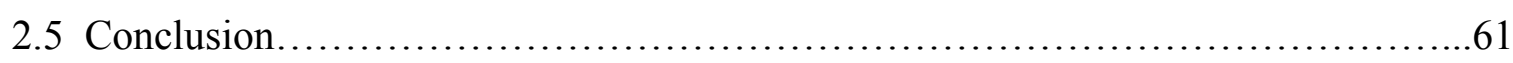

3. A note on "speed of convergence" in regional integration areas....................64

3.1 Introduction...........................................................64

3.2 Econometric Framework...................................................66



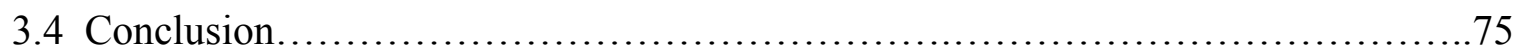

4. Practical tools for monitoring similarity and development with an application to integration processes................................................... 77

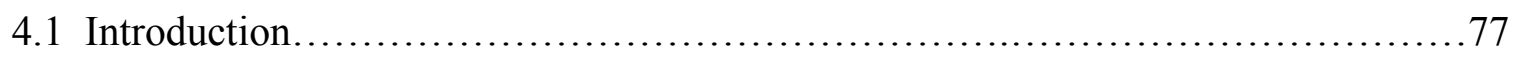

4.2 A brief review........................................................ 79

4.3 Conceptual framework, variable selection and methods..........................85

4.4 Integration in North-North; South-South and North-South Agreements: A comparison study on convergence to equality and development............................91

4.5 Conclusions and final remarks .......................................... 101 


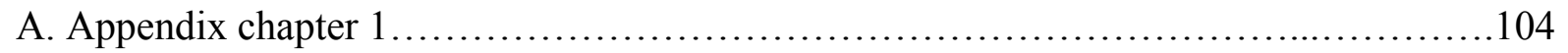

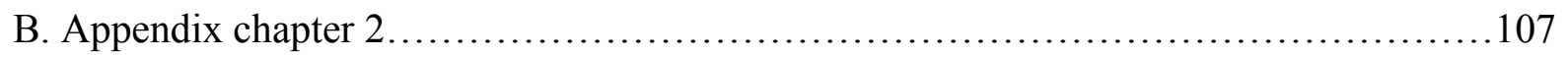

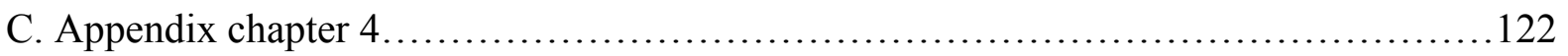

Bibliography............................................................. 131

Letter of affidavit 


\section{List of Tables}

1.1 Unconditional convergence and growth tests for Latin America, 1985-2002............32

1.2 Unconditional convergence and growth tests for East Asia, 1975-2002 .................33

1.3a Unconditional convergence and growth tests for West- /Central Africa, 1975-2002 _.....34

1.3b Unconditional convergence and growth tests for West- /Central Africa, 1975-2002 ......34

1.4 Conditional convergence Latin America, 1985-2002 ............................. 35

1.5a Conditional convergence East Asia, 1975-2002 ...................................36

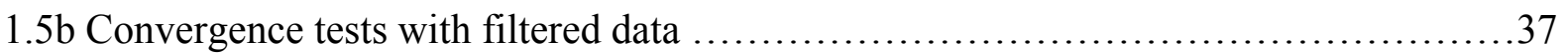

1.6a Conditional convergence West- and Central Africa, 1975-2002 _.....................38

1.6b Conditional convergence West- and Central Africa, 1975-2002 ....................38

1.6c Conditional convergence West- and Central Africa, 1975-2002 .......................39



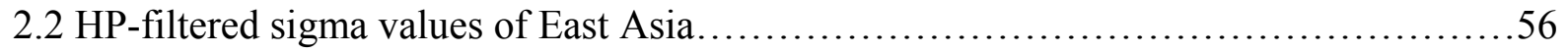

2.3 HP-filtered sigma values of West- and Central Africa................................58

3.1 Estimated results of speed of convergence in Latin America......................... 70

3.2a Estimated results of speed of convergence in East Asia.............................71

3.2b Speed of convergence in East Asia - filtered (corrected for Asia crisis) ................72

3.3 Estimated results of speed of convergence in West- and Central Africa..................74

4.1 Distance indices I.4 and I.2; RIAs in alphabetic order............................93

4.2 IRV for the NAFTA (reference method, unweighted)............................ 96

4.3 IRV for the NAFTA (reference method, weighted)............................. 96

4.4 IRV for the WAEMU (reference method, unweighted).........................97

4.5 IRV for the WAEMU (reference method, weighted)............................97

4.6 IRV for the ANZCER (reference method, unweighted) ........................... 98

4.7 IRV for the ANZCER (reference method, weighted) ..............................99

4.8 IRV for the EU-15 (reference method, unweighted)..............................99

4.9 IRV for the EU-15 (reference method, weighted) ............................ 100 


\section{List of Figures}



2.2. HP-filtered sigma trends in East Asia..........................................57

2.3 HP-filtered sigma trends in West- and Central Africa...............................59

4.1 RIAs in comparison along distance index I.4.................................94

4.2 RIAs in comparison along distance index I.2 .................................95






\section{Introduction and Overview}

Since the end of the Cold War the world experiences a new enormous regionalization movement. Today, according to the World Trade Organization (WTO), more than hundred and fifty free trade and partnership agreements exist, among them several so called SouthSouth agreements based on the Enabling clauses, Article 29. In the 1950s and the 1960s there already existed several regional integration initiatives around the world, but at that time most of these regionalization efforts showed little success.

Before we briefly summarize the research issues and some findings of our four papers (chapters) of this dissertation, we sketch some of the main reasons for the current regional integration efforts (regionalization) and discuss presumable keys to their success. For this purpose we first describe some characteristics of the so called new regionalization following Ethier (1998): First, the members of an integration area are geographical neighbours. Second, most of the agreements founded after the end of the Cold War are based on the target of "deeper integration". That is, trade liberalization is not the main focus of these contracts any more, but has be accomplished by targets like the harmonization and cooperation in several economic respects, social and technology policies, etc. Third, the projected liberalization and cooperation goals are now much more moderate, because the radical liberalization goals of the 1950s and 60s failed. Ethier (1998) mentions one further characteristic, which is still disputed: his hypothesis says that regional integration areas (RIA) always involve one or more (economically) small countries and at least one large partner country. For example, the NAFTA consists of an economically small country (Mexico) and at least a large partner, in this case the USA. However, this part of regional integration theory can only explain NorthSouth RIAs. South-South, as well as North-North agreements, do not necessarily have both a large leader and several small partners, even if - of course - in all RIAs there exist differences in economic size.

It is well known that the main reasons for the new regionalization movement are the following: After the end of the Cold War the world organized newly itself from the twoblock formation to geographical localization and global competition. This was especially important for developing countries. From now on they could focus on the own development process. On the other hand, however, the solution of problems at multilateral level stagnated 
(think e.g. of the WTO Doha round). Finally, with the increasing globalization today, it is even more obvious that national states are not able to solve problems of security, energy and economic politics on their own. Therefore, many countries have become members in regional cooperation areas, often in several.

Borrmann (1997) itemizes several factors of success for regional integration. Welfare gains are higher (a) the less latent conflicts exist within a region; (b) the more stable regulative policy framework is given among the members; (c) the larger the geographical, spatial, and cultural proximity is; and (d) the larger the integration area is.

Before going more into detail, let us first give a theoretical definition of regional integration to work with. Note that regional integration theory is still in its infancy. Until now, we can not find any clear definition of regional integration; all explanation approaches are based on a mixture of models and assumptions from growth, trade, labour market, and political economy theories. Therefore, for this thesis we have opted for the following definition of regional integration: "Regional integration is accordingly an empirically observable, intensifying process of increasing gross-border political, economic and social activities, cooperation and coordination (based on formal treaties) within a geographical region” (Ziltener, 2003).

Within the regional integration theory, being a still young research field, the following fundamental questions are discussed strongly: Do South-South agreements promote or hinder the development of members? Are RIAs stepping stones for multilateral integration or stumbling stones on the way to a successfully globalizing world? How can we construct a monitoring tool in order to observe the performance of RIAs? Concerning the second question we refer to the essays of Baldwin (2004) and Bhagwati et al. (1998). We concentrate in this dissertation on the first and third question.

Since the mid-1990s there have been coming up several articles in the literature about possible unfavourable impacts of regional agreements among low (and lower middle) income countries, i.e. the so-called South-South agreements (for some general discussion see, for example, Venables, 2003). The scientific recommendations target at forcing multilateral liberalization and cooperation as the possibly best solution for all countries, in particular for the developing countries (cf. de Melo and Panagariya, 1993). Since there seems to be hardly any significant progresses at multilateral level, one often recommends so called hub- and 
spoke agreements for developing countries (also called North-South RIAs). Note that we do not favour one over the other but rather think that all kind of regional integration agreements have their eligibility and their particular function.

The first essay of this dissertation, based on joint work with Stefan Sperlich, adds to this research debate and investigates whether South-South integration areas such as ASEAN (Association of South-East Asian Nations) help to improve income growth and convergence among member states. In order to test this hypothesis we consider all three world regions in question: West Africa, East Asia and Latin America. In order to do so we use panel data analysis limiting ourselves to the period starting at the beginning of the particular formal integration processes until 2002. We use different modifications of the Human Capital Augmented (HCA) Solow model, and in particular panel data estimation like GLS fixed regression, IV-panels and unbalanced panel regression. The theoretical economic and econometric models applied in our study are derived and worked out in detail. We find that in all regions, and for all studied models, membership in one of the South-South-Agreements shows a positive impact on income convergence and growth. This is in clear contradiction to many (mostly unproved) statements in the literature.

Our second essay discusses the criticism of the new trade and economic geography theory regarding to these South-South-agreements. Main criticisms are that they would lead to increasing income disparity by similar production structures, agglomeration and trade diversion at the expense of the poorest regions. Our study is intended to contribute to this discussion by means of an empirical analysis of a representative set of typical South-South regional integration areas from all world regions. More specifically, we first describe the following selected integration areas: ASEAN, WAEMU, CEMAC, ECOWAS, ANDEAN and MERCOSUR. For all member countries, we examine their income development and afterwards calculate their sigma convergence (defined and discussed there in detail) of each area. In this context we briefly discuss the concept of sigma convergence compared to that of beta convergence in the context of the classical Solow model. The results show that there may be sigma convergence in some areas, but in general, the sigma (i.e. the per capita income dispersion) is not decreasing but rather increasing. However, even when we correct for possible business cycle effects in a rather generous way (i.e. assuming a quite smooth trend), the sigma path is hardly ever monotone. These results are compared to other papers, especially to those on beta-convergence for the same integration areas. 
In the third essay we calculate and compare the speed of convergence for different regional integration areas. Again, we concentrate on the following sample of (so-called South-South) integration areas: ASEAN, WAEMU, CEMAC, ECOWAS, and MERCOSUR. First we study which of these areas converge faster, together with the probably more interesting question whether they converge indeed faster than non-integrated areas. Second, in order to check for robustness against model specification, the resulting outcomes are compared along various models, for example the unrestricted and the restricted human capital augmented Solow model. Our results reveal that members of RIAs converge much faster than the particular whole regions, whereby the adjustment speeds of RIAs are rather different. Finally, we show that the absolute (in contrast to the relative) information value of the country-specific speed of convergence is basically nil and should therefore not be interpreted.

The fourth essay, also based on joint work with Stefan Sperlich, introduces entirely new indices as practical tools to monitor integration, globalization or development. It is generally believed that an adequate set of indices can serve as a useful tool for monitoring economic processes and developments like (regional) integration, measuring and comparing performance, e.g. for policy evaluation. To this aim, statistical offices all over the world prepare several hundreds of such indicators every year. For example South Africa alone compiles about 350 indicators to monitor their sustainable development targets. This article introduces entirely new indices as practical tools to monitor integration, globalization or development. The main focus is on multidimensionality, feasibility, universality and comparability. Consequently, this indicator system is easily implemented and universally applicable; e.g. it applies equally well to North-North, North-South or South-South agreements. We test our indices by monitoring and comparing the following integration areas: WAEMU (representing so-called South-South areas), NAFTA (representing North-South areas), ANZCERTA and the EU-15 (two kinds of North-North areas) over the period 1980 to 2007, and 1990 to 2007 respectively. Thereby, to avoid biases caused by gaps between integration or development targets compared to real transformation and implementation, we restrict the empirical study to outcome-oriented monitoring, i.e. only variables that describe measurable real effects are considered.

Summarizing, we can say that the four empirical essays of this dissertation add to the current debate about the impact and importance of regional integration areas - in particular for developing countries - over the last decades. In chapter 1 we show that all selected South- 
South RIAs have beta convergence. RIA-memberships have a positive impact on per capita income growth. The next chapter shows increasing income dispersion in almost all RIAs - at least over the observation period, resulting in sigma divergence in these South-South RIAs (except for the WAEMU). In chapter 3 it is pointed out that the speed of convergence is higher for RIAs than the in the literature typically mentioned benchmark of $2 \%$. But we have to be careful with interpreting the calculated values in absolute terms. In chapter 4 we construct two monitoring index approaches: a similarity index and a development index for all kind of RIAs.

Summarizing, this dissertation studies the question whether South-South RIAs promote or rather hinder the development of their member states. We show that South-South RIAs have a positive impact on beta convergence and income growth. But at the same time we observe an increase of inequality of incomes for the considered period, i.e. the dispersion of income rises. The results of chapter 4 (IRV-index) present answers on the entire development as RIApartners. For example, the subindex for the political category shows clear improvements after the foundation of RIAs (above all in the South-South agreement WAEMU). 


\section{CHAPTER 1:}

\section{The Regional Integration Process in South-South-Agreement Areas: Growth and Convergence}

\subsection{Introduction}

This paper is intended to contribute to the controversial discussion on the so called SouthSouth-Agreements regarding income convergence and growth. The discussion is based on mainly three arguments. First, there is the well known general criticism against regional integration agreements, which says that the agreements lead to trade creation but also to trade diversion (Viner, 1950). Whether trade creation exceeds trade diversion (and thus gives positive welfare effects) depends on two points: from the trade share of the regional integration area and from the share of intra-regional trade. Second, regional agreements including the South-South-agreements considered here- are often characterized by different parallel and overlapping agreements which typically favour the economically strongest members and also hinder real (trade) liberalization rather than promote it (Bhagwati, Greenaway, and Panagariya, 1998). Finally, a criticism specifically directed towards the so called South-South-Agreements is the "poor stays poor" argument, saying that since convergence in regional integration areas is mainly caused by knowledge- and technology transfer, by stronger stress of competition and by efficient compensation mechanisms etc., success can only be guaranteed if strong economic regional leaders participate (cf. for example Quah 1993a). Note that empirical studies show that the correlation between per capita growth and the initial income is close to zero in world-wide samples (e. g. Barro 1991). Also Baumol (1986) tested the hypothesis of unconditional convergence in the Maddison sample over the long-run period 1870-1979. While his test outcomes indicated different groups of convergence, the so-called convergence clubs, he claimed that the developments diverge world-wide. However, due to the strong limitations of the used sample - at least over that period - many of his empirical results remain not that informative.

Partly in contrast to the neoclassical growth theory, the new integration- and so-called new economic geography theory suggest explanatory models which implicate - at least in the short 
and medium term - divergence for regional integration areas; see Krugman (1991a, 1991b) for an earlier example and Baldwin, Martin and Ottaviano (2001) or Scott (2006a) for more recent examples. Krugman (1991a, 1991b) shows that economic integration processes induce agglomeration; especially if at the initial state the industrial development (and thus industrial centres) is unequally distributed. The liberalization coming along with the regional integration then leads to a further concentration of economic activities; see also Krugman and Venables (1996). Relevant parameters for the agglomeration tendencies in these economic geography models are increasing returns to scale in the industrial sector, decreasing transport costs over time, and boosting urban centripetal forces (localization economies). Following Goodfriend and McDermott (1998), the key factor of convergence processes is the openness to foreign ideas and technologies. Consequently, a closed regionalism between developing countries must cause divergence due to the lack of new technology and ability of innovation. Giannetti (2002) adds that the intensified knowledge spill over in integration areas entails the risk of income divergence as different economic areas do not benefit uniformly from the knowledge exchange; in particular low developed agricultural areas do not. Finally, Venables (2003) argues with the theory of comparative price advantages; his model theoretical study exhibits income divergence for integration agreements among low-income countries owing to concentration processes of the manufacturing industry into countries with intermediate comparative advantage.

It would be asking too much to argue in favour of or against all the statements given above. In this paper we therefore concentrate on the more general but basic question of income convergence in the Southern regions. At the same time, to counter the argument that convergence is not enough (poor stays poor), we also study the question whether regional integration areas (RIAs henceforth) push growth or not, and to what extent. In order to do so we consider some of the so-called South-South RIAs: MERCOSUR, ASEAN, and ECOWAS $^{1}$ (Economic Community of West African States) plus WAEMU ${ }^{2}$ (West African Economic and Monetary Union) because of overlapping memberships in this area. A detailed description and a brief discussion of this RIA-set is given in Section 1.3. We also account for the states in this area during the time they were non-members performing thereby a natural (counterfactual) experiment to obtain a real ceteris paribus interpretation. To our knowledge,

\footnotetext{
${ }^{1}$ ECOWAS: Benin, Burkina Faso, Cape Verde, Cote d'Ivoire, Gambia, Ghana, Guinea Bissau, Guinea, Liberia, Mali, Mauritania (until 2001), Niger, Nigeria, Senegal, and Togo.

${ }^{2}$ WAEMU: Benin, Burkina Faso, Cote d'Ivoire, Guinea Bissau, Mali, Niger, Senegal, and Togo.
} 
this study is the first to do so. A simple comparison of members versus non-members would not work due to obvious selection bias problems. Using panel data from the period of the beginning of each of the particular integration processes until 2002, we aim to test whether or not these areas experienced income convergence and whether membership did add positively to this convergence.

Although we concentrate here only on the Southern regions, we are aware of the importance of their catching-up to the word-wide economic leaders, and of multilateral liberalization. An argument in favour of studying first the regional agreements (or areas) for low and middle income countries is the gradual opening (trade liberalization), and the solving of intraregional problems; see discussion below. In other words, we understand the South-SouthAgreements only as a first step, actually as the stepping stone, to reach an international ability to compete, to gain access to technology transfers, etc., but we want to assess empirically if this is a forward or a backward step. As the main focus is growth and convergence, we consider only the per capita income. We are not interested in progresses of deeper integration processes of each region as e.g. an increase of intra-regional political institutions. In this study we are interested in the development of income in RIAs, not in the specific integrative stages.

The literature on income convergence and growth is abundant, even if it only concentrates on the most relevant. For example, there are many convergence analyses on special regional integration areas such as MERCOSUR ${ }^{3}$ (Mercado Común del Sur) or on continents like Africa, see Madariaga, Montout, and Ollivaud (2003), Tsangarides (2005) and Camarero, Flôres, and Tamarit (2003) for most recent contributions; for world-wide samples we refer to Mankiw, Romer and Weil (1992), Barro (1991), Sala-i-Martin (1996a), and Lee and Pearsan (1997), to mention only the most relevant and most cited contributions. What they have in common with our study is the question: Do poor countries grow faster than richer countries in the long-run, and finally attain a catching-up? While some papers ask this question in general, others concentrate on particular integration or agreement areas - like we do. In contrast to them, we consider all relevant South-South-Agreements, carefully differentiating between membership and non-membership, and fix the testing period along the real commencements of contracts more carefully than all previous studies.

\footnotetext{
${ }^{3}$ MERCOSUR: Argentina, Brazil, Uruguay, and Paraguay. Venezuela is full member since 2006. Associated members are Peru (2003), Chile (1996), Bolivia (1997), Ecuador (2004) and Colombia (2004).
} 
Still quite recently, the convergence debate has been attracting increasing attention in the integration theory. This might partly be due to the fact that during the last decade, the empirical methods to test convergence became reasonably well developed (cf. abovementioned papers but also Islam (1995) and Lee, Pesaran and Smith (1998) as milestones for panel data analysis in this context, and Bernard and Durlauf (1995) for time series methods (though, not looking for $\beta$ convergence). Today, the integration theory assumes that formation of regional integration areas promotes the increase of welfare as well as the catching up to regional economic leaders. At the same time it stimulates the seemingly unrelated solving of trans-national problems, like environmental pollution and the reduction of extreme poverty (see e.g. the "pact of convergence, stability, growth and solidarity" of WAEMU in 1999), but that it also supports the extension of bargaining power at multilateral level for developing countries. As already mentioned, we are mainly interested in the effect of regional integration in southern areas concentrating on the goal of per capita income growth and convergence. To this aim we will apply the (augmented neoclassical) Solow model; see Solow $(1956,1957)$ and Mankiw, Romer and Weil (1992).

Some discussion about the ECOWAS is given in Jones (2002). He used cross sectional unconditional, also called absolute $\beta$ convergence and time series methods (cf. Bernard and Durlauf, 1995), and finds beta-convergence over the period 1960-1990. For the CFA franc zone (basically WAEMU plus CEMAC ${ }^{4}$ ) Fielding and Shields (2004) investigated whether monetary unions augment the extent of macroeconomic integration. While they identified a positive impact on intra-regional trade, the effect of business cycle synchronicity was found to decline over time. They argued that this was because of both the lack of a common central bank and of coordination of economic policies. Based on their studies, we also include the countries of the whole CFA-zone.

A recent study of integration processes in this region is from Hammouda, Karingi, Njuguna, and Jallab (2007). Their hypothesis is that regional integration does not improve income convergence in Africa. First they show empirically that all three areas, COMESA ${ }^{5}, \mathrm{SADC}^{6}$,

\footnotetext{
${ }^{4}$ CEMAC: "Economic and Monetary Community of Central Africa"; members: Cameroon, Central African Republic, Chad, Rep. Congo, Equatorial Guinea, Gabon.

${ }^{5}$ COMESA (Common Market for Eastern and Southern Africa): Angola, Burundi, Comoros, DR Congo, Djibouti, Egypt, Eritrea, Ethiopia, Kenya, Madagascar, Malawi, Mauritius, Namibia, Rwanda, Seychelles, Sudan, Swaziland, Uganda, Zambia, and Zimbabwe.

${ }^{6}$ SADC (Southern African Development Community): Angola, Botswana, DR Congo, Lesotho, Madagascar, Malawi, Mauritius, Mozambique, Namibia, South Africa, Swaziland, Tanzania, Zambia, and Zimbabwe.
} 
and ECOWAS have quite low unconditional and conditional convergence and conclude that there was little progress in the African integration processes. Interestingly, they fail in answering their own question: "Why doesn't regional integration improve income convergence in Africa?" They tell us only that in African RIAs the convergence rate is low. A possible explanation is that the members of South-South-RIAs are prevailing low and lowermiddle income states. We expect low convergence rates, because of the lack of intra-regional trade activities, small growth rates of total factor productivity (TFP), and fundamental lack in economic and social infrastructure (cf. Wane 2004). Even if one member has an economic boom period, then positive developing effects to the RIA-partners hardly transfer. This does not answer the question, whether membership in integration agreements matters or not. Here, more sophisticated studies are necessary.

For Latin America, the other world region of interest, a quite recent study has been performed by Madariaga, Montout, and Ollivaud (2003). They introduced and tested for various types of convergence, including conditional and unconditional $\beta$ convergence, in the MERCOSUR and NAFTA. Unfortunately they analyze the integration processes only along the pair-wise comparison of the economic leaders, namely Mexico and United States for the NAFTA, and Argentina and Brazil for the MERCOSUR. In their study MERCOSUR shows strong convergence in the period 1985-1991 with a serious slow down thereafter. However, MERCOSUR was only founded in 1991. Possible explanations for the slow down are the devaluation of the Real in Brazil and the recession in Argentina at the end of the nineties. In this paper we investigate whether all founding members converge and maybe even all associated countries. In other words: does participation in this RIA matter? Recently, Camarero, Flôres, and Tamarit (2003) used time series methods to test the MERCOSUR states plus some associated members for long-run convergence. However, this finding was based on data over the period 1960-1999, i.e. including 31 years before the foundation of MERCOSUR. They found convergence between the smaller (as Paraguay) and the larger members (as Brazil).

Finally, for Asia we refer to some recent studies of Park (2000), Van Hoa (2003), and Lim and McAleer (2004). The first one investigated the whole region ASEAN $+5^{7}$ for the period from 1960 to 1995 . He tests convergence via a Theil-inequality index. While his total sample

\footnotetext{
${ }^{7}$ ASEAN +5 are an economic cooperation platform since 1997 and include the ASEAN states plus Japan, South Korea, the VR China as well as New Zealand and Australia.
} 
does not indicate convergences until 1995, excluding the non-open and non-market-oriented economies, in particular VR China, Vietnam, and Burma, he finds evidence for convergence in the sub-period 1975-1995 (like the other papers do). Again, the problem in our opinion is that this does not justify drawing conclusions with respect to RIAs, as the cooperation of ASEAN $+3^{8}$ was founded in 1997, and even if looking at $\mathrm{ASEAN}^{9}$, we have to realize that countries like, for example, Vietnam did not join ASEAN until 1995. So a particularity of this region is the late entry in RIAs of the non-open and non-market-orientated countries, and the network of bilateral agreements for economic cooperation since the end of the Cold War.

To conclude, none of these studies has either really identified the effect of RIAs on convergence, or made a world wide study of South-South-Agreements, or even discussed, for example, the duration of memberships or considered impacts of overlapping contracts. Recall that our contribution is focused on the question whether regional integration areas yield convergence. This hypothesis is tested in particular for the South-South-Agreement areas. In order to answer this question we will be the first to consider all three relevant integration areas: MERCOSUR, ASEAN, and West Africa (especially WAEMU but also ECOWAS and CEMAC). We further include in our study all countries of the corresponding geographical region distinguishing members from non-members (dynamically). We consider only years in which the agreements in question were valid, derive carefully the economic and econometric models, and present a detailed panel data analysis to substantiate our hypotheses.

The rest of the paper is organized as follows. In Section 1.2 we give a detailed derivation of the human capital augmented model (extended to panel data analysis) which will be used to test income convergence and growth in Section 1.4. Before doing so, we first give a brief description of the considered integration areas, introduce our data sets in Section 1.3, and discuss particularities in the estimation method, like problems of endogeneity, possible autocorrelation, heteroscedasticity, etc. Apart from the presentation of our empirical results and conclusions in Section 1.4, we briefly summarize these findings and discuss extensions in Section 1.5. Some tables and descriptive statistics are deferred to the Appendix A.

\footnotetext{
${ }^{8}$ ASEAN +3 is an economic cooperation platform since 1997 and include the ASEAN states plus Japan, South Korea, and the VR China.

${ }^{9}$ ASEAN: Indonesia, Malaysia, Thailand, Singapore, Philippines, Brunei (1984), Burma/Myanmar (1997), Vietnam (1995), Cambodia (1999), Laos (1997), and Papua New Guinea as associated state (1984).
} 


\subsection{The Theoretical Model}

We studied three panels with different modifications of the HCA Solow model concentrating on the $\beta$ convergence, not stressing the discussion about the most appropriate measure. Instead, we concentrated more on the identification of the above mentioned questions. Before we derive the theoretical model in order to test the convergence hypothesis in all three regions, we revise the definition of the per capita income convergence in general. We derive explicitly the panel model under consideration because we detected many confusing and erroneous (at least imprecise) versions and statements concerning the theoretical model.

The fundamental framework goes back to Solow (1956) and Swan (1956), Cass (1965) and Koopmans (1965), with the crucial assumption of diminishing return on capital in the neoclassical growth model. Poor countries have a higher marginal product of capital and tend to grow faster than richer countries, causing an inverse relationship between the initial level of income per capita and per capita growth rates. This theory is well established and has been extensively discussed. The so-called unconditional or absolute convergence is defined as follows: If countries are similar in their structural parameters related to preferences and technologies, then poor countries grow faster until they catch up to the richer ones. The hypothesis of conditional convergence extends this definition by including other factors that define the steady state of each country, like the level of technology, the propensity to save, or the population growth rate. The per capita incomes of countries converge to one another in the long-run, independently of their initial conditions, if their structural characteristics are similar. In other words, countries further away from their own steady state grow faster. Obviously, the two concepts of convergence coincide if all economies converge to the same steady state. For details see also Sala-i-Martin (1996a). We are aware of the controversy on convergence and divergence of growth rates, see Durlauf (1996), going back to the fact that the alternative endogenous growth models typically (depending on the parameter assumptions) do not allow for convergence.

Starting from the neoclassic Solow model we first consider the extension to the conditional income growth model à la Mankiw, Romer, and Weil (1992), which provides a good basis for our intra-regional convergence analysis. Then we follow ideas of Knight, Loayza, and Villanueva (1993), and Islam (1995) who extended these models for panel data analysis, compile the facts from these different papers, and complete them with some derivation steps. 
The starting point of the Solow model is the Cobb-Douglas production function at time $t$ :

$$
Y_{t}=K_{t}^{\alpha} H_{t}^{\beta}\left(A_{t} L_{t}\right)^{1-\alpha-\beta} \quad \text { with } 0<\alpha+\beta<1,
$$

where $Y$ is real output (i.e. income), $K$ is the stock of physical capital, $L$ is (raw) labour, $H$ is the stock of human capital, and $A$ is the level of technology (the labour augmenting factor). Note that the model assumes constant returns to scales and decreasing marginal returns for all production factors, necessary for the existence of a steady state and convergence. In the following we will work with $k=K / L$, the capital stock per capita, $y=Y / L$, output per capita, and saving rates for capital and human capital, denoted by $s_{K}$ and $s_{H}$, respectively. We know that the Solow model intends to explain the impact of saving and population growth on per capita income. Therefore it is assumed that technology and labour are growing with exogenous rates such that $L_{t}=L_{0} e^{n t}$ and $A_{t}=A_{0} P^{\theta}(t) e^{g t}$, where $n$ denotes the exogenous growth rate of the labour force, and $g$ the one of technological progress. Less typical is the inclusion of a variable $P$, which in our model, can be included optionally, and stands e.g. for openness of the domestic economy with $\theta$ being an unknown constant. This openness can refer e.g. to trade or technology transfer and, in our case, will be the way to control for membership (and/or years of membership) in a particular South-South-Agreement area.

A model for the income per capita is typically developed along the Cobb-Douglas model substituting the steady state intensities of human and real capital for the present ones as an approximation. To determine the steady state, we will briefly derive the human and real capital intensities. To simplify the notation we will always suppress the index $t$ in the formula and only include it if necessary. Let $k_{e}$ and $h_{e}$ denote effective real capital, and human capital intensities respectively. In per effective working units $y_{e}=Y / A L$ we can write $y_{e}=k_{e}^{\alpha} h_{e}^{\beta}$, and with (1) we get our first essential equation

$\ln y_{e}(t)=\ln y_{t}-\ln A_{0}-\theta \ln P(t)-g t$.

The growths rates of $h_{e}$ and $k_{e}$ result from differential equations as follows, where the savings $S_{K}$ are assumed to be exogenous, and $\delta_{K}$ denotes the depreciation rate of real capital:

$\frac{\dot{k}_{e}}{k_{e}}=\frac{\dot{K}}{K}-\frac{\dot{A}}{A}-\frac{\dot{L}}{L}=\frac{s_{K} Y-\delta_{K} K}{K}-g-n=\frac{s_{K} Y}{K}-\left(g+n+\delta_{K}\right)$

$\Leftrightarrow \frac{\dot{k_{e}}}{k_{e}}=s_{K} \frac{y_{e}}{k_{e}}-\left(g+n+\delta_{K}\right)=s_{K} k_{e}^{-(1-\alpha)} h_{e}^{\beta}-\left(n+g+\delta_{K}\right)$. 
In the same way we get

$$
\frac{\dot{h_{e}}}{h_{e}}=s_{H} k_{e}^{\alpha} h_{e}^{-(1-\beta)}-\left(g+n+\delta_{H}\right) \text {, }
$$

where the savings $s_{H}$ are assumed to be exogenous, and $\delta_{H}$ denotes the depreciation rate of human capital: Next we set (4) and (5) to zero and inserted one into the other, so that we ended with equations for two unknown quantities, namely $h_{e}$ and $k_{e}$ in each case.

In the long-run steady state equilibrium, we assume the constancy of human and real capital intensity. In order to show the formula of balanced income $y_{e} *$, we equate both capital intensity equations under the assumption of identical depreciation rates

$$
k_{e}^{*}=\left(\frac{s_{H}}{g+n+\delta_{H}}\right)^{\beta /(1-\alpha-\beta)}\left(\frac{s_{K}}{g+n+\delta_{K}}\right)^{(1-\beta) /(1-\alpha-\beta)}=\left(\frac{s_{K}{ }^{1-\beta} s_{H}{ }^{\beta}}{n+g+\delta}\right)^{1 /(1-\alpha-\beta)},
$$

assuming $\delta_{H}=\delta_{K}=\delta$. Analogously we get for human capital:

$$
h_{e}^{*}=\left(\frac{s_{K}{ }^{\alpha} s_{H}{ }^{1-\alpha}}{n+g+\delta}\right)^{1 /(1-\alpha-\beta)} .
$$

The substituting of (6a) and (6b) in equation (2) leads to

$$
y_{e}^{*}=\left(\frac{s_{K}{ }^{\alpha} s_{H}{ }^{\beta}}{(n+g+\delta)^{\alpha+\beta}}\right)^{1 /(1-\alpha-\beta)} \text {. }
$$

Summarizing, the per capita steady state output is therefore

$$
\ln y_{e}^{*}=\frac{\alpha}{1-\alpha-\beta} \ln s_{K}+\frac{\beta}{1-\alpha-\beta} \ln s_{H}-\frac{\alpha+\beta}{1-\alpha-\beta} \ln (n+g+\delta) \text {. }
$$

Next, we determine the transitional dynamics over the changes of capital intensities, i.e.

$$
\begin{aligned}
& \frac{\dot{k}_{e}}{k_{e}} \equiv \Phi\left(k_{e}, h_{e}\right)=\frac{s_{K} k_{e}{ }^{\alpha} h_{e}^{\beta}}{k_{e}}-\left(n+g+\delta_{K}\right) \cong \Phi\left(k_{e}{ }^{*}, h_{e}{ }^{*}\right)+\Phi_{k_{e}{ }^{*}}\left(k_{e}{ }^{*}, h_{e}{ }^{*}\right)\left(k_{e}-k_{e}{ }^{*}\right) \\
& +\Phi_{h_{e}{ }^{*}}\left(k_{e}{ }^{*}, h_{e}{ }^{*}\right)\left(h_{e}-h_{e}{ }^{*}\right)
\end{aligned}
$$

Because the effective capital intensity is in the place of $k_{e}{ }^{*}, h_{e}{ }^{*}$, the steady state, constant, we resume $\Phi\left(k_{e}{ }^{*}, h_{e}{ }^{*}\right)=0$. The partial derivatives are

$$
\Phi_{k_{e} *}\left(k_{e}^{*}, h_{e}^{*}\right)=s_{K}(\alpha-1) k_{e}{ }^{* \alpha-1} h_{e}{ }^{* \beta} / k_{e}^{*} \text {, and } \Phi_{h_{e}{ }^{*}}\left(k_{e}^{*}, h_{e}{ }^{*}\right)=s_{K} \beta k_{e}{ }^{* \alpha} h_{e}{ }^{* \beta-1} / k_{e}{ }^{*} \text {. }
$$

Inserting this in (9) gives: 


$$
\begin{aligned}
& \frac{\dot{k}_{e}}{k_{e}} \cong \frac{s_{K}(\alpha-1) k_{e}^{* \alpha-1} h_{e}^{* \beta}}{k_{e}^{*}}\left(k_{e}-k_{e}^{*}\right)+\frac{s_{K} \beta k_{e}^{* \alpha} h_{e}^{* \beta-1}}{k_{e}^{*}}\left(h_{e}-h_{e}^{*}\right)= \\
& (\alpha-1) \frac{s_{K} k_{e}^{* \alpha} h_{e}^{* \beta}}{k_{e}^{*}} \frac{\left(k_{e}-k_{e}^{*}\right)}{k_{e}^{*}}+\frac{s_{K} \beta k_{e}{ }^{* \alpha} h_{e}^{* \beta}}{k_{e}^{*}} \frac{\left(h_{e}-h_{e}^{*}\right)}{h_{e}^{*}}
\end{aligned}
$$

In the steady state, $\frac{s_{K} k_{e}{ }^{\alpha} h_{e}{ }^{\beta}}{k_{e}{ }^{*}}$ is equal to $\left(g+n+\delta_{K}\right)$. Then, for $k_{e}$ close to $k_{e}{ }^{*}$ and $\mathrm{h}_{\mathrm{e}}$ close to $h_{e} *$ we can approximate (11) by

$$
\begin{aligned}
& \frac{\dot{k}_{e}}{k_{e}} \cong(\alpha-1)\left(n+g+\delta_{K}\right) \ln \left(k_{e} / k_{e}^{*}\right)+\beta\left(n+g+\delta_{K}\right) \ln \left(h_{e} / h_{e}{ }^{*}\right) \\
& \Leftrightarrow \frac{\dot{k}_{e}}{k_{e}} \cong\left(g+n+\delta_{K}\right)\left[(\alpha-1) \ln \left(k_{e} / k_{e}^{*}\right)+\beta \ln \left(h_{e} / h_{e}{ }^{*}\right)\right]
\end{aligned}
$$

Analogously for the growth rates of effective human capital intensity we obtain

$$
\frac{\dot{h}_{e}}{h_{e}}=\left(n+g+\delta_{H}\right)\left[\alpha \ln \left(k_{e} / k_{e}^{*}\right)+(\beta-1) \ln \left(h_{e} / h_{e}{ }^{*}\right)\right] .
$$

Using both approximations in the partial derivatives gives

$$
\begin{aligned}
& \frac{\dot{y}_{e}}{y_{e}}=\alpha \frac{\dot{k}_{e}}{k_{e}}+\beta \frac{\dot{h}_{e}}{h_{e}}, \text { so that } \\
& \frac{\dot{y}_{e}}{y_{e}} \cong\left[(\alpha-1)\left(n+g+\delta_{K}\right)+\beta\left(n+g+\delta_{H}\right)\right] \alpha \ln \left(k_{e} / k_{e}^{*}\right) \\
& +\left[\alpha\left(n+g+\delta_{K}\right)+(\beta-1)\left(n+g+\delta_{H}\right)\right] \beta \ln \left(h_{e} / h_{e}{ }^{*}\right)
\end{aligned}
$$

Recalling that $\delta_{H}=\delta_{K}=\delta$ the above expression simplifies to

$$
\begin{aligned}
& \frac{\dot{y}_{e}}{y_{e}} \cong(\alpha-1+\beta)(n+g+\delta) \alpha \ln \left(k_{e} / k_{e}^{*}\right)+(\alpha+\beta-1)(n+g+\delta) \beta \ln \left(h_{e} / h_{e}^{*}\right), \text { and } \\
& \frac{\dot{y}_{e}}{y_{e}} \cong-(1-\alpha-\beta)(n+g+\delta)\left[\alpha \ln \left(k_{e} / k_{e}^{*}\right)+\beta \ln \left(h_{e} / h_{e}^{*}\right)\right], \text { so that we end up with } \\
& \frac{\dot{y}_{e}}{y_{e}}=-(1-\alpha-\beta)(n+g+\delta) \ln \left(y_{e} / y_{e}^{*}\right), \text { i.e. } \\
& \frac{\dot{y}_{e}}{y_{e}} \cong-\lambda \ln \left(y_{e} / y_{e}^{*}\right) \quad \text { with } \quad \lambda=(n+g+\delta)(1-\alpha-\beta),
\end{aligned}
$$


or $\frac{d \ln \left(y_{e}(t)\right)}{d t}=\frac{\dot{y}_{e}}{y_{e}} \cong-\lambda \ln \left(y_{e} / y_{e}^{*}\right)$.

Factor $\lambda$ is known as the so called convergence coefficient, which determines the speed of adjustment to the steady state $y_{e} *$. Clearly, the speed of convergence is not constant and depends on the respective distance to the steady state, or, in other words, growth depends on the "initial" state i.e. on the state at time $t-1$ for longitudinal data. The hypothesis is that the further a country is distant from the steady state, the faster is its speed of adjustment. In this model, the speed does not depend on the levels of capital quotas $s_{K}$ and $s_{H}$. When capital intensities increase the speed of convergence also increases, but, at the same time, the increasing capital saving rates reduce the average product of capital near the equilibrium.

If we integrate (12) with respect to time from $t_{1}$ to $t_{2}$ by using results from the analysis of differential equations, we obtain

$\frac{\ln \left(y_{e}\left(t_{2}\right) / y_{e}^{*}\right)}{\ln \left(y_{e}\left(t_{1}\right) / y_{e}^{*}\right)}=e^{-\lambda\left(t_{2}-t_{1}\right)}$.

This now is equivalent to

$$
\begin{aligned}
& \ln \left(y_{e}\left(t_{2}\right)\right)=\left(1-e^{-\lambda \tau}\right) \ln \left(y_{e}{ }^{*}\right)+e^{-\lambda \tau} \ln \left(y_{e}\left(t_{1}\right)\right), \text { where } \tau=t_{2}-t_{1}, \text { or } \\
& \ln \left(y_{e}\left(t_{2}\right)\right)-\ln \left(y_{e}\left(t_{1}\right)\right)=\left(1-e^{-\lambda \tau}\right) \ln \left(y_{e}{ }^{*}\right)-\left(1-e^{-\lambda \tau}\right) \ln \left(y_{e}\left(t_{1}\right)\right) .
\end{aligned}
$$

Recall that the steady state may vary over the countries depending on $s_{H}, s_{K}$ leading to the conditional growth, respectively income model. In the literature of panel analysis of growth and income, see Islam (1995), Knight, Loayza, and Villanueva (1993), it has not been discussed and clarified in depth from which period $t$ the factors $n, s_{H}, s_{K}$ have to be taken. Typically they take them from period $t_{2}$. In that case, however, there might be a problem of endogeneity due to simultaneity when estimating the model; see discussion in the next section. The same holds for the factors $P$ and $n$. Then, substituting for $y_{e}^{*}$ in (15) gives

$$
\begin{aligned}
& \ln \left(y_{e}\left(t_{2}\right)\right)-\ln \left(y_{e}\left(t_{1}\right)\right)=\left(1-e^{-\lambda \tau}\right) \frac{\alpha}{1-\alpha-\beta} \ln \left(s_{K}\left(t_{2}\right)\right)+\left(1-e^{-\lambda \tau}\right) \frac{\beta}{1-\alpha-\beta} \ln \left(s_{H}\left(t_{2}\right)\right) \\
& -\left(1-e^{-\lambda \tau}\right) \frac{\alpha+\beta}{1-\alpha-\beta} \ln \left(n\left(t_{2}\right)+g+\delta\right)-\left(1-e^{-\lambda \tau}\right) \ln \left(y_{e}\left(t_{1}\right)\right)
\end{aligned}
$$

for the conditional panel data model. Similar to Mankiw, Romer, and Weil (1992), we get finally the (standard) conditional growth model, our equation (17) 


$$
\begin{aligned}
& \ln \left(y\left(t_{2}\right)\right)-\ln \left(y\left(t_{1}\right)\right)=\left(1-e^{-\lambda \tau}\right) \frac{\alpha}{1-\alpha-\beta} \ln \left(s_{K}\left(t_{2}\right)\right)+\left(1-e^{-\lambda \tau}\right) \frac{\beta}{1-\alpha-\beta} \ln \left(s_{H}\left(t_{2}\right)\right)-\left(1-e^{-\lambda \tau}\right) \\
& \frac{\alpha+\beta}{1-\alpha-\beta} \ln \left(n\left(t_{2}\right)+g+\delta\right)-\left(1-e^{-\lambda \tau}\right) \ln y\left(t_{1}\right)+\left(1-e^{-\lambda \tau}\right) \ln A_{0}+\left(1-e^{-\lambda \tau}\right) \theta \ln P\left(t_{2}\right)+g\left(t_{2}-t_{1} e^{-\lambda \tau}\right) ;
\end{aligned}
$$

compare the definition of $y_{e}$, equation (2). It is important to have in mind that in several steps of its derivation we used rather rough approximations, so that this formula is not only subject to several economic assumptions and country-specific distortions but also to rough approximations. Actually, while some literature develops the income per capita, respectively the growth model, approximating it by the first order Taylor terms around the $y^{*}$, one can simply think of all income levels as being deviations around the steady state income. One would start from $\ln y_{i t}=\ln y_{i}^{*}+c_{i}+\eta_{i t}$, with $c_{i}=\gamma_{i}+\gamma^{\mathrm{T}} X_{i t}$, similar to Wane (2004), and $\eta_{i t}$ a random zero mean deviation. Here, $\gamma^{T} X_{i t}$ and $\gamma_{i}$ may describe policy and structural variables. Further decomposition of the Solow residual is commonly done by attributing increasingly larger chunks of it to investment in human capital; see de la Fuente and Domenech (2001) for a general discussion. Not surprisingly, in the end, both approaches yield the same income, respectively growth regression model. If technology $A$ includes not only technology information, but also endowments like climate, institutions, etc, then we can include these also in $c_{i}$ obtaining

$$
\begin{aligned}
& \ln y_{i}\left(t_{2}\right)-\ln y_{i}\left(t_{1}\right)=\left(1-e^{-\lambda \tau}\right) \frac{\alpha}{1-\alpha-\beta} \ln \left(s_{K i}\left(t_{2}\right)\right)+\left(1-e^{-\lambda \tau}\right) \frac{\beta}{1-\alpha-\beta} \ln \left(s_{H i}\left(t_{2}\right)\right)- \\
& \left(1-e^{-\lambda \tau}\right) \frac{\alpha+\beta}{1-\alpha-\beta} \ln \left(n_{i}\left(t_{2}\right)+g+\delta\right)-\left(1-e^{-\lambda \tau}\right) \ln y_{i}\left(t_{1}\right)+\gamma_{i}+\gamma^{T} X_{i t}+g\left(t_{2}-t_{1} e^{-\lambda \tau}\right)+\eta_{i t}
\end{aligned},
$$

where we subsumed $P$ in the country-specific effect. The simplified unconditional model is

$$
\ln y_{i}\left(t_{2}\right)-\ln y_{i}\left(t_{1}\right)=\gamma_{i}+\gamma^{T} X_{i}\left(t_{2}\right)-\left(1-e^{-\lambda \tau}\right) \ln \left(y_{i}\left(t_{1}\right)\right)+g\left(t_{2}-t_{1} e^{-\lambda \tau}\right)+\varepsilon_{i t} \text {, }
$$

where $\varepsilon_{\text {it }}$ summarizes all heterogeneity. In the conditional model (18) one obviously expects positive signs for investment and schooling, but negative signs for initial income and $\ln (\mathrm{n}+\mathrm{g}+\delta)$, i.e. the $\log$ of labour force and technological growth plus depreciation rate. Islam (1995), Knight, Loayza, and Villanueva (1993), among others, included $g\left(t_{2}-t_{1} e^{-\lambda \tau}\right)$ via a time fixed effect. Since this term is linear in $t$ if $\tau$ is constant, they clearly over-parameterize their model strongly. Being aware of the linearity of this term we will simply include time in our model instead. Further modifications of our regression analysis compared to Islam (1995) and other panel studies in this context will be explained in the context of estimation description in Section 1.3, and its application in Section 1.4. 


\subsection{The South-South Integration Areas, Data and Estimation Issues}

We consider various samples, organized in three main data sets as mentioned above. The first set is composed of ten countries, the founding states of MERCOSUR plus the associated members. Although the MERCOSUR was founded in 1991, we chose as the testing period 1985 to 2002. This is because the integration process in this area began via bilateral agreements between Argentina and Brazil (in 1986) and Paraguay (in 1987).

The second set is composed of the twenty one countries of the WAEMU, the CEMAC and ECOWAS. This panel starts with the foundation of the ECOWAS in 1975 and goes, like the other sets until 2002. Due to lack of data we had to drop Liberia, and could include Equatorial Guinea, Guinea and Cape Verde only since the mid eighties.

Finally, our third set contains the countries of ASEAN, ASEAN+3, and ASEAN+5 (also called ANZ-ASEAN). The core RIA, the ASEAN agreement, was already founded in 1967, but at that time the cooperation was only security politics oriented, for example because of regional instabilities in regarding to the Spratly-islands. Since 1975 annual meetings of the ministers for economic affairs have been held, and the character of the cooperation has changed towards a more economically orientated one. Therefore our testing period is from 1975 to 2002. Because of missing data we had to exclude Brunei and Burma (Myanmar) completely, while we could not include Cambodia, Vietnam and Laos before the eighties.

Before we discuss the data set used in this study, we start with a short review of the considered South-South integration areas.

\section{MERCOSUR}

The oil crises in the 70s caused inflation, recession and poverty in some South American countries, especially in Brazil and Argentina. At the same time, most industrialized countries strengthened their policy of protectionism, such that potential regional trade partners became more important alternatives. Therefore, in 1986 Argentina and Brazil not only signed a bilateral agreement, but also started negotiations with Uruguay and Paraguay. The so-called MERCOSUR treatment of Asuncion was concluded in 1991. The intended objectives at the time were the creation of an internal market with a free flow of goods, services, and any production factors between the member states. This was to be achieved by the reduction of 
tariff and non-tariff trade barriers, a common customs and trade policy, the coordination of macroeconomic and sectoral policy in agriculture and industry, as well as fiscal and monetary policy including exchange rates, etc. After different crises the member states tried a restart in 2000 (Relanzamiento del Mercosur). Basically, without changing the targets, they intensified their macroeconomic coordination, with some success in the formation of an internal market and a customs union. But a continuing problem is the weak institutions of MERCOSUR, and the differences of trade rules between full and associated members.

\section{ASEAN, ASEAN +3 and ASEAN+5}

One may say that the ASEAN agreement started in 1967 with the declaration of Bangkok. It formed a basis for an economic opening though the motivation was driven more by security policy. Then in 1976 there followed the treaty of amity and cooperation with principles like the one of non-intervention in internal affairs and national sovereignty. The cooperation became more dynamic after the end of the cold war, especially by new entries. In 1992 the ASEAN-FTA (ASEAN free trade agreement) was signed, followed already in 1994 by the ASEAN-RF (ASEAN Regional Forum). This forum has formed as platform for security questions between the ASEAN member states plus 17 other countries like the USA, Japan, China, or North Korea, etc. Finally, in 2007 the ASEAN Charter was signed, a common constitution accounting for the new economic situation, the so called globalization. This Charter was to be the basis for national reforms to reach rules of law and the protection of human rights. Further an ASEAN Investment area (AIA) is planned for 2010. Besides, it is envisaging free trade areas with the PR China and Japan. ASEAN+3 was founded 1997 in Kuala Lumpur and goes back to a Japanese initiative to give the region a unique political voice. It comprises ASEAN, PR China, Japan, and South Korea. In 2005 New Zealand and Australia commenced free trade agreement negotiations with ASEAN +3 yielding the ASEAN+5 (or ANZ-ASEAN). A correct dating of the foundation is hardly possible though, as Australia and New Zealand already had bilateral agreements with several of the ASEAN+3 countries years before. Note that ASEAN +3 is hardly, and in ASEAN +5 definitely not, a typical South-South RIA with Japan, Australia, and New Zealand included. For that reason we may expect different results concerning convergence and growth, compared to the other RIAs. Because of missing data we had to exclude Brunei and Burma (Myanmar) completely, while we could not include Cambodia, Vietnam and Laos before the eighties. And note that Papua New Guinea is not a full member but it is an associated one, and is therefore included. 


\section{ECOWAS}

The ECOWAS was founded in 1975, ratified through the treaty of Lagos and includes 15 members. Since 1999 the ECOWAS is a free trade area and is planning a customs and monetary union (deferred to 2009). An important cooperation field is the sectoral programs to intra-connection of national electric grids and a regional pipeline for the distribution of natural gas as well as the improvement of regional infrastructure (e.g. Trans-African-Highway 7: Dakar-Lagos). Since the end of Cold War an effective regional security mechanism has become important for this world region (see the ECOMOG in Liberia). Due to the lack of data we had to drop Liberia. We could include Equatorial Guinea, Guinea and Cape Verde only from the mid eighties onwards.

\section{WAEMU}

The West-African custom and monetary union was founded in 1994 and has eight members. The common currency is the CFA-France with the common central bank BCEAO in Dakar. The WAEMU has a regional parliamentary committee and a common court of law since 1998. The sectoral cooperation concentrates on the improvement of the infrastructure, the efficient energy policy and programmes for poverty reduction.

\section{CEMAC}

The custom and monetary union was founded in 1994 and has six member countries. The common currency is the CFA-Franc with the common central bank BEAC in Yaoundé. The main targets of the RIA are macroeconomic coordination between all members, development of a common market, improvement of the infrastructure and reduction of poverty and AIDS.

\section{The CFA-Zone}

Originally, the CFA-Zone goes back to the initiative of the (former) colonial power France in 1945. The CFA had a fixed exchange rate to the French Franc and later (since 2001) to the Euro. However, as noted above, the zone comprises two monetary areas: the WAEMU with the CFA- Franc BCEAO, and the CEMAC with the CFA-Franc BEAC, with two central banks and two (different) monetary policies. Although Central African CFA francs and West African CFA francs have the same peg to the other currencies (Euro), West African CFA coins and banknotes are not accepted in countries using Central African CFA francs, and vice versa. Nevertheless, these two areas certainly practice economic cooperation. 
Note that currently there are numerous overlapping RIAs in Africa. According to the UNECA 2004, there existed in each region in Africa three or four RIAs, e.g. in West Africa ECOWAS, WAEMU and the Mano River Union ${ }^{10}$. In Central Africa the CEMAC coexists with the ECCAS (Economic Community of Central African States) and CEPGL (Economic Community of the Great Lakes Countries) ${ }^{11}$. One goal of the Organization of the African Union is the rationalization of regional integration areas. A possible scenario would be the enlargement of the CFA zone to comprise also the other countries of ECOWAS. The UNECA recommends that all RIAs of West- and Central Africa institutionally join the framework of ECOWAS. But these ideas are in conflict with the simple fact that the different memberships have also varied functions. The CEMAC and the WAEMU are two country groups with the CFA franc bound to the French Franc and today to the Euro. At the same time, the WAEMU is - at least geographically - a sub-region of the ECOWAS.

Recall that the main focus of this study is the question on per capita growth and convergence due to or in spite of South-South RIAs. We believe that to this aim the above introduced set offers a good coverage of the three important world regions for such a study: South America, Central and West Africa, and Southern Asia. For such a general question it is important not to stick to only one region; about ASEAN for example it has been argued that convergence is rather due to the economic cross linking with Japan and China but not due to the agreement. Note that for Africa many different and overlapping RIAs exists from which we chose the four mentioned. With this selection we hope to control for specific factors like (civil) war or restrictions due to the explicit grouping together of anglo-/ francophone areas respectively. An important criterion is certainly the enabling clause of the GATT, so that one could also have chosen COMESA and SADC, from which the latter is often referred to be a quite successful one. However, trouble spots like Angola, Congo, and Zimbabwe yield a quite inhomogeneous pattern over both time and countries. Furthermore, while there are at least dissensions about the role of South Africa in the SADC, it is well known that some member states did not even sign several of the most important protocols for trade liberalization. COMESA has not been considered because this union with 24 countries spread out all over Africa with enormous distances, and with the lack of infrastructure to overcome them, turned out to be simply too big.

\footnotetext{
${ }^{10}$ The Mano River Union was founded in 1973 by Liberia, Guinea, and Sierra Leone.

${ }^{11}$ The CEPGL was founded in 1976 entailing the former Belgian colonies Burundi, Rwanda and the Democratic Republic of Congo (former Zaire).
} 
The common features of the selected South-South agreements show the importance of such partnerships but also their difficulties:

- Strong economic trade dependence to USA, Japan and Europe, which leads to low intra-regional trade and common economic activities.

- Cross-national problems such as poverty, low per capita income, weak infrastructure and insufficient institutions etc.

- Strong emphasis on sovereignty and non-intervention (see e.g. non-uniform voting of members at multilateral level as WTO or UN)

- Hardly any terms-of-trade gains, since the integration area is economically relatively small compared to the ROW.

\section{The Data and Estimation Issues}

To test our theoretical hypotheses, we use data selected from different official sources of administrative data sets. The data are mostly taken from the Penn World tables by Summer and Heston (version 6.1), which include real investment shares to GDP. The real GDP per capita in international PPP\$ and the growth rates of population are from the World Development Indicator database of 2007. In order to account for the criticism of Pritchett (2001) we work with the schooling years of the working-age population as proxy of human capital provided in the education data set of Barro and Lee (2002). We established the panels for Africa, Latin-America and Asia with 3-year intervals and consider the average values over the years inside each interval. This way we achieve a prior smoothing of the data over time which corrects temporal variations in our macro data. We ran all regressions with two measures of growth rate per capita income: first, approximating it by the log differences such that one of our conditional models coincides with the model of Islam (1995); second, calculating the yearly growth by $\left(\left\{y_{i}(\right.\right.$ year $)-y_{i}$ (basisyear $\left.)\right\} / y_{i}($ basisyear $\left.)\right)^{1 / r}$ where $r$ is the number of years between the year of interest and the basis year. Note that this makes a major difference only for countries with partly high growth rates or with strong variations in growth from year to year. As the second calculation is more accurate for modelling growth rather than income, and for the sake of brevity, we will only report regression results based on the second measure. When we consider a certain time period (always intervals of three years), we have taken the first year as the basis year. This differs slightly from the notation used in Section 1.2, where the basis year was automatically the lagged period's income. This reduces 
the autocorrelation of the panel and avoids (in contrast to Islam, 1995) the Nickell-bias when using the Within-estimator (only for subgroup-estimation); see also Binder, Hsiao and Pesaran (2005) or Lee, Pesaran and Smith (1998) for more discussion on estimation problems when studying growth by panel data. For the conditional growth model we also included (log) investment, the growth rate of population as well as the constant rates of depreciation and technology, all these being interval averages.

When estimating our different models to test for growth and convergence, we faced several possible problems, which could have led to inconsistent results and misleading interpretations. From the discussions in the literature we mainly identify two important sources of inconsistency: omission of individual country specific effects ( $c_{i}$ in our model), endogeneity due to simultaneity (of $s_{H}, s_{K}$, and / or $n$ ), and possible inconsistency due to the dynamics in our panel model; see for example Islam (1995), Caselli, Esquivel, and Lefort (1996), or Lee and Pearsan (1997). We solve the first problem by considering fixed effects models (in our case $\gamma_{i}$ ) and using Least-Square Dummy Variable estimators (LSDV). For comparison we also estimated the same panel models without fixed effects and finally also with random effects. While the first resulted in models with mostly insignificant coefficients, the second came closer to our results from fixed effects models. However, the necessary assumption of independence between our covariates and the (country specific) random effects is rather questionable in both the conditional and the unconditional model. We further allow for additional (country specific) heterogeneity by including panel specific AR(1) autocorrelation and arbitrary heteroscedasticity in our regressions. By applying feasible weighted least squares estimators (GLS hereafter) we make use of this variance-covariance structure to obtain efficient estimates. Note that ignoring these covariance structures leads to more variation but qualitatively the same results (not shown in this paper). The second problem (inconsistency due to endogeneity) refers to potential simultaneity between per capita income, respectively growth, and population growth or investment. We tried to counteract this problem with instruments for population growth, and investments respectively. We first used, as mentioned above, interval-averages instead of the observations of the same year records. Then we repeated all estimations with lagged interval averages. However, the latter turned out to be rather weak instruments for most areas, leading to large variances and insignificant results almost throughout. The last problem, due to the dynamic modelling, also called the Nickell-bias, can be reduced by GLS with LSDE. This works for the full sample analysis (tables presented in Section 1.4) but will not work for the small and unbalanced 
panels we analyze in the counterfactual exercise (tables presented in the appendix A). Therefore we use the per capita income of the first year of each time interval (always 3 years in our case) as an instrument for the initial income (referring to the basis year).

As indicated in the introduction we are interested in estimating and testing the impact of membership in South-South-Agreements on both growth and convergence. Instead of sampling data from member and non-member countries separately to compare the regression results, we decided to compare the effect of membership versus non-membership for the same set of countries (i.e. including only countries experiencing both). This is possible thanks to the panel structure of our data samples. Moreover, by this approach we try to mitigate a potential selection bias which is quite probable when looking at exclusive members versus nonmembers - though we emphasize that our approach is conservative in favour ${ }^{12}$ of the criticisms against South-South-RIAs. To our knowledge we are the first to perform such a counterfactual exercise that compares the effect of membership on growth and convergence for RIA-agreements empirically, in particular for South-South-Agreements.

In this approach we have different options for comparing the effect of membership: the inclusion of membership-dummies, or the number of membership-years (introduced via $c_{i}$, or $X_{i}(t)$ ), and comparing the sub-samples comprising only the observations when membership was active with the subsamples when membership was not active ${ }^{13}$. As a consequence, in the last step we face unbalanced panel regression because the time points of entries of the considered countries in a particular RIA vary substantially (for example, Brunei has been a member of the ASEAN since 1984, Vietnam since 1995, etc.).

Recall that for the conditional growth model we used the standard covariates introduced by Mankiw, Romer, and Weil (1992) and added time; see discussion at the end of the previous section. As a measure for human capital we chose schooling years instead of enrolment rates, accounting this way for Pritchett (2001)'s criticism. Missing data were replaced by estimated

\footnotetext{
12 This means: when estimating the beta coefficient we only allow for positive biases pushing beta towards zero. If then the t-statistics still exhibit significant (negative) betas, we can be sure about convergence.

${ }_{13}$ We deliberately declined to include an interaction term basisyear times membership to estimate the convergence effect of RIAs from the entire sample. The reasons are twofold: First, it is not clear how the macroeconomic source model can be modified to end up in a regression model with such a dynamic interaction model; see derivation of our model in Section 2. Such a regression would be estimating without a model. Second, even if such a regression would be derivable from some macroeconomic model, it either imposes the restriction that membership only affects convergence speed but no other return, not even the fixed effects, or we would have to include many more interaction terms which is equivalent to sample splitting.
} 
schooling years. More specifically, first we ran a linear regression for Asia and Africa respectively, explaining schooling years $\operatorname{syr}_{i t}$ by literacy rates $l_{i t}$ in a fixed effects panel model: $s y r_{i t}=\beta_{1} \cdot l i t_{i t}+\gamma_{t}+\varepsilon_{i t}$. Then, for those countries for which we observed literacy rates lit $_{i t}$ but not schooling years $\operatorname{syr}_{i t}$ we estimated schooling years via this model. Specifically, this was done for Cambodia, China, Lao and Vietnam in Asia, and in Africa for Burkina Faso, Cote d'Ivoire, Cape Verde, Nigeria Chad and Mauritania. However, for Gabon, Guinea and Equatorial Guinea, for which we had no information about schooling years, literacy or enrolment rates, we had to estimate the schooling years from their geographical neighbours with similar economic structures.

Note finally that, as might be seen from this section, our regression analysis is rather flexible and in this sense robust against possible model misspecification. As a consequence our inference is quite conservative (in favour of the critics of South-South-RIAs, see footnote 12). A disadvantage may be the resulting (low) number of degrees of freedom. For this reason we (a) tried several more restrictive specifications, and (b) disregarded in this article further studies about the integration depth which inevitably would lead to over-parameterization. A detailed study on robustness of the augmented Solow model and consequences of misspecification can be found in Temple (1998).

\subsection{The Empirical Analysis}

In this section we present the most important estimation results of our analysis. Concerning the full samples, we present only the estimation results with a GLS least squares dummy variable regression with panel-specific AR(1) errors, allowing for heteroscedasticity, and using fixed effects; see discussion in Sections 1.2 and 1.3. However, the qualitative results are robust with respect to the following alternatives: within-between fixed effects regression, random effects models, neglecting possible AR error structure, or assuming homoscedasticity. For the unbalanced and much smaller split samples we present results based on the same method but ignoring fixed effects, and results based on (within) fixed-effects-estimation. We first discuss the findings for the regression models for unconditional convergence for the three regions considered (Asia, South America and Africa); recall equation (19). Then, in a second step, we study in detail the conditional models; recall equation (18). For both studies we 
estimated equations (18) and (19) for all RIAs, for full and split samples (according membership) as explained above.

Concerning unconditional convergence, Tables 1.1, 1.2, 1.3a, 1.3b, and A in Appendix A show that our hypothesis of convergence, faster convergence and larger growth inside the considered RIAs, is supported by the empirical findings in several respects. Certainly we found significant unconditional convergence in all world regions irrespective of membership. However, when including the variables membership for the relevant South-South RIAs, the coefficients of initial income become more negative and more significant (smaller standard deviation), except for ASEAN+3 and ASEAN+5. This indicates strong heterogeneity between members vs. non members with respect to convergence speed. Note that in all RIAs membership has a positive and highly significant effect on economic growth. When we split each sample into two unbalanced samples containing exactly the same sets of countries but either including only the data when being a member of the considered RIA, and including only the data when not being a member respectively (see Tables A in the Appendix A), we always found stronger convergence in the first sub-sample than in the second one. This finding is in contrast to many statements so far made in the literature; recall the discussion in the previous sections.

Table 1.1: Unconditional convergence and growth tests for Latin America, 1985-2002 GLS-Regression with panel-specific AR(1), heteroscedasticity and fixed effects

Initial Income $-.0764(.011)$ $-.1052(.014)$ $-.0489(.015)$ $-.0898(.015)$ MERCOSUR mem $.0210(.006)$

No. of observ.

60

60

60

60

Prob $>$ chi 2

0.000

0.000

0.000 0.000

Note: Standard deviations for coefficient estimates are in parenthesis. Mem stays for membership (here in MERCOSUR), years for the number of years the country staid in the RIA. If time was included, time showed to be insignificant with p-values larger than $60 \%$.

For the exercise with un-split, i.e. full samples, we found that the effect of membership is significantly positive, except for ASEAN+3 and ASEAN+5 (Table 1.2) as above. This answers our question on whether membership has a positive impact, not only on convergence, but also on growth. Evidently, membership (even) in a South-South RIA has a positive impact on the growth rate of per capita income. 
Table 1.2: Unconditional convergence and growth tests for East Asia, 1975-2002

GLS-Regression with panel-specific AR(1), heteroscedasticity and fixed effects

\begin{tabular}{rrrrrrr} 
Initial Income & $-.0457(.003)$ & $-.0501(.003)$ & $-.0348(.004)$ & $-.0347(.003)$ & $-.0351(.003)$ & $-.0382(.004)$ \\
ASEAN years & - & - & $-.0018(.000)$ & - & - & $-.0021(.000)$ \\
ASEAN mem & - & $.0161(.004)$ & - & - & - & $.0235(.003)$ \\
ASEAN+3 mem & - & - & - & $-.0269(.005)$ & - & - \\
ASEAN+5 mem & - & - & - & - & $-.0237(.005)$ & - \\
& & & & & 115 & 115 \\
No. of observ. & 115 & 115 & 115 & 0.000 & 0.000 & 0.000 \\
Prob>chi2 & 0.000 & 0.000 & 0.000 & 0.000 \\
\hline \hline
\end{tabular}

Note: Standard deviations for coefficient estimates are in parenthesis. Mem stays for membership, member years for the number of years the country staid in the RIA. If time was included, time showed to be insignificant with p-values larger than $60 \%$.

This again is in contrast to the literature arguing that South-South agreements remain in the trap "poor stays poor" even if they converge among themselves. We will come back later to the seemingly negative impacts of membership found for ASEAN+3 and ASEAN+5. Note finally that the impact of time was insignificant in the unconditional regression models for South America and Asia but not for West Africa, where it is positive, as it is supposed to be according to equation (19).

A further finding concerning the impact of RIAs is the negative sign of the coefficients of member years in East Asia and Latin America, see Tables 1.1, 1.2. This is, we observe decreasing marginal utility effects for the ASEAN. For Africa, however, the impact of years is positive which indicates increasing marginal utility effects but is insignificant for CEMAC.

Before we turn to the more sophisticated conditional growth models, we look at the counterfactual exercise when model (19) is estimated only on samples with exclusively member states or non-member states, respectively. Note that these estimates are therefore based on unbalanced samples. 
Table 1.3a: Unconditional convergence and growth tests for West- and Central Africa, 1975-2002 GLS-Regressions with panel-specific AR(1), heteroscedasticity and fixed effects

\begin{tabular}{|c|c|c|c|c|c|c|c|c|}
\hline Initial Income & $\begin{array}{r}-.0404 \\
(.007)\end{array}$ & $\begin{array}{r}-.0991 \\
(.019)\end{array}$ & $\begin{array}{r}-.0999 \\
(.019)\end{array}$ & $\begin{array}{r}-.1107 \\
(.020)\end{array}$ & $\begin{array}{r}-.0913 \\
(.021)\end{array}$ & $\begin{array}{r}-.0988 \\
(.020)\end{array}$ & $\begin{array}{r}-.0915 \\
(.018)\end{array}$ & $\begin{array}{r}-.0924 \\
(.018)\end{array}$ \\
\hline Time & - & $\begin{array}{l}.0070 \\
(.002)\end{array}$ & $\begin{array}{l}.0074 \\
(.002)\end{array}$ & $\begin{array}{l}.0043 \\
(.002)\end{array}$ & $\begin{array}{l}.0038 \\
(.002)\end{array}$ & $\begin{array}{l}.0047 \\
(.002)\end{array}$ & $\begin{array}{l}.0045 \\
(.002)\end{array}$ & $\begin{array}{l}.0047 \\
(.002)\end{array}$ \\
\hline ECOWAS mem & - & - & $\begin{array}{c}.0511 \\
(.027)\end{array}$ & - & - & - & - & - \\
\hline ECOWAS years & - & - & - & $\begin{array}{l}.0017 \\
.000)\end{array}$ & - & - & - & - \\
\hline CEMAC mem & - & - & - & - & $\begin{array}{l}.0177 \\
(.013)\end{array}$ & - & - & - \\
\hline CEMAC years & - & - & - & - & - & $\begin{array}{l}.0015 \\
(.001)\end{array}$ & - & - \\
\hline WAEMU mem & - & - & - & - & - & - & $\begin{array}{c}.0254 \\
(.007)\end{array}$ & - \\
\hline WAEMU years & - & - & - & - & - & - & - & $\begin{array}{c}.0038 \\
(.001)\end{array}$ \\
\hline No. of observ. & 180 & 180 & 180 & 180 & 180 & 180 & 180 & 180 \\
\hline Prob $>$ chi 2 & 0.000 & 0.000 & 0.000 & 0.000 & 0.000 & 0.000 & 0.000 & 0.000 \\
\hline
\end{tabular}

As we can see in Tables A.1 to A.3c in the Appendix A, we find that convergence is much stronger for all studied areas, i.e. the absolute values of the impact of initial income goes up clearly (except for CEMAC and ECOWAS in the GLS regression with AR(1) autocorrelation and heteroscedasticity but without fixed effects - the latter being a possible source of omitted variable bias. However, significance is stronger for members). The weak result for CEMAC can have different reasons, for example that WAEMU and ECOWAS are simply more successful and exactly the member states of these RIAs may dominate the "CEMAC $=0$ " sample. Another possible reason is that the "CEMAC $=1$ " sample is too small (relative to the heterogeneity inside CEMAC) to establish statistical significance.

Table 1.3b: Unconditional convergence and growth tests for West- and Central Africa, 1975-2002 GLS-Regression with panel-specific AR(1), heteroscedasticity and fixed effects

Initial Income
Time
ECOWAS mem
ECOWAS years
CEMAC mem
CEMAC years
WAEMU mem
WAEMU years

No. of observ. Prob $>$ chi 2

$$
\begin{array}{rr}
-.1117 & (.020) \\
.0043 & (.002) \\
.0493 & (.028) \\
.0017 & (.000)
\end{array}
$$

$-.0912(.022)$ $.0043(.002)$

$\begin{array}{rr}-.0913 & (.018) \\ .0043 & (.002) \\ & - \\ & - \\ & - \\ & - \\ .0107 & (.014) \\ .0025 & (.002) \\ & \\ & 180 \\ 0.000\end{array}$


To summarize the result for unconditional growth regression: the exercise with the full samples, but including membership dummies or years, has shown that, among other things, not only beta convergence in all considered regions, but also that membership has had a significant positive impact on growth. The second (counterfactual) exercise with split samples has shown, that additionally, convergence is clearly faster for members of the considered RIAs. A general finding of the conditional convergence estimation results (see Tables 1.4 to $1.6 \mathrm{~b}$ and Tables $\mathrm{B}$ in the Appendix A) is that the conditional tests confirm the evidence of the first (unconditional) part. When running the conditional regressions with unlagged variables, the results were again reasonably robust against particular specifications (with or without GLS, AR(1), heteroscedasticity, fixed or random effects). As already indicated, the lagged covariates turned out to be rather weak instruments, which is not particularly surprising when we remember that we are using a time lag of about 3 years (considering 3-year averages).

Similar to the unconditional case, when we include the variable membership, the return of initial income is more negative than without membership. In these regression models the variable time has sometimes an unexpected significant negative sign. In the extended Solow model for panel data (cf. equations (18)-(19)) the coefficients should be positive. In practice this is only a necessary conclusion if the assumption of constant return to scale holds true over the whole time period, if the (linear first order Taylor) approximations are sufficiently exact, and if there is no co-linearity with initial income; see Durlauf and Quah (1999).

Table 1.4: Conditional convergence Latin America 1985-2002 and membership in MERCOSUR

\begin{tabular}{|c|c|c|c|c|c|c|c|}
\hline \multirow{4}{*}{ Initial Income } & \multicolumn{7}{|c|}{ "GLS-Regression with panel-specific AR(1), heteroscedasticity and fixed effects } \\
\hline & \multicolumn{4}{|c|}{ With non-lagged covariates } & \multicolumn{3}{|c|}{ With lagged covariates } \\
\hline & -.1291 & -.1051 & -.1156 & -.1040 & -.1461 & -.1356 & -.1194 \\
\hline & $(.031)$ & $(.032)$ & $(.033)$ & $(.031)$ & $(.046)$ & $(.043)$ & $(.047)$ \\
\hline \multirow[t]{2}{*}{ Time } & -.0035 & -.0070 & -.0088 & -.0048 & -.0037 & -.0103 & -.0042 \\
\hline & $(.004)$ & $(.004)$ & $(.003)$ & $(.004)$ & $(.006)$ & $(.006)$ & $(.006)$ \\
\hline \multirow[t]{2}{*}{ Log Investment } & .0701 & .0833 & .0794 & .0784 & .0732 & .0370 & .0805 \\
\hline & $(.021)$ & $(.021)$ & $(.021)$ & $(.021)$ & $(.048)$ & $(.048)$ & $(.036)$ \\
\hline \multirow[t]{2}{*}{ Log Schooling } & .0519 & .1017 & .1014 & .0884 & -.0014 & .0606 & -.0376 \\
\hline & $(.058)$ & $(.059)$ & $(.052)$ & $(.061)$ & $(.087)$ & $(.085)$ & $(.089)$ \\
\hline \multirow[t]{2}{*}{$\log (\mathrm{n}+\mathrm{g}+\delta)$} & -.0651 & -.0808 & -.0824 & -.0741 & -.1167 & -.1093 & -.1355 \\
\hline & $(.035)$ & $(.039)$ & $(.037)$ & $(.039)$ & $(.073)$ & $(.072)$ & $(.056)$ \\
\hline MERCOSUR & .0199 & - & .0114 & - & - & .0259 & - \\
\hline mem & $(.007)$ & & $(.007)$ & & & $(.010)$ & \\
\hline MERCOSUR & -.0018 & - & - & -.0009 & - & - & -.0019 \\
\hline years & $(.000)$ & & & $(.000)$ & & & $(.001)$ \\
\hline No. of observ. & 60 & 60 & 60 & 60 & 50 & 50 & 50 \\
\hline Prob $>$ Chi 2 & 0.000 & 0.000 & 0.000 & 0.000 & 0.000 & 0.000 & 0.000 \\
\hline
\end{tabular}


Otherwise, intuitively, a negative sign for time supports the hypothesis of income convergence, because it simply indicates that in our selected samples growth rates decreases over time. The other variables have - except for Africa in the full sample regression - the expected signs, or they are insignificant, i.e. investment as well as schooling has positive impact and $\log (\mathrm{n}+\mathrm{g}+\delta)$ has a negative sign. In Table 1.4 and A.B.1 we see only expected results for South America. It is maybe interesting to see that in the counterfactual exercise, Table A.B.1, the return of investment and schooling increases for the states when they become members of MERCOSUR.

Table 1.5a: Conditional convergence East Asia 1975-2002

\begin{tabular}{|c|c|c|c|c|c|c|}
\hline \multirow[b]{3}{*}{ Initial income } & \multicolumn{6}{|c|}{ GLS-Regression with panel-specific AR(1), heteroscedasticity and fixed effects } \\
\hline & \multicolumn{3}{|c|}{ with non-lagged covariates } & \multicolumn{3}{|c|}{ with lagged covariates } \\
\hline & $-.0451(.009)$ & $-.0505(.010)$ & $-.0537(.009)$ & $-.0396(.011)$ & $-.0394(.013)$ & $-.0527(.012)$ \\
\hline Time & $-.0040(.002)$ & $-.0031(.002)$ & $-.0009(.002)$ & $-.0054(.002)$ & $-.0053(.002)$ & $-.0019(.002)$ \\
\hline Log Investment & $.0514(.008)$ & $.0586(.013)$ & $.0413(.009)$ & $-.0194(.013)$ & $-.0188(.018)$ & $-.0305(.015)$ \\
\hline Log schooling & $.0632(.027)$ & $.0763(.027)$ & $.0945(.028)$ & $.0758(.027)$ & $.0719(.032)$ & $.1128(.033)$ \\
\hline $\log (n+g+\delta)$ & $.0052(.005)$ & $.0060(.005)$ & $.0105(.005)$ & $.0008(.006)$ & $.0007(.006)$ & $.0020(.005)$ \\
\hline ASEAN mem & - & $-.0238(.011)$ & - & - & $.0041(.016)$ & - \\
\hline ASEAN years & - & - & $-.0019(.000)$ & - & - & $-.0017(.006)$ \\
\hline No. of observ. & 115 & 115 & 115 & 101 & 101 & 101 \\
\hline Prob $>$ Chi 2 & 0.000 & 0.000 & 0.000 & 0.000 & 0.000 & 0.000 \\
\hline
\end{tabular}

Table 1.5a presents the results for East Asia and indicates that the return of initial income becomes more negative when including membership or years as covariates. For the ASEAN+3 and ASEAN+5 we cannot make a statement for convergence effects because of the short observation period (1997-2002), of non-existence of formal economic partnership agreements for these greater regions (excluding the bilateral SWAP-agreements and bilateral FTA, e.g. VR China and the ASEAN), and because of the 1997/98 crisis. Our estimation (only ASEAN) shows a surprising negative linkage between membership and per capita income growth. One of the main reasons could be the Asian crisis 1997/98, because the ASEAN members were exceptionally hard hit, and the negative economic effects persisted the longest in the ASEAN states Indonesia and Malaysia. In order to filter out the impact of the Asian economic crisis, we corrected our data for 1997 and 1998 by linear interpolation and rerun the regressions, see Table $1.5 \mathrm{~b}$. 
Table 1.5b: Convergence test with filtered data (corrected for 1997/98 crisis, with non-lagged covariates)

\begin{tabular}{|c|c|c|c|c|c|c|}
\hline \multirow[b]{3}{*}{ Initial income } & \multicolumn{6}{|c|}{ "GLS-Regression with panel-specific AR(1), heteroscedasticity and fixed effects } \\
\hline & & unconditional & & & conditional & \\
\hline & $-.0365(.003)$ & $-.0419(.002)$ & $-.0291(.002)$ & $-.0447(.009)$ & $-.0476(.010)$ & $-.0473(.009)$ \\
\hline Time & - & - & - & $-.0028(.002)$ & $-.0023(.002)$ & $-.0008(.002)$ \\
\hline Log Investment & - & - & - & $.0302(.007)$ & $.0389(.012)$ & $.0248(.008)$ \\
\hline Log schooling & - & - & - & $.0732(.024)$ & $.0768(.023)$ & $.0922(.025)$ \\
\hline $\log (n+g+\delta)$ & - & - & - & $.0022(.007)$ & $.0035(.005)$ & $.0059(.005)$ \\
\hline ASEAN mem & - & $.0163(.002)$ & - & - & $-.0134(.009)$ & - \\
\hline ASEAN year & - & - & $-.0014(.001)$ & - & - & $-.0016(.000)$ \\
\hline No. of observ. & 115 & 115 & 115 & 115 & 115 & 115 \\
\hline Prob $>$ Chi2 & 0.000 & 0.000 & 0.000 & 0.000 & 0.000 & 0.000 \\
\hline
\end{tabular}

But membership has a negative, significant effect on growth in the conditional model with filtered data, too. The reason for the negative linkage between ASEAN-membership and per capita growth is that in the whole East Asia area, the non-ASEAN-members like Japan or South Korea are the best economic performers during the considered period. Of course, Singapore is also an Asian country with rapid economic growth, but only one of ten ASEANmembers. Furthermore, the negative sign of membership might partly be also explained by the entries of some really poor countries in ASEAN, namely Vietnam and Cambodia. We further observe that the coefficients of initial income are less negative in Table 1.5b. This means that the Asian crisis led to more convergence in the whole East Asia area, because the newly industrialized countries with their very high growth rates (as in Thailand) were strongly negatively affected by the crisis, whereas the poorer late-comers were not (as e.g. Cambodia).

Considering the conditional convergence models with the split samples (Table B.2, Appendix A) we again find our hypothesis confirmed that membership has a positive impact on convergence. The coefficients of initial income are more negative and significant in the "member sample". Also, while investment and schooling both have positive returns for all samples, it seems that at lest the return of investment is much stronger in the member states.

For the West African RIAs (ECOWAS, CEMAC, and WAEMU) we found significant beta convergence for all (sub-) samples (see Tables 1.6a to 1.6c, and B.3a to B.3c in the Appendix A) and also in the conditional growth model. Investment and time have the model-consistent positive signs throughout (see equation (18) in Section 1.2). The CFA has not been considered in the counterfactual exercise as it has existed since 1949 so that we have no information about states having been in and out of CFA during the observation period. As already mentioned we again find positive influences of membership and years (when years were 
included separately) on growth (Tables 1.6a to 1.6c), which strongly supports our previous findings. When we include both membership and years in the same model, we see a significant positive impact on growth and an insignificant decrease of marginal utility (except for ECOWAS in the GLS regression without fixed effects, compare discussion above for the unconditional model).

Table 1.6a: Conditional convergence West- and Central Africa 1975-2002

\begin{tabular}{|c|c|c|c|c|c|}
\hline \multirow[b]{3}{*}{ Initial income } & \multicolumn{5}{|c|}{ GLS-Regression with panel-specific AR(1), heteroscedasticity and fixed effects } \\
\hline & All & CFA & $\mathrm{ECO}$ & & \\
\hline & $-.0895(.019)$ & $-.0761(.021)$ & $-.0910(.019)$ & -.0974 & $(.020)$ \\
\hline Time & $.0123(.002)$ & $.0052(.003)$ & $.0128(.002)$ & .0100 & $(.003)$ \\
\hline Log Investment & $.0336(.007)$ & $.0219(.009)$ & $.0341(.007)$ & .0332 & $(.007)$ \\
\hline Log schooling & $-.0534(.013)$ & $-.0631(.018)$ & $-.0762(.013)$ & -.0597 & $(.015)$ \\
\hline $\log (n+g+\delta)$ & $.0145(.011)$ & $-.0056(.011)$ & $.0182(.011)$ & .0086 & $(.013)$ \\
\hline Member & - & - & $.0693(.045)$ & - & \\
\hline Member years & - & - & - & .0005 & $(.000)$ \\
\hline No. of. observ. & 180 & 180 & 180 & & 180 \\
\hline Prob $>$ Chi 2 & 0.000 & 0.000 & 0.000 & & 0.000 \\
\hline
\end{tabular}

Table 1.6b: Conditional convergence West- and Central Africa 1975-2002

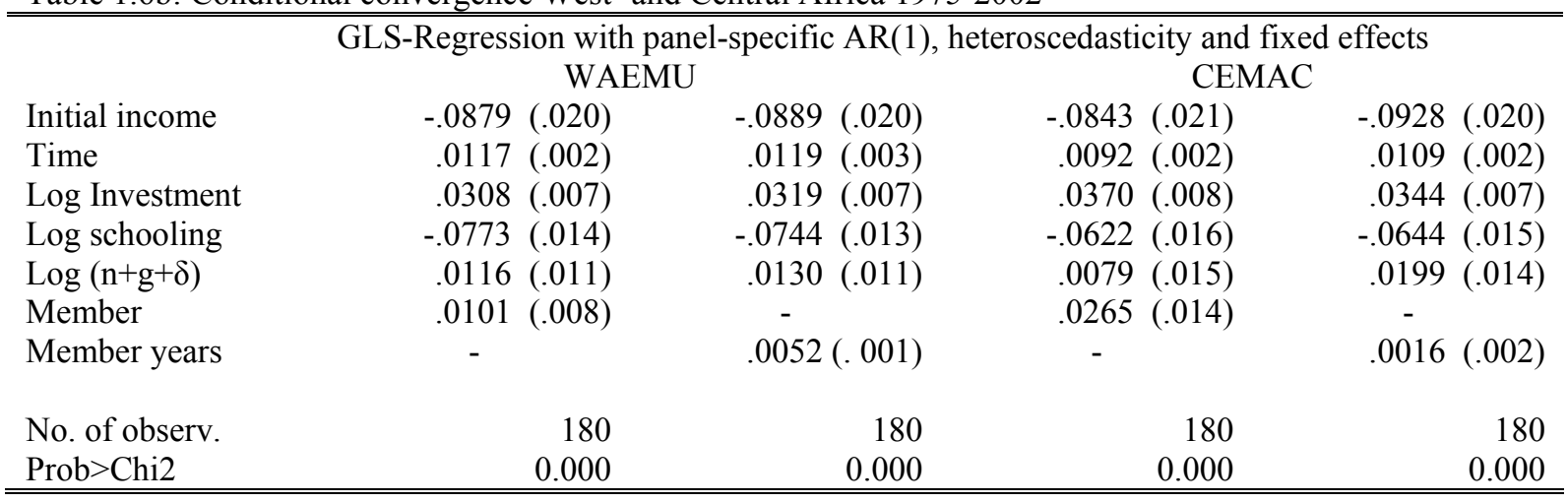

Quite typical for West and Central Africa is the seemingly consistent negative return to schooling shown in Tables 1.6a and 1.6c. The reason is that several of the states, despite their relatively high per capita income thanks to natural resources, hardly ever invest in human capital, whereas the poorer countries without natural resources do. Until now, however, the return of this investment has not yet produced a catching up to the per capita income of the other countries. Interestingly, the clustering caused by the sample split in our counterfactual exercise yields positive returns for member states but negative or insignificant returns to schooling for the non-member states; see Tables A.B.3a to A.B.3c. 
Table 1.6c: Conditional convergence West- and Central Africa 1975-2002

\begin{tabular}{|c|c|c|c|}
\hline \multicolumn{4}{|c|}{ "GLS-Regression with panel-specific AR(1), heteroscedasticity and fixed effects } \\
\hline & ECOWAS & WAEMU & CEMAC \\
\hline Initial income & $-.0975(.020)$ & $-.0915(.020)$ & $-.0814(.021)$ \\
\hline Time & $.0104(.003)$ & $.0125(.002)$ & $.0092(.002)$ \\
\hline Log Investment & $.0340(.007)$ & $.0328 \quad(.007)$ & $.0358(.008)$ \\
\hline Log schooling & $-.0611(.015)$ & $-.0794(.014)$ & $-.0638(.015)$ \\
\hline $\log (n+g+\delta)$ & $.0109(.013)$ & $.0139(.011)$ & $.0022(.015)$ \\
\hline Member & $.0651(.045)$ & $.0196 \quad(.016)$ & $.0410(.027)$ \\
\hline Member years & $.0005(.000)$ & $-.0017 \quad(.002)$ & $-.0029(.004)$ \\
\hline No. of observ. & 180 & 180 & 180 \\
\hline Prob $>$ Chi2 & 0.000 & 0.000 & 0.000 \\
\hline
\end{tabular}

Also, from model (19) one expects negative signs for population growth $(\log (n+g+\delta))$. Tables 1.6a-1.6c show insignificant coefficients for population growth. One might argue that in Africa it is not clear whether the marginal utility of labour force is still positive due to the low technological standards and the high proportion of labour-intensive production in gross domestic income. Consequently, positive and negative effects neutralize. Note that when we split members and non-members in different samples, i.e. estimate with more homogeneous country sets, then the returns of $\log (\mathrm{n}+\mathrm{g}+\delta)$ become either insignificant or negative.

\subsection{Conclusions and Extensions}

After a brief review of the controversial discussion about regional integration areas and in particular South-South-agreements we state the hypothesis that South-South-agreements promote faster convergence and stronger growth. We tested this hypothesis by studying a set of those RIAs including the three main world regions West and Central Africa, South America, and South Asia. These sets were introduced in Section 1.3. Our analysis is based on the neoclassical growth model (Solow-model) which has been derived in detail for panel data in Section 1.2. Therein as well as in Sections 1.3 and 1.4 possible econometric problems were discussed. Our analysis shows that for all RIAs (see Tables A and B in the Appendix A) the coefficient of initial income is higher (in absolute values with negative signs) for members compared to non-members. We therefore conclude that South-South-RIAs lead to faster beta convergence. In addition, since additionally the return on membership is significantly positive (except for ASEAN in the conditional regression) we also conclude that they produce stronger growth. Furthermore, while the marginal utility of membership seems to be decreasing, on average, the returns on investment and schooling are sometimes higher inside RIAs than they 
are outside. One reason for this finding could be the successful sectoral coordination between the RIA-partners.

Finally, we also considered and discussed various particularities of the specific regions.

It is well known that in the neoclassical Solow model applied here, beta convergence implicates either monotone sigma convergence or monotone sigma divergence, where the latter makes sense only in the conditional model which allows for different steady states among the countries. This certainly is only true if the model is not mispecified. Therefore it would be interesting to compare our findings on beta convergence with the development of the standard deviation of per capita income in these RIAs to understand better what the found beta convergence really means for each area.

Another interesting point is to investigate the impact of RIAs on the speed of convergence among members and to see what we can learn about the country-specific differences in the speed of convergence. The growth theoretical approach forecasts for example that, landlocked countries such as Mali or Paraguay should show lower adjustment rates. This, together with the present paper and a study about sigma convergence, can again help us to understand the impact of South-South-agreements on growth and convergence better. 


\section{CHAPTER 2:}

\section{Income Dispersion and Sigma convergence in South-South- Agreement Areas}

\subsection{Introduction}

Until today, it is disputed to what extend South-South-Agreements is boon or bane for growth and development. This paper gives a survey of empirical facts about the income development in these integration areas. Moreover, this article discusses a particular aspect of income inequality and convergence, namely the per capita income development and dispersion of per capita income within the so-called South-South areas. To this aim we have chosen a representative sample of regional integration areas (RIAs henceforth) in the three world regions South Asia, South America, and West and Central Africa. We study the development of per-capita inequality across all member countries from the foundation of the particular integration areas up to 2002.

The three most used measures to analyze the income inequality at national or regional level are the sigma dispersion, the Theil populations-weighted index, and the Gini index, see Duro (2004) or Rey and Janikas (2005) for details. The Gini index is inadequate for small samples, and the Theil index is mainly interesting for decomposing the cross-national disparity of inequality within and between groups. But here we are more interested in the convergence and divergence dynamics between countries in order to study the effect of South-South agreements. In contrast to the also quite popular $\beta$-convergence approach, there is not necessarily an econometric model behind $\sigma$-convergence. Indeed, we just measure the percapita dispersion across countries at different time points over a certain test period. Therefore each sigma-path will allow us to draw conclusions about convergence and divergence without necessarily having to specify a particular income or growth model. Nevertheless, if we additionally consult, for example, the well-known unconditional Solow growth model, we can certainly make further conclusions, as we will do in the next section. 
In the first chapter we analyze the so called $\beta$-convergence inside the integration areas ASEAN, WAEMU, CEMAC, ECOWAS, ANDEAN and MERCOSUR based on the Solow growth model. We found conditional and unconditional $\beta$-convergence for basically all areas. However, Barro and Sala-i-Martin (1992) have shown why it is interesting and important to consider both the $\beta$ - and the $\sigma$-convergence of income development. Clearly they are conceptually different; while $\sigma$-convergence shows the distribution or disparity of income over time among members, $\beta$-convergence (and the adjustment speed calculated by it) represents the long-term mobility of income; see Sala-i-Martin (1996). These two concepts are related in that, in the unconditional Solow model, $\beta$-convergence is a necessary though not sufficient condition for $\sigma$-convergence; see Sala-i-Martin (1996) or Quah (1995). Actually, $\sigma$-convergence in the sense we use it means simply that the log-income dispersion inside a set of countries decreases over time.

So this paper also contributes to the controversial discussion on the extend to which SouthSouth-Agreements add to income convergence across its member states. Concerning this discussion, recall that there exists the general criticism against regional integration agreements saying that they would lead to trade creation but also to trade diversion (Viner 1950) and it is not clear a priori whether the trade creation exceeds the trade diversion, which would mean positive net welfare effects. Further, most of the South-South-integration areas involve several parallel and overlapping agreements which typically favor the economically stronger members impeding real (trade) liberalization rather than promoting it; see e.g. Bhagwati, Greenaway, and Panagariya (1998). South-South-Agreements are especially subject to the poor stays poor criticism, coinciding with the hypothesis of club convergence. This club convergence hypothesis was originally considered as a competitor to the absolute and or conditional convergence hypotheses; see Galor (1996) for an early theoretical discussion. A main factor causing convergence in regional integration areas is the knowledgeand technology transfer, stronger stress of competition and efficient compensation mechanisms. Consequently, to avoid running into the poverty trap, integration areas need the participation of strong economic leaders; see also Quah (1993). Further arguments supporting the hypothesis of increasing income disparity in South-South-Agreement areas are, for example, the non-complementary (i.e. similar) production and trade structures of the member states, the agglomeration of manufacturing industries in relatively richer countries and the stronger trade diversion at the cost of the poorest members. The necessary transfer of 
technology and terms of trade gains are hardly possible among poor states because these lowincome countries trade less amongst themselves. Obviously, following these arguments, the welfare losses are smaller and the gains bigger in North-South or North-North agreements; see again Quah (1993) but also Baldwin, Martin and Ottaviano (2001) who pronounce strongly in favor of free trade to reach perfect international or regional transmission of learning externalities. So typically, it is recommended to practice "open regionalism".

The new economic geography does not offer a uniform model theory for regional integration and convergence. However, it does try to work with more realistic hypotheses favoring endogenous growth models where, for example, technological progress is explained implicitly by the model. The most relevant factors for this school are transport costs, knowledge transfer, demand and realistic scale returns in the context of space-time modeling. For the short- and medium term, these models implicate divergence for RIAs after the foundation, because of negative effects through e.g. market liberalizations etc; see Krugman (1991a, 1991b), Baldwin, Martin and Ottaviano (2001) or Scott (2006). More specifically, Krugman (1991a) shows that economic integration processes induce agglomeration especially if industrial development is unequally distributed at the initial stage. Therefore, liberalization together with regional integration leads to further concentration of economic activities; see also Krugman and Venables (1996). Goodfriend and McDermott (1998) argue that the key factor of convergence processes is openness to foreign ideas and technologies; a closed regionalism between developing countries must cause divergence due to of the lack of new technology and ability of innovation. According to Giannetti (2002) initially unequally distributed manufacturing industry locations lead to income divergence at country or even regional level, because convergence depends on the possibility of knowledge spillover. She points out that member states therefore do not benefit uniformly from the knowledge exchange and that agglomeration effects arise in short- and middle-terms. A similar argument is used by Venables (2003) who looked at comparative price advantages; his theory entails income divergence for regional integration areas of low-income countries due to concentration processes of manufacturing industry towards countries with comparative technological advantages. This advantage causes trade divergence as the poorer members will import from those partners who would probably not be competitive on the global market. The poor members, however, have internationally competitive prices for unskilled labor. If comparative advantages are associated with the GDP per capita, e.g. via physical and human capital endowments, then RIAs can promote income convergence, but the unequal cost and 
benefits in South-South areas could potentially lead to divergence. An instrument to reduce unequal integration costs is a functioning compensation fund.

Summarizing, the trade theory, as well as the new economic geography, advises against regional integration among low income countries, arguing that this would lead to income divergence and inequality. Our study of the dispersion of income in all South-South areas is to test for this negative hypothesis. One of the main points we make is that almost all these studies have abstracted from other long-term targets, for example important mechanisms, such as political stabilization of regions, which we expect to have an extremely important impact on economic development and which should contribute to intra-regional increase in welfare.

In this study we first look at the GDP per capita, and afterwards at the $\sigma$-path, i.e. the development of the dispersion of log per capita income, in various regional integration areas (henceforth RIAs) of low income countries, say South-South-Agreement areas. We will speak of $\sigma$-convergence when the dispersion of log income per capita among member countries tends to fall over time. There are some studies about $\sigma$-convergence in some of the specific RIAs considered here. For example, Hammouda, Karingi, Njuguna, and Jallab (2007) show that income disparity declines within the CEMAC and the WAEMU, but not in the ECOWAS, where they find an increasing disparity for the period 1980-2003. For ECOWAS they find, similar to Jones (2002), that the sigma values first decline up to 1990 and thereafter then rise. For the MERCOSUR, Blyde (2005) finds out that the income disparity increases during the 1990s, i.e. during the starting period of this agreement. For this reason we study MERCOSUR founders separately and afterwards the whole MERCOSUR and the Andean group. Finally, for ASEAN, Lim and McAleer (2004) test the five founding members and find increasing income dispersion from 1965 to 1991 . We use our extended sample to test whether the whole ASEAN area (ten members) exhibits sigma convergence (until 2002), and compare the results with those for the ASEAN +3 and the ASEAN +5 respectively.

The rest of the paper is organized as follows. In the next section we briefly outline the concepts of sigma and beta convergence and how they are related to each other. We further introduce the studied data samples and additional methods used in this study. In Section 2.3 we introduce the different RIAs in detail, also for a better understanding of the country specific per capita income growth, and for an easier understanding and comparison of the sigma developments of each RIA. Then, in Section 2.4, we discuss the per capita income 
growth path of the member states of specific RIAs before we present and discuss the empirical results on convergence in Section 2.5. In Section 2.6 we summarize and conclude. Most of the figures are deferred to the Appendix B.

\subsection{The Methodology and Data}

We start from the classical unconditional Solow model:

$$
\ln y_{i, t}-\ln y_{i, t-1}=a-\left(1-e^{-\gamma \tau}\right) \ln \left(y_{i, t-1}\right)+\varepsilon_{i, t}, \text { where } i=1,2, \ldots, N ; t=1,2, . ., T
$$

employing the usual notation, denoting by $\ln y_{i, t}$ the logarithm of per capita income of country $\mathrm{i}$ and time $\mathrm{t}$, a constant $a$, a parameter $\gamma$ which is proportional to the sum of labor force growth, technological progress, and depreciation rate, and finally a mean zero disturbance term $\varepsilon_{i, t}$ to capture heterogeneity over time and within countries. For each period then, $y_{i, t-1}$ is the initial per capita income. Replacing $\left(1-e^{-\gamma \tau}\right)$ by $b$ (better known as the negative beta, $-\beta$, to which the popular beta-convergence refers) we obtain

$$
\ln y_{i, t}=a+(1-b) \ln y_{i, t-1}+\varepsilon_{i, t} \text {. }
$$

For the ease of calculus, the shocks $\varepsilon_{i, t}$ with $E\left(\varepsilon_{i, t}\right)=0$ are typically assumed to be independently distributed over time and space and also homoscedastic, that is they have the same variance $\sigma_{\varepsilon}{ }^{2}$ for each country $\mathrm{i}$ and time t. Clearly, this is a strong and unrealistic simplification with some important implications; see also discussion below.

The cross-sectional dispersion of log income is estimated via

$$
\hat{\sigma}_{t}^{2}=(1 / N) \sum_{i=1}^{N}\left[\ln \left(y_{i, t}\right)-\overline{\ln \left(y_{t}\right)}\right]^{2},
$$

where $\overline{\ln \left(y_{t}\right)}$ is the average of the $\mathrm{N} \log$ GDPs per capita in year $\mathrm{t}$. Next, the variance decomposition of the linear model, equation (1), gives directly

$$
\sigma_{t}^{2}=\sigma_{t-1}^{2}(1-b)^{2}+\sigma_{\varepsilon}^{2}, \text { where } \sigma_{t}^{2}=\operatorname{Var}\left(\ln y_{t}\right) \text {. }
$$

For more discussion see Barro and Sala-i-Martin (1992) or Young, Higgins and Levy (2007). If we do not assume that the income dispersion tends to zero but consider a steady state of the Solow model instead, in which $\sigma_{t-1}=\sigma_{t}=\sigma^{*}$, then it follows (under the strong assumption of homoscedasticity): 
$\left(\sigma^{*}\right)^{2}=(1-b)^{2}\left(\sigma^{*}\right)^{2}+\sigma_{\varepsilon}^{2} \Leftrightarrow\left[1-(1-b)^{2}\right]\left(\sigma^{*}\right)^{2}=\sigma_{\varepsilon}{ }^{2}$

which is only defined for $0 \leq b \leq 2$. Thus, the steady state variance depends on the shock dispersion and on $b$ with $\sigma_{\varepsilon}=\sigma^{*}$ for $b=1$ and $\sigma_{\varepsilon} \leq \sigma^{*}$ otherwise.

Plugging equation (4) into equation (3) gives

or

$$
\begin{array}{r}
\sigma_{t}^{2}=\left(\sigma_{t-1}\right)^{2}(1-b)^{2}+\left(\sigma^{*}\right)^{2}-(1-b)^{2}\left(\sigma^{*}\right)^{2} \\
\sigma_{t}^{2}-\left(\sigma^{*}\right)^{2}=(1-b)^{2}\left[\sigma_{t-1}{ }^{2}-\left(\sigma^{*}\right)^{2}\right] .
\end{array}
$$

Obviously, if $0<\mathrm{b} \leq 1$ (i.e. $0>\beta \geq-1$ ) also called $\beta$-convergence, then we have convergence of the $\log$ income dispersion towards $\sigma^{*}$ which is not necessarily smaller than the present value (dispersion). In other words, beta convergence does not necessarily entail sigma convergence.

Furthermore, due to our linear model, the sigma evolution to the steady state runs monotonically. Sigma can rise or fall over the time, depending upon whether the value of $\sigma_{t-1}^{2}$ lies over or under the steady state level. That is, beta convergence is a necessary but not a sufficient condition for sigma convergence because beta convergence allows for sigma divergence (that is increasing log income dispersion). Therefore we may easily find beta convergence for some RIAs within a certain period but with increasing sigma at the same time. For the unconditional Solow model this simply means that the value of $\sigma_{t-1}^{2}$ is above the steady state-level. Additionally, but not further discussed here, we could redefine the model such that there could even be an oscillating adjustment of sigmas to their steady states. However, this would be beyond the scope of this paper.

There exist several concerns regarding this rather simple criterion. In the literature, sigma convergence has mainly been criticized for the following reasons. First, the model framework is based on the assumptions that the residuals $\varepsilon_{i, t}$ are independent over time and space and, in particular, homoscedastic over the different countries. This implies automatically that all heterogeneity, and even most of the natural dynamics, are ignored. In particular, country- or country group- specific shocks are thus neglected; see discussion of Quah (1993). Second, the sigma-concept not only ignores important covariates (being based on the idea of unconditional convergence); it does not consider the initial levels of per capita income of the different countries although we know of the persistence of initial conditions. The sigma convergence simply captures the evolution of cross-section income distribution towards an invariant measure; see discussion of Durlauf, Johnson, and Temple (2005). Or, as Quah 
(1993) mentioned, sigma convergence means that each country eventually becomes as rich as all the others - the cross section dispersion diminishes over time. As a consequence, no information is obtained about distribution dynamics within the considered group(s), such as mobility, stratification, and polarization (see the numerous papers of Quah 1993a, 1993b, 1996a, 1996b, 1996c, 1997). Durlauf, Johnson, and Temple (2005) therefore state the importance and necessity of developing tools which allow distribution methods to adjudicate substantive growth questions. The last criticism, however, holds equally well for the different regression approaches to study convergence.

For our empirical study, the real GDP per capita in international PPP\$ is taken from the World Development Indicator database of 2007. We compute the standard deviation of log per capita income for all RIAs with the simple formula already given in (2).

In order to eliminate business cycle effects, we use the Hodrick-Prescott (henceforth HP) filter to separate the trend from the cyclical component. The HP filter computes a stochastic trend $\left\{g_{t}\right\}_{t=1}^{T}$, in the following the series of interest, by minimizing the sum of squares of its second difference (see Hodrick and Prescott (1997) for details). That is, we consider the $\ln y_{t}=g_{t}+c_{t}$ for $\mathrm{t}=1, \ldots, \mathrm{T}$, where $\ln y_{t}$ is the logarithm of GDP per capita, $c_{t}$ the cyclical component to be filtered out, and $g_{t}$ the growth component of interest. As only the $\ln y_{t}$ are observed, the trend has to be calculated via a linear programming problem of the form

$$
\underset{\left\{g_{t}\right\}_{t=1}^{T}}{\min } \sum_{t=1}^{T}\left(\ln y_{t}-g_{t}\right)^{2}+\lambda \sum_{t=2}^{T-1}\left[\left(g_{t+1}-g_{t}\right)-\left(g_{t}-g_{t-1}\right)\right]^{2} .
$$

The smoothing parameter $\lambda$ penalizes the variability in this time series and is fixed in our context to be 100, following the arguments of Hodrick and Prescott (1997); note that we have annual data ${ }^{14}$.

Generally, there is no perfect method to eliminate business cycle effects, because of the natural distortion in the data. In order to assess the impact of the smoothing parameter $\lambda$, which was chosen subjectively, we repeated the study with the three-year moving averages of

\footnotetext{
${ }^{14}$ They show that this parameter should be approximately the ratio of the variance of the cyclical component divided by the variance of the second differences of the growth components. This gives a value of 1600 for $\lambda$ when we assume a 5 percent cyclical component and a one-eighth of 1 percent change in the growth rate in a quarter. Note that therefore in STATA, 1600 is the default for $\lambda$ which, however, refers to quarterly data.
} 
all unfiltered GDP series to compute the sigma values of all RIAs and country sets under consideration. These studies, however, lead to basically the same results (not shown here).

\subsection{Discussion of Per Capita Growth}

\section{MERCOSUR}

We start with a discussion of our results for the MERCOSUR. Figures B.1.1 to B.1.3 show the HP-filtered log per capita income developments first for MERCOSUR plus associated countries together, then separately for the four founders only, and finally for the ANDEAN countries (Bolivia, Columbia, Ecuador, and Peru). In Figures B.1.4 to B.1.6 the corresponding unfiltered log per capita developments are given, and in Figures B.1.7 to B.1.9 the unfiltered per capita growth paths.

After important severance charges conducted by the introduction of the currencies Plano Austro and Plano Cruzado in Argentina and Brazil respectively, the economies recovered only momentarily, and then both countries reached an inflation rate of more than 1000 percent before they used Brady Bonds in 1989 to securitize credits yielding a successful financial restructuring in cooperation with the International Monetary Fund; see Bulmer-Thomas (2003) and Thorp (1998). We then observe a quite steady economic growth until the recession in 1998 and the impact of the financial crisis in 2001, especially for Argentina. Uruguay participated in the Brady Bonds round and also succeeded in stopping serious inflation. Otherwise, having hardly FDIs, but depending mainly on Argentina and Brazil, its economic growth has basically been moving alongside that of Argentina since 1990. Paraguay is the smallest founder of MERCOSUR; its agriculture still makes almost 30 percent of the GDP, and it suffers from the typical Latin America afflictions, namely high inflation, a serious national debt, strong inequality, etc. Since its economic crisis of 1997 the per capita income has stagnated.

If we look at the ANDEAN countries, what maybe strikes us most is the different development of Peru compared to the rest, especially from about 1987 to 1995 . The reason for this was a bundle of economic reforms towards liberalization (decentralization, opening for 
FDIs, many $\mathrm{ODA}^{15}$ projects for creation and improvement of infrastructure) after a long period of dictatorships ${ }^{16}$. These reforms have shown their positive returns since the mid 1990s but were realized at that time without an adequate social protection provoking serious social inequality and conflicts at the beginning; see Bulmer-Thomas (2003). Ecuador is the second poorest country of Latin America; $60 \%$ of its export is petroleum so that we can see here a small effect of the OPEC crises in 1986. At the end of the 1990s hyperinflation and recession led to a general economic crisis ending basically with the substitution of their own currency by the US\$ in 2000. One should also mention how amazing well Columbia performed despite the permanent conflicts with drug syndicates and the $\mathrm{FARC}^{17}$. It efficiently used its natural commodities for infrastructure and further industrialization.

Chile is the second richest country of Latin America behind Argentina but with a serious problem of inequality and poverty. Today it has a mainly market oriented system with a treasury rate below 20 percent. It is the largest exporter of copper; the crumbling of copper prices around 1998 is evident in Figure B.1.7. The oil price decline had disastrous consequences for Venezuela where oil export has a share of about $60 \%$ of total exports. High national debts, hunger revolts, e.g. in 1989, and the IMF policy (1994-1998) led finally to Chavez' socialism of the $21^{\text {st }}$ century with several nationalizations etc., after 2002 accompanied by economic stagnation and finally recession.

\section{ASEAN}

Figures B.2.1 to B.2.9 show the per capita development for the ASEAN members, the ASEAN founder states, and most of the East Asia countries pooled. The organization is as above (for MERCOSUR) plotting first the HP-filtered log per capita incomes, then the unfiltered, and finally the unfiltered absolute values, i.e. without taking logs.

Not surprisingly, among the founders, the city state Singapore has experienced the strongest economic growth. Today, services make about $70 \%$ of the GDP. The main reasons are an extremely deregulated financial center and the harbor being an important trans-shipment center for overseas trade. Additionally, Singapore benefits from a high potential

\footnotetext{
${ }^{15}$ ODA $=$ official development assistance.

${ }^{16}$ The military dictatorship lasted from 1968 until 1980.

${ }^{17}$ FARC = Fuerzas Armadas Revolucionarias de Colombia, an officially communist guerrilla group that is specialized on drug trafficking and kidnapping.
} 
biotechnology (Biopolis). In contrast, Indonesia has always been the poorest founder state although it participated in the general upwards trend (see Figures B.2.2 and B.2.5) until the Asian crisis in 1997. Malaysia and Thailand exhibit rather similar per capita paths except that Malaysia stagnated for three years around 1985. Both have coped with a slow but steady industrialization. Thailand also experienced a slow and difficult process of democratization since the 80s. The Philippines exhibit a serious inequality between the poor agrarian south and the industrialized north (the main island Luzon). In its per capita growth path we see the impact of the economic crisis and riots against the dictator Marcos in the mid 80s, and the eruption of the volcano Pinatubo in 1991. Though now a democratic republic (Marcos left in 1986) the political situation is quite unstable and the country suffers from various Maoist and Muslim guerillas and from terrorism. Note that all ASEAN founders are export oriented and therefore also depend on global business cycles today.

Let us briefly summarize the outcome for the ASEAN newcomers; Vietnam, Cambodia, Laos, and Papua New Guinea. We will not discuss PR China, South Korea, Japan, New Zealand, and Australia. Brunei and Burma (Myanmar) are excluded owing to lack of data (Brunei is a Sultanate that does not publish its data; in Burma a military junta is in power). Although not documented in the figures, it is well known that Vietnam was very poor until the 80 s, even to the point of famine. It had a centrally planned economy and suffered embargoes and various consequences of the civil war. The US embargos ended in 1993 after several economic reforms since 1986 including privatization and liberalization entailing FDIs and finally, as we can see in the figures, a steady economic growth; cf. Minot and Goletti (1998). Laos also started its economic reforms in 1986, again a communist planned economy until then, with similar success. We have data for Cambodia starting from 1993 when a democratic monarchy was (re-) established. More than Vietnam and Laos it is an agrarian country with recent economic reforms. Papua New Guinea has a strong informal agricultural sector and exports mainly agricultural products like cacao and palm oil. Its economy therefore is strongly dependent on world market prices; compare its development path with international price developments. It has been associated with ASEAN since 1984. Note that from the plots for East Asia North Korea and Taiwan are excluded due to the lack of data. 


\section{West and Central Africa}

We start by considering CEMAC. In about 1960 Equatorial Guinea, due to its cacao production, enjoyed one of the highest per capita incomes in Africa. In 1996 large oil reserves were discovered. Their subsequent exploitation contributed to a dramatic increase in government revenue. However, despite a per capita GDP of more than US\$30,000 in 2008 (the ninth highest in the world) it ranks 121st (out of 177 countries) on the Human Development Index of the UN. Also Gabon is rich in natural resources. It has an important timber and paper industry, but 80 percent of its export is oil and thus its economy strongly depends on the international oil market. We can detect clearly the oil crisis in 1979 and the price slumps from 1986 to 1989 when looking at its per capita development. The latter is actually true for basically all CEMAC countries as their exports are mainly based on primary goods. Cameroon had been in recession from the mid 80s until the mid 90s due to a overrated currency, political mismanagement and high corruption (like many African states). In 1994 it started with devaluation and an IMF advised restructuring of their economy. The Republic of Central Africa is very much affected by the civil wars in Sudan, experiencing an enormous migration of refugees. Additionally, their own democratization process went slowly until 1995 due to its many military revolts. Also Chad has been suffering different internal political and military conflicts, except maybe from 1990 to 1999. In the 90 s oil reserves were discovered but Chad exported no oil or very little before 2002. Finally, the Republic of Congo had a socialist economy until 1990 with high unemployment and serious external debts. From 1997 to 2002 alone, three civil wars took place.

Before we start to list and discuss the per capita developments of the member states of WAEMU we should mention that these countries used the end of the Cold War to integrate into the world market. For most of them this globalization has resulted in a steady economic upturn. Most of these countries are still largely agriculturally oriented.

Benin has important external debts; its cultivation is mainly traditional. The main export goods are cotton and cashew nuts. Burkina Faso is one of the poorest countries in the world, also with important external debts. It has no natural resources and produces mainly cotton and peanuts. After a putsch in 1982/83 and severe riots, it started an IMF adjustment program in 1991. In Mali more than 80 percent of the labour force is dedicated to traditional agriculture entailing a high risk of crop failures. It cultivates mainly peanuts, maize, cotton and sorghum. 
However, after some economic reforms in 1992, the industrial share of the GDP has increased substantially. Note also that Mali has one of the highest fertility rates in Africa.

Cote d'Ivoire is the world's leader in cacao production and was therefore especially affected by the price decrease for cacao since 1980 followed by economic crises and a civil war in 2002. Besides, Cote d'Ivoire is the only oil-exporting country among the WAEMU-countries and profits from oil-price increases; cf. Goretti and Weisfeld (2008). Togo's economic situation improved notably after some IMF reforms in 1979. Nevertheless, its economy still depends strongly on its traditional products cacao, coffee and, since 1990, also cotton. But Togo is also an important re-export port for automobiles. Riots and the price decrease of export goods were followed by a recession in the 90s. Guinea-Bissau had had a steady growth until the beginning of political unrests in 1997. Until the mid 80s Niger had implemented a policy of development agencies. Unfortunately, several bad harvests and a quite high fertility rate led to subsequent stagnation. In contrast to the other WAEMU members, Senegal has a significant industry for the subsequent processing of primary goods, especially for food and textiles. Therefore, though its main export goods are based on peanuts and cotton, it is less affected by price changes for primary goods on the world market. Actually, in 2000, primary goods constituted only 2 percent of Senegal's total export.

We finally turn to ECOWAS. Its member states are Benin, Burkina Faso, Cape Verde, Cote d'Ivoire, Gambia, Ghana, Guinea Bissau, Guinea, Liberia, Niger, Nigeria, Senegal, Togo, and until 2001 also Mauritania. Due to the overlapping memberships we have already discussed most of them.

Since 1983 Ghana has participated in an IMF restructuring program with a devaluation of its currency. Its export is dominated by gold, diamonds, and some agricultural goods. The economic growth of Nigeria was based on oil export since the 1960s but was thwarted by mismanagement, corruption and a military regime from 1993 to 1998; cf. Khan (1994). Today it has a growing telecommunication sector. Guinea implemented some economic reforms in 1985, liberalized its rules for FDIs in 1998, and has several joint ventures today, especially in the mining sector. In contrast, Gambia has hardly any natural resources, acts as a re-exporter instead, but has suffered a recession since 2000. More then 80 percent of Sierra Leone's exports are raw minerals. Since 1991, the exploitation of diamonds has decreased due to a civil war, and a main part of its "export" is simply illegal diamond smuggling. From its independence in 1975 until 1990 Cape Verde had been a communist system. In 1991 it 
changed to a neoliberal service-oriented market economy living from tourism and trade. It has a rather important money transfer from emigrants amounting to about 20 percent of the GDP.

\subsection{Empirical Results for sigma-convergence}

Before looking at our outcomes for sigma convergence we first briefly recall and summarize the findings of Chapter 1 for beta convergence in these South-South RIAs. Significant unconditional and conditional beta convergence was found for all world regions that we consider in this paper. Moreover, the analysis showed that membership has had a positive impact on both beta convergence and growth, again for all RIAs considered here. In order to compare these results with sigma development, we use the same data set and compute the standard deviation of log income per capita for all RIAs, i.e. the standard deviation over the different countries within each integration area.

As is known from the literature and as indicated above, in a linear separable Solow growth model, beta convergence can lead to either a monotone decrease or a monotone increase of the standard deviation when neglecting the business cycles. In other words, sigma divergence is not in contradiction to beta convergence, and thus, sigma divergence would not be in conflict with the findings of Chapter 1.

\section{MERCOSUR}

We again start with the MERCOSUR. Table 2.1 compares the dispersion of income in Latin America. The first column describes a divergent sigma trend of the four MERCOSUR founder states. The second column shows sigma divergence for the set of all MERCOSUR plus associated states. The values for the ANDEAN $^{18}$ as a country subset increase until 1995 and fall marginally afterwards. Actually, we can say that for the ANDEAN countries the dispersion of the per capita income stays nearly at the same level from 1985-2002. Moreover, when looking at Figure 2.1 we find a monotone increasing dispersion of per capita income for the four MERCOSUR founders as well as for the whole region, at least for the period 19852002. In Table 2.1, if we compare only the years 1985 and 2002, we find in both sets (only founders and all members, respectively) much higher sigma values for 2002. These results

\footnotetext{
${ }^{18}$ The ANDEAN community was founded in 1969. Its members were Bolivia, Colombia, Ecuador, Peru and until 2006 Venezuela.
} 
coincide with Blyde (2005) who also applied the Hodrick-Prescott filter. However, he concentrated only on the four MERCOSUR founder states.

Table 2.1: Sigma convergence in Latin America

\begin{tabular}{llll}
\hline \hline & HP-founder & HP- Assoc. & HP_ANDEAN \\
1985 & 0.3071 & 0.4157 & 0.4138 \\
1990 & 0.3172 & 0.4358 & 0.4268 \\
1995 & 0.3593 & 0.4699 & 0.4259 \\
2002 & 0.3973 & 0.4905 & 0.4085 \\
$\begin{array}{l}\text { No. of } \\
\text { countries }\end{array}$ & 4 & 10 & 4 \\
\hline \hline
\end{tabular}

If we compare these results with the findings of Chapter 1, then we have beta convergence but sigma divergence in the MERCOSUR. The explanation can be found in Figures B.1.1 to B.1.9 in Appendix B. One reason is the fact that poorer countries like Bolivia grew faster (in percentage) than the richer countries as e.g. Argentina. This causes beta convergence. But if we compare the absolute values or the logarithm of per capita income of the countries over time in this RIA, we see that the income dispersion increases (compare left hand side 1985 with right hand side 2003 in Figures B.1.4-B.1.6). When just looking at the extreme cases, i.e. Argentina and Bolivia, one notes that the income gap becomes slightly larger. Moreover if we look at the MERCOSUR founders (see Figure B.1.5) the gap between poorest (Paraguay) and richest (Argentina) increases significantly from 1985 (0.75 log points) to 2003 (0.95 log points). Otherwise, the tables as well as the figures show - not surprisingly - that the four MERCOSUR founders show a much lower variance than the ten partner countries. In other words, the dispersion of per capita income is lower in the four MERCOSUR founders (Figure 2.1). Another example, which explains the difference between sigma and beta convergence, is that on average the per capita income increase was 1.7\% p.a. in Argentina, and 5.5\% p.a. in Chile. Nevertheless, though this causes beta convergence, the gap between Argentina and the other members increased, resulting in the simultaneously observed sigma divergence. 
Figure 2.1: Sigma trends for Latin America

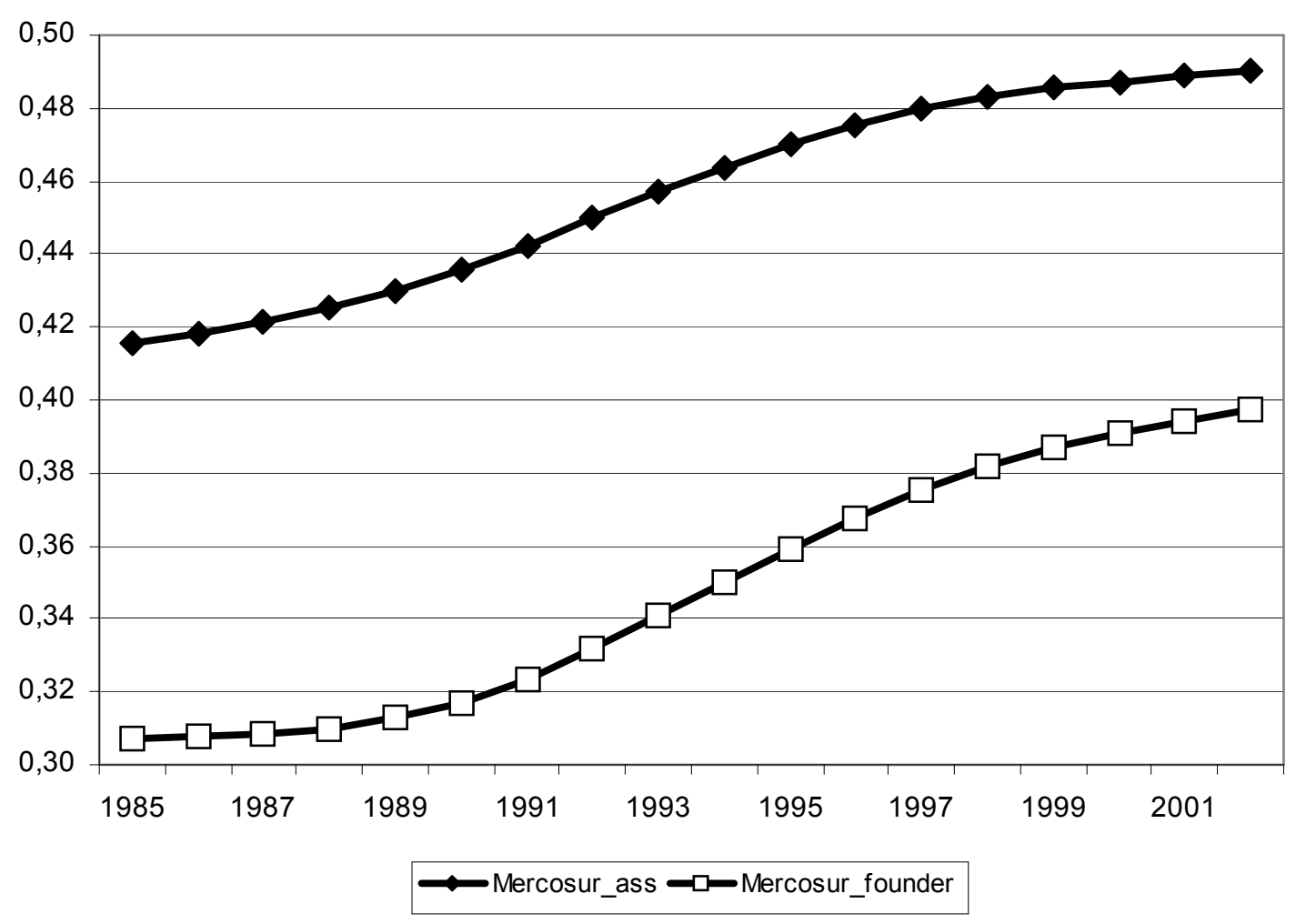

In the subset of ANDEAN countries, however, we observe a marginal decrease of sigma, at least if we only compare 1985 to 2002. In Figures B.1.3, B.1.6 and B.1.9 we can see that the gap between the poorest and the richest country of the ANDEAN states stays nearly the same during that period. In fact, only the income level increased.

Summarizing we realize that, along our empirical results for Latin America, the (log) income inequality between the members of MERCOSUR increased despite the relatively higher growth rates of poorer countries, and it hardly changed for the club of poorer countries organized in the ANDEAN.

\section{ASEAN}

The empirical outcomes for ASEAN are given in Table 2.2 and Figure 2.2. There we see that the income dispersion in ASEAN increased during the period 1975-2002 from 0.6882 in 1975 to 0.9102 in 2002 . The upward jump of sigma at the beginning of the $1980 \mathrm{~s}$ is due to the entries of new (poor) members. These new member states were mainly developing countries like Cambodia, Vietnam, and Laos ${ }^{19}$. The dispersion of per capita income among the five

\footnotetext{
${ }^{19}$ Also Burma (Myanmar) but as already mentioned, this country has not been included in the empirical analyses due to the lack of data.
} 
ASEAN founder states rose from 0.6882 to only 0.7861 during the period from 1975 to 2002 . Note that these results are similar to those of Lim and McAleer (2004). Like us, they also consider the development of sigma without Singapore, today the financial centre of this area, but one of the five founders of ASEAN. While the sigma of the ASEAN founder states has persistently increased since 1967, it oscillated around a certain level when Singapore was excluded from the country set. Lim and McAleer's (2004) results differ because they studied a different time period, namely the period from 1965 to 1991. However, they did not eliminate business cycle effects. Doing so (see Figure 2.2) clearly shows that the per capita income did not "just oscillate"; it clearly went down until the end of the 1980s and thereafter went up continuously to a similar level as at the end of the 1970 s.

If we compare only the values of 1975 versus 2002 (still Table 2.2), we find a marginal reduction of dispersion for the ASEAN without Singapore, from 0.55 to 0.48 points. Actually, the figures in the appendix (Figure B.2.2 to B.2.9) confirm that the gap between Indonesia, Malaysia, Thailand and the Philippines decreased in the considered period. Although we can observe that the poorest country, i.e. Indonesia, grew faster than the other four ASEAN founders, thus implying beta convergence, the income gap between the states slowly widened. In other words, the growth path of the poorer countries did not increase dramatically enough to catch up with the economic leader Singapore. This effect is less pronounced when we consider the enlarged RIAs.

Table 2.2: HP-filtered sigma values of East Asia

\begin{tabular}{llllll}
\hline \hline & ASEAN & $\begin{array}{l}\text { ASEAN- } \\
\text { founder }\end{array}$ & $\begin{array}{l}\text { ASEAN- } \\
\text { founder without } \\
\text { Singapore }\end{array}$ & ASEAN+3 & ASEAN+5 \\
1975 & 0.6882 & 0.6882 & 0.5565 & 1.0169 & 1.0984 \\
1980 & 0.6851 & 0.6851 & 0.4913 & 0.9760 & 1.0475 \\
1985 & 0.8547 & 0.6761 & 0.4147 & 1.0110 & 1.0793 \\
1990 & 0.9268 & 0.6819 & 0.3778 & 1.0439 & 1.0967 \\
1995 & 0.9446 & 0.7232 & 0.4226 & 1.0461 & 1.0908 \\
2002 & 0.9102 & 0.7861 & 0.4869 & 0.9953 & 1.0490 \\
$\begin{array}{l}\text { No. of } \\
\text { countries }\end{array}$ & 10 & 5 & 4 & 13 & 15 \\
\hline \hline
\end{tabular}


Figure 2.2: HP-filtered sigma trends in East Asia

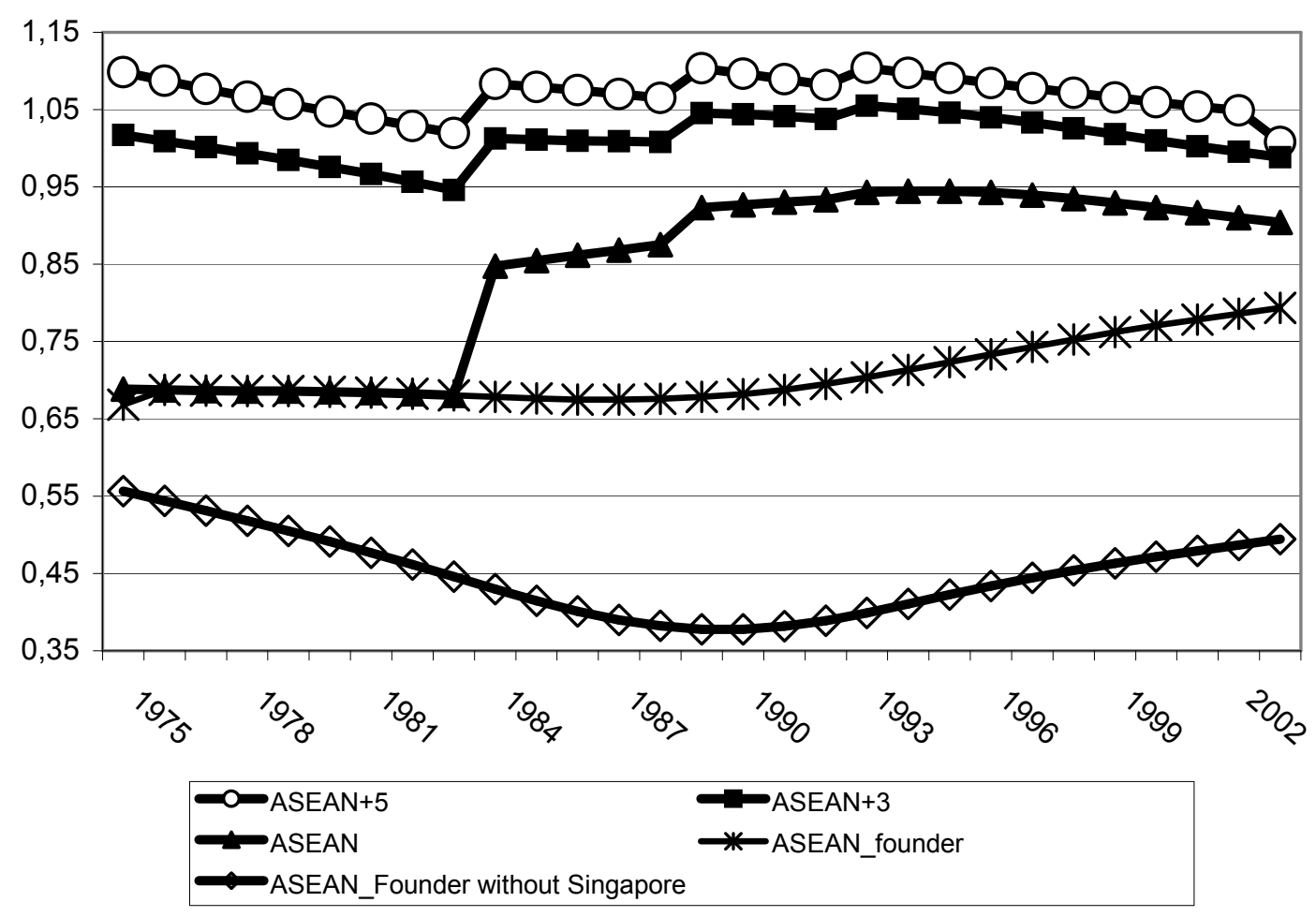

Figure B.2.3 shows the HP-filtered per capita log income of the whole area of East Asia, including ASEAN+3 and ASEAN+5. As expected, we see a marginal fall of sigma after 1995 (i.e. the economic crises). Obviously, the Asian crisis slowed down the growth of the new industrialized countries as well as of the high income countries like Japan. Therefore we can conclude that in general, while we find a slight sigma convergence for ASEAN founder (without Singapore), ASEAN+3 and ASEAN+5 (only interrupted by upward jumps due to new entries), we observe sigma divergence for the subgroup of founder states. Note that Myanmar (formerly Burma) is excluded from this study due to the lack of data. This conclusion can only be made if we correct for the late-entries. They are basically all developing countries, i.e. first they cause a sigma jump upwards before the sigma falls again due to their faster growth (after their entries) in both relative and absolute terms.

To summarize once more, we would say that the RIA(s) in South-East-Asia indeed lead to sigma convergence, i.e. decreasing income inequality at the intra-regional level. However, at the same time, if we compare the results for ASEAN with the findings for MERCOSUR or ANDEAN, then we realize a much higher inequality level in the ASEAN than in the Latin America South-South agreements. One reason is obvious: Since the mid 90s three of the least 
developing countries (LDCs) in South-East-Asia belong to ASEAN, but at the same time Singapore, one of the famous Asian tigers and today a high income country (HIC), is also member of ASEAN. There are neither real "least developing" nor "high income" countries in MERCOSUR

\section{West and Central Africa}

Table 2.3: HP-filtered sigma values of West- and Central Africa

\begin{tabular}{llllll}
\hline \hline & ECOWAS & WAEMU & CEMAC & CFA & West Africa \\
1975 & 0.3884 & 0.4382 & 1.0323 & 0.7148 & 0.6181 \\
1980 & 0.3734 & 0.4171 & 0.9144 & 0.6521 & 0.5681 \\
1985 & 0.3590 & 0.3846 & 0.7575 & 0.5843 & 0.5208 \\
1990 & 0.4320 & 0.3508 & 0.7089 & 0.5526 & 0.5193 \\
1995 & 0.4727 & 0.3207 & 0.7262 & 0.5696 & 0.5580 \\
2002 & 0.5885 & 0.3156 & 1.2419 & 0.9057 & 0.8390 \\
& & & $(0.8041)$ & $(0.5605)$ & $(0.6226)$ \\
$\begin{array}{l}\text { No. of } \\
\text { countries }\end{array}$ & 14 & 8 & 6 & 14 & 20 \\
\hline \hline
\end{tabular}

Note: The sigma values in brackets 2002 are calculated without Equatorial Guinea.

The empirical results for West and Central Africa are given in Table 2.3 and Figure 2.3. CEMAC has by far the highest income dispersion among the selected African South-South agreement areas. The lowest dispersion we observe is for WAEMU. Sigma convergence of different African RIAs, including COMESA, was also studied by Hammouda, Karingi, Njuguna, and Jallab (2007). COMESA has a higher sigma since the end of the 1990s. But this is not surprising as it has the special feature of containing 24 countries in North-East Africa, East Africa and Southern Africa, with enormous distances and very heterogeneous structures. This is the reason why we excluded this specific RIA from our study. Note first that for the whole of Africa we find no business cycle synchronicity as we do e.g. in ASEAN.

The per capita income variance of ECOWAS falls from 1975 to 1985, and jumps upwards directly after. This is simply the effect of not having included Cape Verde before 1986 due to lack of data; but currently that country has the highest per capita income in ECOWAS, at least during the period from 1986 to 2002; cf. with Figures B.3.1 and B.3.6. In any case, the 
dispersion of income goes on rising since that jump, because the economic development of Sierra Leone, now the poorest country in the ECOWAS, plummeted. In 1991 a civil war began in that country.

Figure 2.3: HP-filtered sigma trends in West- and Central Africa

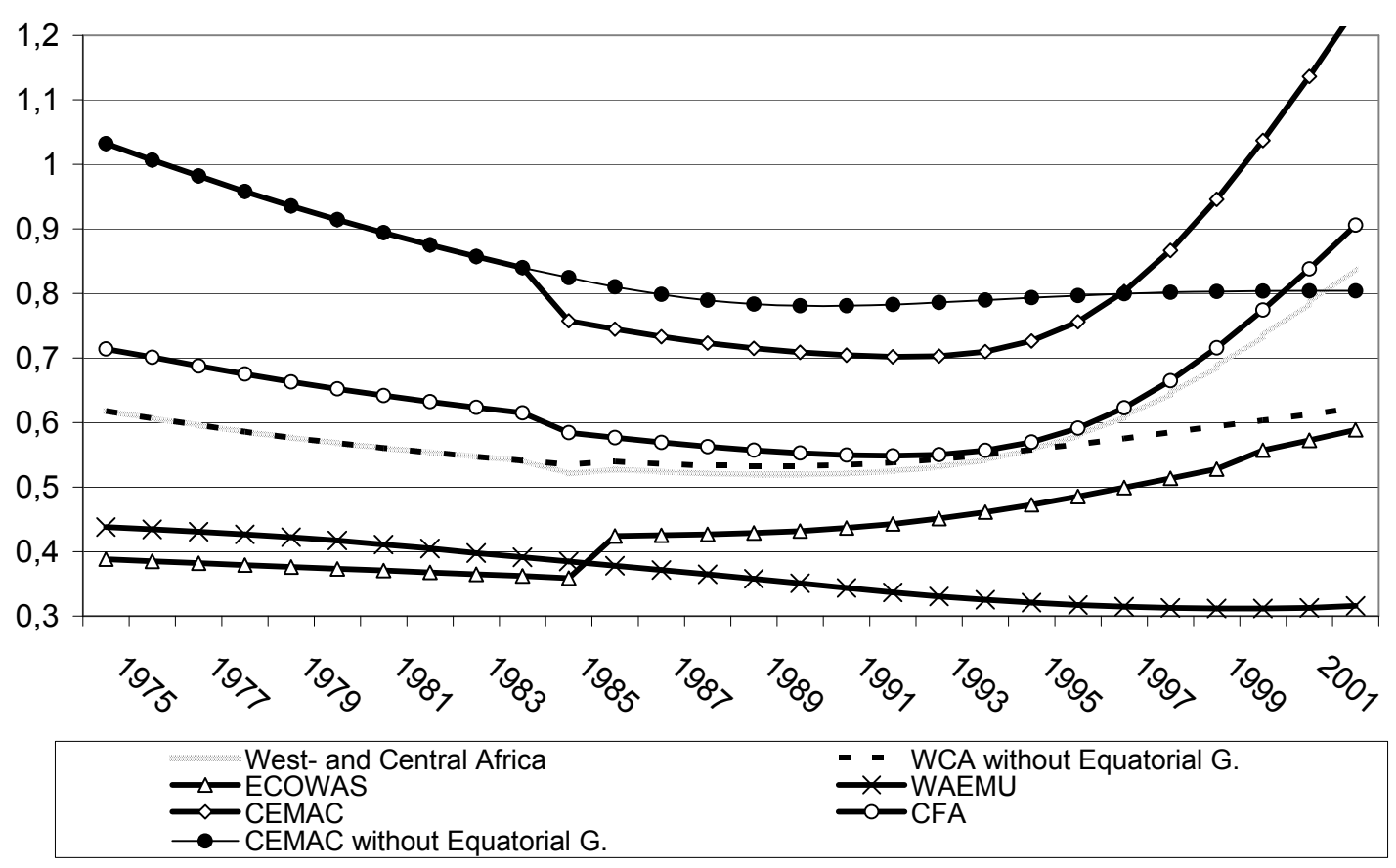

The WAEMU is the only RIA, among all South-South-Agreement areas considered here that exhibits a clear sigma convergence. Taking this together with the findings of Chapter 1 we conclude that here poorer countries indeed grew faster than richer ones (beta convergence) in such a way that the income gap among the member states decreased over time. As can be seen in Figures B.3.2 and B.3.7, the absolute distance of the log per capita income between the richest and the poorest partner respectively became smaller. However, we cannot observe a homogenous development. Nations like Senegal and Togo have caught up to the initial regional economic leader Cote d'Ivoire. Some other countries like Burkina Faso have somewhat reduced the income gap in relation to the richest partner (note that Burkina Faso was the poorest country in 1975). However, the per capita log income of Niger has stagnated since the mid 1980s, and that of Guinea-Bissau since the mid 90s, see Figure B.3.7. In Figures B.3.7 and B.3.10 we see that the recession in Mali increased (since 1985) the income gap within the WAEMU. We also see that the countries separate basically into two convergence clubs, three countries with higher per capita income, specifically Senegal, Togo and Cote d'Ivoire, and a group of poorer countries. Nevertheless, with a sigma level of 0.31 in 2002 
(see Table 2.3) this RIA has by far the lowest sigma value in West- and Central Africa, and even of all South-South RIAs considered in this study.

For CEMAC we first find a convergent sigma development. But after 1990 there is a change in the trend and the log income dispersion rises. Figures B.3.3, B.3.8 and B.3.11 clearly exhibit the reason: the economic boom of Equatorial Guinea, driven by oil compared to relative low growth rates in the other five member states caused an increasing inequality among the member states. Consequently, the CFA-zone as a whole also shows sigma convergence until 1990 but sigma divergence afterwards. Moreover, Figure B.3.4 shows that, until the end of the 1990s, the high per capita log income development of Gabon determined income inequality. For a better comparison we also calculated the income deviation in 2002 without Equatorial Guinea. The resulting sigma values, also shown in Table 2.3, demonstrate that the sharp increase of sigma was indeed only due to the oil fields in Equatorial Guinea. This is confirmed by Figure 2.3 where we see that since 1990 the log income dispersion basically stayed constant when leaving out Equatorial Guinea.

\section{Summarizing Remarks}

While WAEMU has the lowest dispersion of per capita income in 2002, CEMAC has the highest dispersion of all RIAs studied here. ASEAN has the second highest income dispersion. The reasons are that both CEMAC and ASEAN have one economic outlier; that of Equatorial Guinea in CEMAC, a high-income country compared to the other five members, which are lower-middle and low-income countries. Something similar can be observed in ASEAN; here it is Singapore which is, according the country classification of the World Bank in 2008, a high-income country. The rapid economic development of these two economic leaders (of CEMAC and ASEAN, respectively) in the last decades explains perfectly the enormous rise of income dispersion in the two RIAs respectively.

It is hard to assess whether the enormous economic progress of Singapore, or that of Equatorial Guinea, has contributed to (or will be conductive to) regional economic dynamism. First, this is dependent on intra-regional trade regulations, FDI flow between the members and on the functional compensation funds etc. Second, note that we observe a relatively short time period, simply because these integration processes have existed only for a few decades. RIAs do not always benefit from such economic leaders. It is possible that the economically 
strongest country, for example Equatorial Guinea, focuses much more on rich industrialized northern countries, and the neighboring partner countries cannot benefit from the economic cutting-edge. Indeed Equatorial Guinea's most important trade partners are the USA and the PR China. Mainly because of its insufficient infrastructure this country still depends on the cooperation with the partner members to participate in infrastructure improvement programs.

Concerning the WAEMU and its seemingly low income inequality, bear in mind that this is calculated at the national level, giving the same weight to each member country. Further, WAEMU is a group of exclusively low-income countries. Even though we have already considered log per capita income, the ranking of RIAs will change when we look at coefficients of variation or other relative measures rather than at sigma values.

\subsection{Conclusions}

This paper investigates the dispersion of per capita income within a representative set of South-South agreements covering all affected world regions (Latin America, Africa, and South-East Asia). More specifically, we consider MERCOSUR, ASEAN, ECOWAS, CEMAC, and WAEMU. A previous analysis has shown that these South-South- RIAs exhibit unconditional as well conditional beta convergence. Moreover, membership in one of the South-South-Agreements is followed by a positive impact on income convergence and growth. In other words, these co-operations promote not only convergent developments, but also growth for its member states. The classical unconditional Solow model predicts that if there is beta convergence, then the sigma fall or rise monotonically. The empirical results, summarized, are:

For the MERCOSUR, the founder states and the RIA plus its associated members, indicate an almost monotonically increasing dispersion of per capita income, whereas the sub-region ANDEAN generates a temporary and marginal decrease. From Figure 2.1 it is clear that the four MERCOSUR founders have substantially lower income dispersion level than the ten partner countries.

In ASEAN the sigma development is characterized by sudden upward jumps due to the entries of new (typically poor) members, and a slow decrease afterwards. Especially at the beginning of the 1980s, there is the excursive increase of the dispersions due to the entering 
developing countries like Cambodia. However, if we abstract from these entries and only look at the five founders, we notice a rise of income inequality since the 1990s. The ASEAN+3 and ASEAN +5 show an oscillating sigma path, maintaining a rather high level, as expected.

The WAEMU is the only RIA which shows clear sigma convergence. The two other African RIAs considered, CEMAC and ECOWAS, show no clear (i.e. monotone) trend; the inequality first decreases then later increases. The causes are multifarious with "economic shocks" being one reason for this phenomenon, such as the oil-export-driven boom in Equatorial Guinea or the civil war in Sierra Leone.

While beta convergence was found in all of these RIAs (see chapter 1), we found a clear sigma convergence in only one RIA (WAEMU). Certainly, according to the model framework in Section 2.2, beta convergence is a necessary but not sufficient condition for sigma convergence. Moreover, sigma divergence with beta convergence may simply indicate that we face a quite heterogeneous RIA with a steady state sigma consequently (much) larger than the current log income dispersion. This at least is true in case the Solow model is an appropriate econometric model for the time period and country set in question. The reasons can be various, for example single success stories (Singapore in ASEAN or Equatorial Guinea in Africa) or single poor performers (Sierra Leone in Africa or Venezuela in MERCOSUR). In general it is possible for poor countries to grow faster than rich ones, but for the total dispersion to increase.

Possible political implications are that, in spite of the criticism of Venables (2004), the implementation and expansion of integration policies have a clear positive impact on growth and convergence when they lead to an improved intra-regional infrastructure and promote (intra-regional) trade. The installation of fully functional intra-regional institutions like central banks or common courts also seems to be beneficial. Apart from this, the criticism of Venables (i.e. increasing inequality between countries because of possible agglomeration of industrial manufacturing and unequal costs for liberalization) can be countered by cohesion and compensation funds, and an adequate regional policy such as small and medium enterprise promotion etc.

We are aware of the criticism that the lengths of the test periods (in our case the time span the RIAs have been in existence) may be too short to make definitive statements about the 
convergence process. Part of the literature even assumes that convergence or divergence statements can be made only after several hundred years; cf. Baumol (1986) for example. Following this criticism, however, would mean discarding this statistical indicator for the study of RIA effects. Moreover, at least for Africa, it can be said that around 1960 the RIAs here considered were relatively homogeneous regions with respect to their chances and possibilities. The increase in income inequality among partner states has been driven by differences in the speed and success of democratization and industrialization. Consequently, successfully working RIAs can push poorer countries towards growth. Finally, it should be kept in mind that the concept of sigma convergence is not so profound; the sigma being the standard deviation of the per capita log income ignores important information, like the income level and the initial income of each country or the RIA. This is why we believe that it is important to also examine the growth path of the absolute values of the per capita $(\log )$ income - whether it be HP-filtered or not - to assess, for example, the gap between poorest and richest partners. Another problem is the model framework. Despite the HP smoothing, we typically observe non-monotonic sigma trends. This contradicts the model deductions of Section 2.2. Note however, that relaxing the unrealistic assumptions made there, such as the independence between per capita income and disturbance term, or the independence of shocks over time and countries, would lead to more involved consequences for the sigma development and its interpretation. More specifically the resulting relationships would be neither linear nor monotonic. 


\section{CHAPTER 3:}

\section{A Note on "Speed of Convergence" in Regional Integration Areas}

\subsection{Introduction}

This note has basically two aims: while the main focus is to study the speed of convergence within the so-called South-South areas, we also will show why this measure must not be taken too literally, and has basically no meaning in absolute terms. For both issues we consider a sample of regional integration areas that well represents all Southern world regions, namely West Africa, Central Africa, East Asia and Latin America. More specifically, we selected ASEAN $^{20}$ (Association of South-East Asian Nations), WAEMU ${ }^{21}$ (West African Economic and Monetary Union), CEMAC ${ }^{22}$ (Economic and Monetary Community of Central Africa), ECOWAS $^{23}$ (Economic Community of West African States), and MERCOSUR ${ }^{24}$ (Mercado Común del Sur). To get findings that are robust against possible model misspecification, we calculate the speed of convergence based on different modifications of the Solow growth model. We compare the convergence among the regional integration areas (RIAs henceforth) but also with predictions for non-integrated areas.

In Chapter 1 and Chapter 2 of this dissertation we have found empirically that membership in these South-South-Agreements shows a positive impact on income convergence and growth which is partly in contradiction to a significant part of the literature based on economic theory; see e.g. Bhagwati, Greenaway, and Panagariya (1998), Goodfriend and McDermott (1998), Baldwin, Martin and Ottaviano (2001), Giannetti (2002), Venables (2003) or Scott

\footnotetext{
${ }^{20}$ ASEAN: Indonesia, Malaysia, Thailand, Singapore, Philippines, Brunei (1984), Burma/Myanmar (1997), Vietnam (1995), Cambodia (1999), and Laos (1997).

${ }^{21}$ ECOWAS: Benin, Burkina Faso, Cape Verde, Cote d'Ivoire, Gambia, Ghana, Guinea Bissau, Guinea, Liberia, Mali, Mauritania (until 2001), Niger, Nigeria, Senegal, and Togo.

${ }^{22}$ CEMAC: Cameroon, Central African Republic, Chad, Rep. Congo, Equatorial Guinea, Gabon.

${ }^{23}$ ECOWAS: Benin, Burkina Faso, Cape Verde, Cote d'Ivoire, Gambia, Ghana, Guinea Bissau, Guinea, Liberia, Mali, Mauritania (until 2001), Niger, Nigeria, Senegal, and Togo.

${ }^{24}$ MERCOSUR: Argentina, Brazil, Uruguay, and Paraguay. Venezuela is full member since 2006. Associated members are Peru (2003), Chile (1996), Bolivia (1997), Ecuador (2004) and Colombia (2004).
} 
(2006b). In this present study we do not continue the discussion in this direction but investigate in more depth which (kind of) information can be obtained from the speed of convergence, in particular for the South-South integration areas considered here. The question concerning the speed of convergence is typically debated in the context of the recent growth theory, as it is hoped to find out more about the long-term adjustment paths of countries in terms of their per capita income development. The convergence rate provides information about the time period, in which the gap between the recent per capita GDP of one country and the income of the "leading" country within a group is closing. According to different predictions based on the human capital augmented Solow model (HCA), regions are generally expected to converge at a speed of about two per cent per year; see e.g. Sala-i-Martin (1996b). This implies that the half-life distance to its steady is of 35 years. If we take this value as our reference point, say benchmark, it would be interesting, for example to see whether the speed of convergence in South-South RIAs is higher or lower than two per cent p.a. Actually, according to the new integration- and growth theory the speed of convergence in RIAs should be higher than in geographical regions, due to increasing economic cooperation for example; see Smulders and Van de Klundert (1996) or Goodfried and Mc Dermott (1998). But as far as we know, there does not exist any empirical study that compares the speed of convergence between RIAs, and inside versus outside a RIA.

A further interesting point is to look at the empirical growth and convergence studies (with panel data) in the last decades. We find a lively discussion about estimation methods and the interpretation of results concerning the adjustment speed; compare e.g. Caselli, Esquivel and Lefort (1996), Loayza (1994), and Knight, Loayza and Villanueva (1993). It is broadly accepted that the speed of convergence is a useful indicator to compare the convergence performance of different sets of countries and/or when using different criteria or (model) approaches for measuring convergence. In other words, speed of convergence was simply a tool to bring all measures to the same scale making them comparable. At the same time it is quite common to derive direct interpretations from the obtained numbers in an absolute, i.e. not relative, sense. Typically, as we will show in this article, such an interpretation is misleading because the estimated number of years to convergence is often much too variable to provide any reliable information. Although this can be demonstrated mathematically by sophisticated derivations of variances and more complex robustness checks, for the sake of presentation we will simply restrict ourselves to the calculation of confidence intervals. It will be seen that in most cases these are too large (often ranging from 0 to hundred years or more) 
to provide any practical information concerning the time required for convergence. Surprisingly, and also unfortunately, until now convergence speed and half-time to steadystate estimates have always been given without confidence intervals in the literature. However, we will see that these numbers can only be given some credibility when considered together with confidence intervals.

\subsection{Econometric Framework}

Let $y(t)$ be the per capita income at time point $t, y^{*}$ the steady state income, $n$ the exogenous growth rate of the labour force, $g$ the technological progress, and $\delta$ the depreciation rate. The speed of convergence $\lambda$ is proportional to the distance to steady state, cf. Barro and Salai-Martin (1995).

$$
\frac{d \ln (y(t))}{d t}=\frac{\dot{y}}{y} \cong-\lambda \ln (y / y *) \text { for a particular } \lambda \text {. }
$$

Let us consider the panel data equation for measuring unconditional $\beta$-convergence, see for example chapter 1 :

$$
\ln y_{i}\left(t_{2}\right)-\ln y_{i}\left(t_{1}\right)=\gamma_{i}+\gamma^{T} X_{i}\left(t_{2}\right)-\left(1-e^{-\lambda \tau}\right) \ln \left(y_{i}\left(t_{1}\right)\right)+g\left(t_{2}-t_{1} e^{-\lambda \tau}\right)+\varepsilon_{i t},
$$

where $\varepsilon_{\text {it }}$ summarizes all heterogeneity, $\gamma$ and $\gamma_{i}$ unknown coefficients, and $g\left(t_{2}-t_{1} e^{-\lambda \tau}\right)$ reflects the time effects. Often $\left(1-e^{-\lambda \tau}\right) / \tau$ is denoted by $\beta$. A particular case of the above equation is the human capital augmented (HCA)-Solow-model for panel data with saving rates for capital and human capital, $s_{K}$ and $s_{H}$ constant returns to scale:

$$
\begin{aligned}
& \left(\ln y_{i}\left(t_{2}\right)-\ln y_{i}\left(t_{1}\right)\right)=\left(1-e^{-\lambda \tau}\right) \frac{\alpha}{1-\alpha-\pi} \ln \left(s_{K i}\left(t_{2}\right)\right)+\left(1-e^{-\lambda \tau}\right) \frac{\pi}{1-\alpha-\pi} \ln \left(s_{H i}\left(t_{2}\right)\right)- \\
& \left(1-e^{-\lambda \tau}\right) \frac{\alpha+\pi}{1-\alpha-\pi} \ln \left(n_{i}\left(t_{2}\right)+g+\delta\right)-\left(1-e^{-\lambda \tau}\right) \ln y_{i}\left(t_{1}\right)+\gamma_{i}+\gamma^{T} X_{i t}+g\left(t_{2}-t_{1} e^{-\lambda \tau}\right)+\eta_{i t}
\end{aligned}
$$

with $\alpha$ and $\pi$ being the unknown elasticises. The so-called convergence rate $\lambda$ is used for the estimation of the speed at which countries, respectively areas, converge to its steady state. According to the panel equation above, the convergence rate $\lambda$ is calculated via $\hat{\lambda}=-\ln (1-\tau \hat{\beta}) / \tau$ obtaining the annual adjustment rate of each region. The conditional Solow-model with typical assumption of diminishing returns predicts $\alpha=\pi=1 / 3$ and $n+g+\delta=0.06$, so that the convergence rate $\lambda$ would equal 0.02 , i.e. two per cent per year. This implies that the half-life time for closing the income gap to the steady state is thirty five 
years; see Sala-i-Martin (1996b). The halfway to steady state is calculated by $\ln (2) / \lambda$ delivering an often used approximation of the half-life. The half-life time $h l$ to closing the income gap results from the solution of the equation: $e^{-\lambda t}=0,5$. If one excludes human capital, the model predicts a speed of convergence of four percent per year and the economy covers the halfway to steady state in seventeen years; see Mankiw (1992). If the Solow-model is confirmed, then $\hat{\lambda}$ might be computed from the restricted regression with constant returns to scale. We can give up this restriction and estimate the corresponding unrestricted HCA.

The estimation of country-specific convergence rates would mean further splitting-up of information, which is already based on aggregated values, short time periods and neoclassical model assumptions. In order to demonstrate the problem concerning the information content of parameter $\lambda$, we will examine the confidence intervals of $\beta$.

We use panel structures for this as we know that in cross-section regression the convergence rates are underestimated. In the literature we identify three important sources of inconsistency in the analyses of growth and convergence: omission of individual country specific effects, endogeneity due to simultaneity (of $s_{H}, s_{K}$, and/or $n$ ), and possible inconsistency due to the dynamics in the panel; see for example Islam (1995), Caselli, Esquivel, and Lefort (1996), or Lee and Pearsan (1997). The first problem we solve by considering fixed effects models and using Least-Square Dummy Variable estimators (LSDV). We further allow for additional (country specific) heterogeneity by including panel specific $\operatorname{AR}(1)$ autocorrelation and arbitrary heteroscedasticity in our regressions. By applying feasible weighted least squares estimators (GLS hereafter) we make use of this variance-covariance structure to obtain efficient estimates though they suffer from Nickel-bias. Due to significant autocorrelation, none of the standard IV methods would work here. The second problem (inconsistency due to potential simultaneity between per capita income, respectively growth, and population growth or investment) we counteract with instruments for population growth, and investments respectively, using interval-averages instead of annual observations.

For all regions we give in total six estimates ( 2 estimates per 3 models) for the return to initial income, the so called $\beta$ : first for the unconditional, the unrestricted conditional, and the restricted conditional model; second, for each model we used two estimation procedures, a) the simple (in literature mostly used) fixed effect (within) regression, and b) the GSL fixed effects regression with panel specific $\operatorname{AR}(1)$ and heteroscedasticity. The latter is marked in all tables with a hyper-index ${ }^{\text {a }}$. As this very flexible model requires a large sample size ' $N$ ', this 
estimation procedure was not applied to the split samples when we looked at unbalanced panels separating countries and years strictly according to their membership in the considered RIA.

Note that for comparing membership versus non-membership we applied the sample split approach, i.e. looking always not only at the same geographical region but also at the same countries. In other words we do not compare countries willing and allowed to participate versus the rest because this would automatically lead to sample selection bias in the estimation. Rather, we simply compare the performance of the same (set of) countries inside and outside the particular RIA. We are aware that this still does not guarantee perfect counterfactuality and neglects those countries that definitely do not want to participate, but it gives us a conservative estimate for the impact of membership on convergence. 'Conservative' here means that we risk underestimating the gap between convergence speed inside and outside the RIAs.

The confidence intervals for the convergence speed measured in the so called 'half-lifecoefficient' (H1 henceforth) were also calculated in a conservative but simple way. Our panel estimation procedure provides us directly with confidence intervals for all the coefficients of our model, and therefore for the implied estimate $\hat{\lambda}$. Taking the lower- and upper bounds, say $l b(\hat{\lambda})$ and $u b(\hat{\lambda})$, we can obtain a coarse estimate of the Hl-confidence interval via $u b(\mathrm{Hl})=\ln (2) / l b(\hat{\lambda})$, and $l b(\mathrm{Hl})=\ln (2) / u b(\hat{\lambda})$ respectively. We give here confidence intervals with an approximate coverage probability of 95 per cent. Certainly, it could be argued that other, more sophisticated approaches might be somewhat more exact, the delta method is probably the most popular one. However, the delta method is a linear approximation which, in an exponential context like ours, is inappropriate.

\subsection{Empirical results}

If we compare the speed of convergences in the studies of Caselli, Esquivel and Lefort (1996), Barro and Lee (1994), Lee, Persaran and Smith (1997), and Knight, Loayza and Villanueva (1993), the estimates for $\lambda$ vary between 0.6 per cent and more than 13 per cent for the world-wide sample (considering only conditional tests). Before we discuss the outcomes for each particular region, it should be mentioned that all our estimates lie in this range except 
for the restricted (often rejected) conditional HCA growth model. Typically one would concentrate on the interpretation of absolute values, since although this study shows that secured statements can solely be made on the base of relative comparisons, the absolute values only will be discussed briefly.

\section{Latin America}

We start with discussing our findings for Latin America. In Table 3.1 we can first see the region as a whole, 10 countries in total, converges at rate of between 3.9 (smallest estimate) to 5.8 (largest estimate) per cent p.a. to their steady state in the period from 1985-2002. Therefore the halfway to steady state amounts to between 11.7 to 17.5 years depending on the model and estimation method. The members of MERCOSUR converge with a rate between 12.7 and 15.5 percent p.a., which implicates in absolute values a half-life time of 4.5 respectively 5.4 years. Note that the GLS estimates based on more flexible models give - as expected - not only much narrower confidence intervals but moreover these lie inside the confidence intervals of the within-estimates of the more restrictive simple fixed effects models.

As already indicated above, the values for "members" and "non-members" were calculated from unbalanced samples over the same time period as for the full sample but included for each year only the members, respectively non-members.

When we concentrate on relative comparison we see clearly that we find much faster convergence for the member-sample than for the whole region although referring to the same geographical region and to the same countries - just at different time points, and therefore probably even underestimate this gap, see discussion above. Note that for the non-member sample we get even infinite upper bounds for the estimated half-life when taking the standard deviation into account. In other words, there is probably no convergence at all. This certainly coincides with the fact that the so-called beta-convergence is not significant outside the RIAs. We can conclude from this that we only find convergence for the whole sample thanks to the MERCOSUR. 
Table 3.1: Estimated results of speed of convergence in Latin America

\begin{tabular}{llrrr}
\hline \hline & & $\begin{array}{r}\text { Unconditional } \\
\text { growth model }\end{array}$ & $\begin{array}{r}\text { Conditional } \\
\text { growth model }\end{array}$ & $\begin{array}{r}\text { Restricted cond. } \\
\text { growth model }\end{array}$ \\
Full sample & $(-\hat{\beta})$ & $-.0410(.011)$ & $-.0544(.019)$ & $-.0556(.019)$ \\
$\mathrm{N}=60$ & & $-.0382(.006)^{\mathrm{a}}$ & $-.0528(.016)^{\mathrm{a}}$ & $-.0503(.015)^{\mathrm{a}}$ \\
& implied $\hat{\lambda}$ & .0428 & .0575 & .0589 \\
& & $.0397^{\mathrm{a}}$ & $.0558^{\mathrm{a}}$ & $.0530^{\mathrm{a}}$ \\
& Hl \& & $16.2[10.3,35.1]$ & $12.1[6.7,43.7]$ & $11.7[6.6,40.8]$ \\
conf. intervals & $17.5[13.3 ; 25.1]^{\mathrm{a}}$ & $12.4[7.5,31.8]^{\mathrm{a}}$ & $13.1[7.9,34.3]^{\mathrm{a}}$ \\
$\mathrm{N}=25$ & $(-\hat{\beta})$ mem & $-.1125(.022)$ & $-.1659(.053)$ & $-.1333(.054)$ \\
& implied $\hat{\lambda}$ & .1274 & .2015 & .1550 \\
Non-members & Hl \& c.i. & $5.4[3.6,9.9]$ & $3.4[1.6,13.7]$ & $4.5[2.0,44.4]$ \\
$\mathrm{N}=35$ & $(-\hat{\beta})$ non_mem & $-.0513(.024)$ & $-.0473(.034)$ & $-.0471(.035)$ \\
& implied $\hat{\lambda}$ & .0541 & .0497 & .0495 \\
& Hl \& c.i. & $12.8[6.0, \infty]$ & $13.9[5.1, \infty]$ & $14.0[5.1, \infty]$ \\
Full Sample & $\begin{array}{l}\text { Wald-Test: p-value } \\
\text { for restriction }\end{array}$ & - & - & .1440 \\
\hline \hline
\end{tabular}

Note: Standard errors for coefficients estimates are in parenthesis. Hl [lb, ub] stands for half-life in years, and the confidence intervals (lower bound, upper bound) are also in half-life years. The results with a were estimated with GLS, panel-specific AR (1) and heteroscedasticity. N indicates the number of observations (note that some panels are unbalanced; and so N is not necessary the product of the numbers of countries with the number of time periods).

The findings obtained coincide over the different models and estimation methods. The Waldtest checking the constant returns to scale restrictions cannot reject at the nominal 10 percent level but gives a p-value of 14.4 percent which is still not high indicating therefore that the restricted model is hardly credible. In any case, this all confirms that our results are quite robust against different econometric specifications. Concerning the interpretation of the absolute values in terms of half-life to convergence, we see quite implausible estimates. They become more reasonable when looking at their confidence intervals which basically say: for members the $\mathrm{Hl}$ time interval is between 2 and over 44 years under constant returns to scale. Although this sounds sensible, we would not regard it as being especially informative.

\section{South-East Asia}

Next we turn to Asia. Table 3.2a shows the results for speeds of convergence in East Asia. The full sample of the region consists of 15 countries over the period from 1975 to 2002 . The Wald test tells us that we must reject the constant returns to scale hypothesis at the $1 \%$ nominal level and should therefore not consider further the last column of Table 3.2a though the estimates seemingly confirm all trends we derive from the other estimates. Like for Latin America we get the intuitive results that conditional convergence is always (much) faster than the unconditional one. 
Table 3.2a: Estimated results of speed of convergence in East Asia

\begin{tabular}{llrrr}
\hline \hline & & $\begin{array}{r}\text { Unconditional } \\
\text { growth model }\end{array}$ & $\begin{array}{r}\text { Conditional } \\
\text { growth model }\end{array}$ & $\begin{array}{r}\text { Restricted cond. } \\
\text { growth model }\end{array}$ \\
Full sample & $(-\hat{\beta})$ & $-.0224(.002)$ & $-.0318(.004)$ & $-.0213(.003)$ \\
$\mathrm{N}=115$ & & $-.0228(.001)^{\mathrm{a}}$ & $-.0225(.004)^{\mathrm{a}}$ & $-.0164(005)^{\mathrm{a}}$ \\
& implied $\hat{\lambda}$ & .0229 & .0328 & .0217 \\
& & $.0233^{\mathrm{a}}$ & $.0230^{\mathrm{a}}$ & $.0166^{\mathrm{a}}$ \\
& Hl \& & $30.3[24.4,40.1]$ & $21.1[16.3,29.6]$ & $31.9[23.9,47.1]$ \\
Members & conf. intervals & $29.7[26.3,34.3]^{\mathrm{a}}$ & $30.1[20.8,53.3]^{\mathrm{a}}$ & $41.7[25.3,111.6]^{\mathrm{a}}$ \\
$\mathrm{N}=59$ & $(-\hat{\beta}$ ) mem & $-.0299(.004)$ & $-.0438(.008)$ & $-.0267(.005)$ \\
& implied $\hat{\lambda}$ & .0308 & .0458 & .0274 \\
Non & Hl \& c.i. & $22.5[17.2,32.7]$ & $15.1[10.5,25.9]$ & $25.3[17.4,45.6]$ \\
Members & $(-\hat{\beta})$ non_mem & $-.0160(.003)$ & $-.0275(.004)$ & $-.0166(.003)$ \\
$\mathrm{N}=56$ & & & & .0282 \\
& implied $\hat{\lambda}$ & .0162 & & .0169 \\
& Hl \& c.i. & $42.8[30.8,69.3]$ & $24.6[17.9,38.3]$ & $41.0[27.6,78.9]$ \\
Full sample & Wald-Test: $\mathrm{p}$-value & & & .000 \\
\hline \hline
\end{tabular}

Note: Standard errors for coefficients estimates are in parenthesis. H1 [lb, ub] stands for half-life in years, and the confidence intervals (lower bound, upper bound) are also in half-life years. The results with ${ }^{\text {a }}$ were estimated with GLS, panel-specific AR (1) and heteroscedasticity. The variable mem stands for ASEAN membership. $\mathrm{N}$ indicates the number of observations (note that some panels are unbalanced; and so $\mathrm{N}$ is not necessary the product of the numbers of countries and the number of time periods).

The most flexible model and estimator tells us that this whole region converges at an absolute rate of about 2.3 per cent p.a. with a half-life to steady state of circa 30 years. But as already mentioned above, we should only consult relative comparisons in order to be able to make secured statements about convergent or divergent developments. Again, there is a serious gap in convergence speed between the members- and the non-members sample. Both the unconditional and conditional tests show that ASEAN members converge faster than nonmember in this region of Asia. When we compare the results for Latin America and East Asia, we observe that the MERCOSUR clearly converges faster than the ASEAN area. The ASEAN members converge at a rate of approximately $3.0 \%$ (unconditionally) or $4.6 \%$ (conditionally). In contrast, the non-members have a speed of convergence of $1.6 \%$ (unconditional) and $2.8 \%$ (conditional). This is nearly half of the convergence speed we observe for the members sample. For unconditional convergence the Hl confidence intervals hardly overlap. The full sample reveals a convergence rate of around 2.3-3.2\% p.a. for all countries in the period from 1975 to 2002 . This implies a half-life of 30.3 , respectively 21.1 years. However, looking at the confidence intervals we see again that they are much too wide to yield reliable information. 


\begin{tabular}{llrrr}
\hline \hline & & $\begin{array}{r}\text { Unconditional } \\
\text { growth model }\end{array}$ & $\begin{array}{r}\text { Conditional } \\
\text { growth model }\end{array}$ & $\begin{array}{r}\text { Restricted cond. } \\
\text { growth model }\end{array}$ \\
Full sample & $(-\hat{\beta})$ & $-.0182(.002)$ & $-.0270(.004)$ & $-.0182(.003)$ \\
$\mathrm{N}=115$ & & $-.0182(.001)^{\mathrm{a}}$ & $-.0223(.004)^{\mathrm{a}}$ & $-.0137(.004)^{\mathrm{a}}$ \\
& implied $\hat{\lambda}$ & .0186 & .0277 & .0186 \\
& Hl \& & $.0186^{\mathrm{a}}$ & $.0228^{\mathrm{a}}$ & $.0139^{\mathrm{a}}$ \\
& conf. intervals & $37.3[29.4,51.1]$ & $25.0[19.0,36.3]$ & $37.3[27.7,57.3]$ \\
Members & $(-\hat{\beta}$ ) mem & $-.0239(.004)$ & $-.0356(.008)$ & $-.0225(.005)$ \\
$\mathrm{N}=59$ & implied $\hat{\lambda}$ & .0245 & .0369 & .0230 \\
& Hl \& c.i. & $29.3[20.9,43.6]$ & $18.8[12.5,36.5]$ & $30.1[20.1,57.7]$ \\
Non & $(-\hat{\beta})$ non_mem & $-.0135(.002)$ & $-.0252(.004)$ & $-.0149(.003)$ \\
Members & & & & \\
$\mathrm{N}=56$ & implied $\hat{\lambda}$ & .0136 & .0258 & .0151 \\
& Hl \& c.i. & $50.9[35.4,88.2]$ & $26.9[19.3,43.1]$ & $45.9[30.3,91.2]$ \\
& Wald-Test: $\mathrm{p}$-value & - & & .000 \\
\hline \hline
\end{tabular}

Note: Standard errors for coefficients estimates are in parenthesis. Hl [lb, ub] stands for half-life in years, and the confidence intervals (lower bound, upper bound) are also in half-life years. The results with ${ }^{\text {a }}$ were estimated with GLS, panel-specific AR (1) and heteroscedasticity. The variable mem stands for ASEAN membership. $\mathrm{N}$ indicates the number of observations (note that some panels are unbalanced; and so $\mathrm{N}$ is not necessary the product of the numbers of countries and the number of time periods).

It is well known that the Asian crisis from 1997 to 1998 seriously distorts all empirical research on growth and development. As we are not interested here in 'business cycles' or temporary crisis, we repeated our study on data excluding the years 1997 to 1998 from the sample ${ }^{25}$. As expected, the results corrected for the Asian crisis show lower convergence rates for all considered samples and models, see Table 3.2b. The filtered outcomes for convergence rates lie around 1-2 per cent below the values of Table 3.2a. The Asian crisis feigns an accelerated speed of convergence in the whole region but even more substantially in the ASEAN RIA. We say here "feign" because all that happened is that, due to their strong economic relations and dependencies, the co- movement of GDP inside a RIA is particularly emphasized. This does not necessarily imply convergence. But certainly, the intra-regional cooperation among the ASEAN members was indeed intensified after 1997, for example at the level of monetary policy cooperation and coordination (see ASEAN Capital Market Forum).

Again, the constant return to scale hypothesis is rejected by the Wald test at the $1 \%$ significance levels. The smallest difference to Table 3.2a we detect is for the full sample

\footnotetext{
${ }^{25}$ To be more specific, as we consider panel data we replaced the data served for these years by artificial data created by interpolation along the line described in chapter 1 .
} 
convergence under the most flexible model and estimator. Therefore, the distance to the steady state in the whole region has a half-life time of about 25 to 37 years. The specific finding that members show faster convergence than non-members does not change; just the gap has shrunk in the sense that the $\mathrm{Hl}$ confidence intervals now overlap quite a bit. In any case, our different robustness checks do not show any specification specific contradictions. In general we can confirm that we find regional convergence, and empirical evidences indicate that convergence is fostered by the ASEAN RIA.

\section{West- and Central Africa}

Finally we turn to West- and Central Africa; looking again at the period from 1975 to 2002. Table 3.3 reveals that the whole region experienced relatively weak converges. Since the Wald-test also rejects the restricted Solow-model for West- and Central Africa (even at the one percent level), we concentrate only on the unconditional and the unrestricted conditional regression results. For the simpler estimate without $\mathrm{AR}(1)$ and under homoscedasticity, we have a non-significant rate (cf. the standard deviation of $\hat{\beta}$ and the confidence intervals for $\mathrm{Hl}$ ) of circa 1.5 per cent p.a. for both conditional and unconditional convergence. The more sophisticated GLS estimates indicate convergence speeds between 2.1 (unconditional) and 4.7 percent (conditional). As most of the countries in this geographical region were members of at least one of the RIAs ECOWAS, WAEMU, and CEMAC or belonged to the CFA-zone, a reasonable sample split in members versus non-members is not possible. We will therefore only compare convergence performance of the above RIAs.

The two RIAs, ECOWAS and WAEMU, experienced the highest convergence speeds. For the ECOWAS both the conditional and unconditional convergence rates were approximately $3.3 \%$ p.a. This seems to contradict the findings of Hammouda, Karingi, Njuguna and Jallab (2007). But as they calculate the speed of convergence per period, (not per year), and as the necessary transformation is nonlinear, this is non-valid comparison. This once again confirms our statement that the absolute numbers should not be over-interpreted. For the WAEMU we find only conditional convergence at a rate of more than $22 \%$, but not unconditional convergence. Besides, we can not observe significant convergence for the CEMAC.

We know from previous studies, that the members of the WAEMU are not fast-growing countries (like for example the PR China). Therefore we have to conclude that one reason for 
this extreme high convergence rate is the phenomena of "poor convergence clubs", see Quah (1997). For the CFA-zone, we have a more moderate speed of 5.5 respectively 6.7 per cent p.a. (unconditional as well as conditional). One reason for the moderate speed could be the insignificant results of the six CEMAC members and the relatively fast convergence rate of WAEMU.

Table 3.3: Estimated results of speed of convergence in West- and Central Africa

\begin{tabular}{|c|c|c|c|c|}
\hline & & $\begin{array}{l}\text { Unconditional growth } \\
\text { model }\end{array}$ & $\begin{array}{l}\text { Conditional growth } \\
\text { model }\end{array}$ & $\begin{array}{l}\text { Restricted cond. } \\
\text { growth model }\end{array}$ \\
\hline \multirow{6}{*}{$\begin{array}{l}\text { Full sample } \\
\mathrm{N}=180\end{array}$} & $(-\hat{\beta})$ & $-.0148(.007)$ & $-.0150(.012)$ & $-.0166(.011)$ \\
\hline & & $-.0201(.003)^{\mathrm{a}}$ & $-.0447(.009)^{\mathrm{a}}$ & $-.0480(.009)^{\mathrm{a}}$ \\
\hline & implied $\hat{\lambda}$ & .0150 & .0152 & .0168 \\
\hline & & $.0205^{\mathrm{a}}$ & $.0468^{\mathrm{a}}$ & $.0050^{\mathrm{a}}$ \\
\hline & Hl \& & $46.2[22.4, \infty]$ & $45.6[17.1, \infty]$ & $41.1[16.7, \infty]$ \\
\hline & conf. intervals & $33.8[24.7,52.5]^{\mathrm{a}}$ & $14.8[10.1,26.3]^{\mathrm{a}}$ & $13.7[9.7,22.6]^{\mathrm{a}}$ \\
\hline \multirow{3}{*}{$\begin{array}{l}\text { ECOWAS } \\
\mathrm{N}=119\end{array}$} & $(-\hat{\beta}) \mathrm{mem}$ & $-.0321(.006)$ & $-.0319(.010)$ & $-.0338(.009)$ \\
\hline & implied $\hat{\lambda}$ & .0331 & .0329 & .0349 \\
\hline & Hl \& c.i. & $20.9[14.5,36.9]$ & $21.1[12.3,63.5]$ & $19.8[12.5,44.5]$ \\
\hline \multirow{3}{*}{$\begin{array}{l}\text { WAEMU } \\
\mathrm{N}=24\end{array}$} & $(-\hat{\beta})$ mem & $-.0533(.049)$ & $-.1809(.063)$ & $-.0769(.057)$ \\
\hline & implied $\hat{\lambda}$ & .0563 & .2245 & .0834 \\
\hline & Hl \& c.i. & $12.3[3.6, \infty]$ & $3.1[1.4,15.9]$ & $8.3[2.7, \infty]$ \\
\hline \multirow{3}{*}{$\begin{array}{l}\text { CEMAC } \\
\mathrm{N}=21\end{array}$} & $(-\hat{\beta}) \mathrm{mem}$ & $-.0522(.034)$ & $-.0605(.036)$ & $-.0556(.036)$ \\
\hline & implied $\hat{\lambda}$ & .0551 & .0644 & .0589 \\
\hline & Hl \& c.i. & $12.6[4.7, \infty]$ & $10.7[4.1, \infty]$ & $11.8[4.4, \infty]$ \\
\hline \multirow{3}{*}{$\begin{array}{l}\text { CFA-Zone } \\
\mathrm{N}=45\end{array}$} & $(-\hat{\beta}) \mathrm{mem}$ & $-.0523(.024)$ & $-.0633(.025)$ & $-.0570(.025)$ \\
\hline & implied $\hat{\lambda}$ & .0552 & .0676 & .0605 \\
\hline & Hl \& c.i. & $12.5[6.1,256.0]$ & $10.2[5.3,55.6]$ & $11.5[5.7,114.1]$ \\
\hline Full sample & $\begin{array}{l}\text { Wald-Test: p-value } \\
\text { for restriction }\end{array}$ & - & - & .008 \\
\hline
\end{tabular}

Note: Standard errors for coefficients estimates are in parenthesis. Hl [lb, ub] stands for half-life in years, and the confidence intervals (lower bound, upper bound) are also in half-life years. The results with ${ }^{\text {a }}$ were estimated with GLS, panel-specific AR (1) and heteroscedasticity. $\mathrm{N}$ indicates the number of observations (note that some panels are unbalanced; and so $\mathrm{N}$ is not necessary the product of the numbers of countries and the number of time periods).

We see that all general convergence findings are robust against the different here studied model specification, not so the absolute values. In particular we would like to remark once again that the convergence speed -- in absolute values, especially thinking here of $\mathrm{Hl}$ in years -- is not very informative. That means the $\mathrm{Hl}$ estimates are too imprecise to be reliable for decision making. We can see here confidence intervals that range from almost 4 to infinity or from 6 to 256 years. 
If we look at Table 3.3 we are able to give some certain evidences: The country-cooperations WAEMU, ECOWAS and the CFA zone converge much faster than the whole region Westand Central Africa and faster than the non-members (not shown in Table 3.3). In our study the WAEMU has the fastest adjustment speed among RIA members; but we would assume that they will converge to a common low-income steady state, because most of the members are low income countries (according to the World Bank country classification list in 2007). If we compare the results for Africa with those for Latin America and Asia, then, as a whole, Latin America converges fastest. And if we exclude WAEMU (for the reasons specified above), then the MERCOSUR members have the highest adjustment speed, followed by ASEAN and finally ECOWAS.

\subsection{Conclusion}

In this article we have investigated the speed of convergence within the so called South-South agreements on the basis of different growth models and estimators. According to the present literature a worldwide speed of convergence of around two per cent per year is expected. Our investigations of the RIAs show that adjustment speeds within an integration area are much higher than two percent. Furthermore all selected RIAs with the exception of CEMAC converge faster than the corresponding whole regions and the non-members. We could show that the adjustment speeds between the South-South RIAs are different. However, we have to be careful with the interpretation of absolute and extreme values; see below. The MERCOSUR exhibits high $\lambda$-values of between 12.7-15.5 per cent, which would imply that the income gap between the members of MERCOSUR will close in around five years, which is clearly unrealistic. This example illustrates that the numerical values of lamda do not permit reliable statements regarding the exact number of years it will take to close the income gap. One external or internal shock would be enough to render this forecast entirely inaccurate.

When we consider the confidence intervals for the half-life, we see huge, often infinite ranges. Even if we have significant convergence, such estimates are not very useful (see the example of CFA-zone with an adjustment period of between 6 and 256 years). Thus it would not make much sense to split up the information in order to calculate country-specific adjustment speeds within the RIAs. We are afraid that all so far done research faces the same problem without noticing. Instead, they interpret those numbers taking them quite uncritically for their 
conclusions. Actually, to our knowledge we are the first presenting the Hl-time together with a robustness check and definitely the first ones providing confidence intervals. The estimations of $\mathrm{Hl}$ are too imprecise to be reliable for decision making. 


\section{CHAPTER 4:}

\section{Practical tools for monitoring similarity and convergence with an application to integration areas}

\subsection{Introduction}

During recent years a growing number of regional integration agreements have been reported to the WTO. Furthermore from the 193 regional preferential agreements in 2008, 92 of them were South-South RIAs, and 65 North-South RIAs. This process goes along with a controversial discussion about pros and cons of those integration areas. We observe a similar discussion for the globalization process. As a consequence, there has been an urgent demand from politicians and economists for appropriate monitoring instruments to observe, evaluate, and compare regional integration. A good and practicable instrument has the capacity to make the policies better focused and hence more efficient and more transparent. Furthermore, from such monitoring, De Lombaerde, Pietrangeli and Weeratunge (2006) expect a possible increase of participation and acceptance of regional integration agreements and processes.

A popular method to measure the effectiveness of integration processes (the dynamic approach) is the growth and convergence analysis. However, economic and political alliances like regional integration areas (RIAs henceforth) take time in order to bear fruit. To observe the comprehensive developing process of a RIA from the outset, a monitoring system is needed that is universally applicable and worldwide. Another challenge, when creating a monitoring system, is to consider the differences between RIAs, i.e. to compare North-South, North-North and South-South agreements. A good indicator system should measure success or failure in cooperation fields as diverse as policy, social issues, institutions, and wealth. Evidently, a crucial issue is the selection of a sufficient set of indicator variables for each category of interest (economical, political, technological, etc). Thereby we want to try and avoid excessive focusing on a particular kind of integration (political vs. economic) or specific types of countries, e.g. RIAs between developing or industrialized countries. At the same time it should be a small set of variables comprising easily available data of high 
quality, as one of the objectives of our indicator system is practical feasibility. Specifically, both indicator variables and all calculation methods should be designed and explained in such a way that the final numbers are numerically replicable for others without further help (provision of scores, own data sources and processing, own software, etc.). Finally, the indices should have a clear interpretation even though reflecting the multidimensionality of the process.

We are confronted with a measurement problem when trying to quantify regional integration (cf. Section 4.3). So, before one starts with constructing an indicator system, it would be extremely useful to have a definition of regional integration to work with. Note that there is not a unique definition in the literature; we opted for a definition based on Nye (1968) and Ziltener (2003) giving the following conceptual description: "Regional integration is accordingly an empirically observable, intensifying process of increasing cross-border political, economic and social activities, cooperation and coordination within a region". This concept leaves it open, whether the process is market- or institutionally- driven, and whether founding targets exist(ed) or not. Because of the latter point we will propose two sets of indices: one looking for integration in the sense of convergence towards similarity, and one being a development index with a focus on integration issues. In this paper we concentrate on outcome-oriented monitoring; we only monitor integrative effects, not integration targets and intentions. One could even go a step further by taking 'integration' in its original Greek or Latin sense of becoming one entity or unity. On the basis of this 'working definition' of integration, we distinguish five categories: social, political, technological/infrastructural, institutional, and economic.

Our monitoring tool will be applied on selected regional integration areas which have been in existence for at least a decade and which, in our opinion, typically represent RIAs for SouthSouth, North-South, and North-North agreements: for South-South the WAEMU; for NorthSouth the NAFTA, and for North-North the ANZCERTA and the EU-15. This selection of RIAs with quite different characteristics, allows us to illustrate the achievement of basically all of our objectives: practical feasibility, multidimensionality, comparability, and interpretability.

In the next section we start with a literature review discussing briefly existing indices with their shortcomings to better highlight our concern and contribution. In Section 4.3 we 
introduce the conceptual framework in more depth and the construction of the different indices and subindices including the proposed set of indicator variables. The realization, i.e. the implementation, calculation, interpretation and comparison along the five selected RIAs is done in Section 4.4. We give our conclusions in Section 4.5. Tables and Figures are deferred to the Appendices C.

\subsection{A Brief Review}

We will focus on the currently existing academic and institutional proposals for monitoring regional integration processes. In the last twenty years, several indicator systems have been developed to evaluate (mainly regional) integration, see e.g. Hufbauer and Schott (1994), Dorrucci, Firpo, Fratscher, and Mongelli (2002), Dennis and Yusof (2003), Feng and Genna (2003), and Ruiz Estrada (2004) to mention only some of them. As a comprehensive review is far beyond the scope of this paper, we restrict ourselves to a particular set of more recently proposed, but nevertheless quite different, indices. Thereby we will consider conceptual questions regarding these indicators, such as the level of specificity (i.e. the number of aspects that are covered) and the methodological (i.e. statistical) approach.

We start with an indicator system that is based purely on coding and scoring, and which is mainly subjective, namely the Integration Achievement Score (IAS) of Hufbauer and Schott (1994). Their monitoring system contains two sets of indicators to analyse economic integration processes. In their article they discuss their proposed indicators and assign a score to each country for each indicator. Thereby they concentrate on South and North America during the period of 1981 to 1992 . While one index is intended to evaluate the level of economic integration achieved by each RIA (e.g. the first step is free trade in goods and services), another index scores the degree of macroeconomic potential for coordination using five indicators, for example price stability and market-oriented policy. Following their scoring, interestingly and maybe surprisingly, the ANDEAN group outperforms - at least marginally - the MERCOSUR (even when only the founders are considered).

Genna (2005) extends the IAS system of Hufbauer and Schott (2004) by splitting it up into more categories (six in total); the integration measure is simply the average of these six equally weighted values. More specifically, regional integration is measured by the following 
categories: trade, capital mobility, labor mobility, monetary policy coordination, supranational institutions, and fiscal policy coordination. The IAS coding system of Genna (2005) splits the categories into five levels and applies the 'Guttman scale' for the scaling procedure. According to his results, in 2000 the European Union showed the highest value of economic integration, and ASEAN the lowest. It should be noted that the IAS tries to measure the homogenization among the member countries only in the macro-economic context. Using his system Genna (2005) tests the hypothesis that the critical condition for successful economic integration is the homogenization of domestic institutions. He considers a set of different RIAs in Africa, Asia and Latin America.

Ruiz Estrada (2004) developed what he calls Global Dimension of Regional Integration (GDRI). It assesses regional integration from a global perspective with social, political, technological and economic categories. His study is based on the theoretical approach of open regionalism of Bhagwati (1999), among others, and of the so-called second-best theory of Lypsey and Lancaster (1997). Ruiz Estrada (2004) creates a large multi-input database with 98 variables, of which 19 are for the political, 15 for the social, 54 for the economic and 10 for the technological category. He then applies a binary coding to each data set based on the measurement of regional variation rates and codes with " 0 " or " 1 " (above or below the regional average). A reason to select the binary coding is to ensure the same importance and the same weighting for all variables. He does not use statistical methods, such as a principle component or factor analysis. The weights are the same for all four sub-indices $X_{i}$. Estrada uses the formula:

$$
X_{i}=\sum_{i=1}^{4} X_{i}=\sum A S(i) * 100 / \sum \operatorname{TPR}(i),
$$

where AS presents the actual values of indicators, TPR their total possible results, and $X_{i}$ should represent the $\mathrm{i}^{\text {th }}$ subindex. The above formula is incorrect if the intention is to compute the sum of the four subindices. (The sum of four fractions is not equal to the sum of the numerators divided by the sum of the denominators. Note also that the notation is inconsistent; the symbol $\mathrm{X}_{\mathrm{i}}$ on the left-hand side represents something different to the symbol $\mathrm{X}_{\mathrm{i}}$ on the right-hand side.) Case studies with the GDRI system are available for the CACM, NAFTA, ASEAN, Andean and MERCOSUR with no particularly new findings.

The UNECA-Index (2004) is an example for administrative monitoring systems which try to evaluate progress of all RIAs in Africa by rather specific objectives. The indicators are based 
on the following eight sectors: trade, money, finance, transport, communication, energy, agriculture, manufacturing, labor market and human development. The performance is calculated using selected convergence criteria (e.g. inflation rate in per cent) for each RIA and for each member. Then, computing of the composite regional integration index is carried out on the basis of scoring from zero (worst) to ten (best performance) points. These scores $\mathrm{X}_{\mathrm{ij}, \mathrm{t}}$ of indicator $\mathrm{i}$, country $\mathrm{j}$ at time $\mathrm{t}$ are normalized by the base year value $\mathrm{X}_{\mathrm{ij}, 0}$ and multiplied by hundred:

$$
I_{i j, t}=\frac{X_{i j, t}}{X_{i j, o}} * 100 .
$$

Finally, it is proposed to consider the average over time, i.e.

$$
\bar{I}_{i j}=\sum_{t=1}^{T} I_{i j, t} / T
$$

These normalized indicators are compared either to given or to calculated yardsticks (by averaging over the best indicators, or countries; here there are several contradictory statements and formulas in the document). They also define a kind of standard deviation to construct strange intervals which are used for comparing the performance of countries against the yardstick. According to this UNECA index, the ECOWAS, the WAEMU and the SADC made good integration progresses between 1994 and 1999, whereas the AMU, the CEMAC and the ECA stagnated. When looking at the UNECA subindices, then we see that the SADC has the highest increment in intra-regional trade; the AMU was the RIA with the lowest inflation rate and the only community with budget surplus.

The ASEAN-REPSF of Yusof and Dennis (2003) is a set of indicators to measure progress towards economic integration among the ten ASEAN countries. It is based on the framework of Balassa (1961), allows for comparison between RIAs, and introduces a weighting by base year and GDP. The selection for the categories results from the list of criteria like policy relevance. They reject statistical criteria, stating, certainly erroneously, that statistical weighting could be affected subjectively due to the lack of hard rules. They used international data sources, like the World Bank and the IMF, but also regional ones, like the annual ASEAN Statistical year books. Although they first suggest an extensive, sectororiented system of indicators to monitor the progress of integration, for the general index they use only FDI and trade flow:

$$
I N T E G A_{t}=\left(T R A D E A_{t}+F D I I N T_{t}\right) / 2
$$




$$
\begin{aligned}
& \text { with } \quad T R A D E A_{t}=\left[\frac{A T R A D E_{t}}{G D P_{t}} / \frac{A T R A D E_{0}}{G D P_{0}}\right] * 100 \text {, } \\
& \text { and } \quad F D I I N T_{t}=\left[\frac{I N T F D_{t}}{G D P_{t}} / \frac{I N T F D_{0}}{G D P_{0}}\right] * 100 \text {, }
\end{aligned}
$$

where $A T R A D E_{t}$ is the value of intra-ASEAN trade (exports plus imports), and INTFD the FDI for ASEAN as a whole in year t. The authors present additional indices, like an index for the intra-ASEAN transport improvement, but these do not enter the general economic ASEAN index INTEGA.

The DFFM-Index of Dorrucci, Firpo, Fratscher, and Mongelli (2002) was constructed for comparing the MERCOSUR with the European integration experiences, and to test the hypothesis whether the institutional integration interacts with economic integration at the regional level. Therefore the authors define institutional integration as the outcome of policy decisions which influence the depth and broadness of RIAs. This institution index is based on the five stages of integration according to Balassa (1961). For the economic integration index they start out from the optimum currency area (OCA) theory of Mundell (1961) and McKinnon (1963). Actually, the OCA theory acts as an analytical framework to study preconditions for the building of a monetary union among member-countries. Key variables for this question are, for example, the degree of synchronization of business cycles (looking in their study at monthly data, de-trended by the HP-filter), the inflation convergence (measured there by the difference of the 12-month percentage changes in the consumer price indices), intra-regional exchange rate variability, the ratio of intra-regional trade to GDP, and the real GDP per capita percentage difference to the regional average. However, the DFFM-index does not contain any social and technological categories. Further, the institution index measures the economic integration stages (free trade area, economic union, etc.), but not the quality of intra-regional institutions. Quite different to all previous studies, the methodology they use is based on a (hierarchical) cluster analysis to measure the similarity among countries in terms of the Euclidean distance, i.e.

$$
\left.D(i, j)=\sqrt{\sum_{k=1}^{p}\left(x_{k i}\right.}-x_{k j}\right)^{2},
$$

where $\mathrm{D}(\mathrm{i}, \mathrm{j})$ measures the dissimilarity between countries $\mathrm{i}$ and $\mathrm{j}$ for all integrative indicator variables $\mathrm{x}_{\mathrm{k}}$. 
In their paper, Dorrucci, Firpo, Fratscher, and Mongelli (2002) find a strong correlation between institutional and economic integration but they do not test the direction of causality between them.

To conclude the brief review of existing monitoring proposals, we find the following alignment of these systems: They were constructed

- to observe the level of integration of RIAs (GDRI and IAS),

- to analyse the pre-conditions for integration (IAS),

- to evaluate regional integration objectives (ASEAN-REPSF), or

- to compare different RIAs in different regions (UNECA, DFFM-Index, GDRI and IAS).

Next we consider the monitoring approaches of global integration (respectively globalization). Note that the phenomenon of globalization is comparable to that of regional integration; in fact, in both cases we observe intensifying interdependences, cooperation, coordination and networking in all spheres of economic, social and political life.

The Kearney index (see Kearney, 2002, 2003) is the first attempt to construct a multidimensional globalization index. The index quantified economic integration through some key variables like trade and FDI flows, political integration through e.g. participation in international organizations, technological integration via instruments such as the accounting of internet users, and personal integration, by recording travel data etc. The index first normalizes each variable within each year by the span of the variable in that year. It allows for $J$ main components with $M$ indicator variables in each. Allowing for a two stage weighting scheme, Heshmati (2006) proposed the following indicator for country $i$ at time t:

$$
G I_{i t}=\sum_{j=1}^{J} w_{j}\left(\sum_{m=1}^{M} \omega_{m}\left(\frac{X_{j m i t}-X_{j m t}^{\min }}{X_{j m t}^{\max }-X_{j m t}^{\min }}\right)\right),
$$

where $m$ and $j$ indicate the major component variables within and between with weights $\omega_{m}$ within a component $j$, and weights $w_{j}$ attached to each of the $J$ main components. Finally, one sums up the GI over the countries for each year and considers the development of that final index over the years. In practice Heshmati's formula (1) does not make much sense for several reasons: first, $M$ may vary over the $J$ main components; second, the $X_{j m}$ are different for each $m$ and / or $j$, and thus the weights $\omega_{m}$ should be different for each $j$. This is 
particularly problematic if we wish to use alternatives to subjective 'ad hoc' weights. Finally, he normalizes the indicators within each year by the reported span of the indicator in that particular year. Firstly, it is well known in statistics that the extreme values are the most problematic observations in theory and practice - apart from the fact that the extreme values are the most prone to reporting or measurement errors. Therefore, an estimate of any percentile (including its variation over the years) is more robust than this type of span-based estimate. Secondly, a normalization specific to each year unnecessarily complicates the comparison of indices between years, typically leading to wrong conclusions. Thirdly, it is evident that both problems combined, i.e. taking the span and allowing for yearly variation could easily lead to a meaningless interpretation. We will come back to these points in the next section.

The KOF-index of Dreher (2006) is also based on the Kearney index, but it contains more dimensions, countries and a longer observation period. The weights of sub-indices are no longer ad-hoc or subjective but are calculated by the principle component analysis. For some numerical reason the normalized indicator variables were multiplied by ten, but else follow the normalization strategy of (1). Furthermore, he discusses the use of more indicator variables, and completes the panel by imputing missing data via linear interpolation. In his study he calculates the KOF-indices from a self-composed panel containing 123 countries over the period from 1970 to 2004. Despite the use of PCA, he points out that global integration is not objectively measurable, because of the high correlation among the different subjective sub-indices, and certainly also because of the selection of variables and categories.

We can summarize for at least the enumerated list of indices the following points: Only a few proposals are based on theoretical concepts, leading in many cases to the lack of reproducible selection of variables. Most of the index systems share methodological problems with aggregation and weighing. The normalization and weighting is partly ad hoc, partly year or sub-group specific, sometimes statistically problematic (if not wrong), and in many cases impedes comparability. The aspect of multidimensionality is treated in Dorrucci, Firpo, Fratscher, and Mongelli (2002) via the Euclidian distance, in others via PCA, but is otherwise neglected. Given a non-reproducible choice of variables, data sources or processing, or even simply erroneous formulas, it is pretty hard to speak of replicable methods when it comes to the numerical results for those indices. There is no doubt that most of the defects - where present - could be fixed; but it should be obvious now that there is still the need to study the 
provision of practical tools for monitoring regional integration and development in more detail.

\subsection{Conceptual framework, variable selection, and methods}

We start with a discussion of the theoretical background of our monitoring tool, before we turn to the indicator selection and discuss the methodological issues.

As mentioned in Section 4.1, there is no unique definition of the phenomenon of regional integration. Instead, one can find numerous conceptual approaches within the regional integration theory, which are based on different aspects of processes, such as the tradeoriented theories of Viner (1956) or the political-economic theories of Krugman (1991). The integration theory is indeed not a closed theory, but rather a mixture of models and theorems: e.g. the Heckscher-Ohlin model, the Kemp-Wan theorem or the optimal current area theory of Mundell (1961). However, most of the existing indicator systems are based on the integration stages of Balassa (1961) as for example the DFFM-index of Dorrucci, Firpo, Fratscher, and Mongelli (2002) or the ASEAN-REPSF system of Dennis and Yusof (2003). Balassa (1961) distinguished the often cited five integration phases: free trade areas, custom union, common economic market, economic union, and finally the monetary union. His model is based on the assumption of the Ricardo-Model which assumes that the extension of free trade over the comparative cost advantages leads to welfare benefits for all countries.

We use the Balassa model as our theoretical basic framework and extend it with political, technological and social aspects. In order to select the indicator variables for each of these aspects, we define the economic, political and social, technological and institutional regional integration (RI hereafter) following De Lombaerde Pietrangeli and Weeratunge (2006) and Dennis and Yusof (2003). Accordingly, economic RI is defined as an increasing interdependence of economies within a region on the basis of trade and capital flow as well as economic coordination and cooperation. To measure the degree of economic integration we consider the following static effects: changes in intra-regional trade and the net inflow of foreign direct investment (in percent of the GDP). As dynamic effects of economic integration are measured the GDP growth per capita as evidence for development of welfare, and the inflation rate as well as the national budget deficit as proxies for economic stability. Trade progress between members is measured by the intra-regional trade - here as a percentage 
share of the region's total trade (regional total imports plus regional total exports). FDI inflow is taken as a proxy for capital mobility. We prefer this proxy to intra-regional FDI since we are more interested in the location attraction increase after forming stable RIAs (consider for example, South-South areas) rather than in intra-regional capital ties.

When speaking of political RI we mean the increasing intra-regional political interaction and coordination, mainly to reach regional stability and security. The degree of political integration is measured by the democracy-dummy, a corruption-index, and two variables (political rights and civil liberties) for rules of laws. Increasing coordination of political affairs between member states is a clear indicator for intensified integration. And, according to political integration theory, the RIA-members have better chances for successful integration in all aspects when they jointly progress in the rule of law. It is for that reason that we consider related variables like democracy or political rights. Moreover, it is of interest whether member-states agree upon obligatory political targets such as the reduction of corruption with (ideally) some kinds of control mechanisms (e.g. a common court of law). We use the sum of all armed conflicts as a proxy for regional stability. Political integration has actually two main goals: stronger domestic stability \& security (via more rule of law) as well as more supra-national security \& neighboring goodwill. Here we assume that regional stability is the absence of armed conflicts in a RIA. One may argue that we left out other important targets of political integration, like the strengthening of bargaining power at multilateral level; recall however, as said at the beginning that we wish to focus on easy available and clearly measurable quantities and variables.

The social RI covers the rising similarity in social structures, norms and values. To estimate the social "convergence" we use life expectancy, years of schooling and the Gini index for inequality. According to the integration theory members of a RIA benefit from regional integration via prosperity rising. When the inequality in the countries is not too extreme, we can observe that average living conditions become better. Nevertheless we believe that life expectancy and education are good initial indicators for improving welfare. Clearly it also would be interesting to have more information about the intra-regional labour market; e.g. liberalization of this market is expected to lead to more labour mobility between the members and therefore less unemployment. Again, however, reliable data are not available for most parts of the world. 
We define the technological RI as an increasing exchange, transfer and cooperation in the areas of technology and infrastructure. It is certainly assumed that thanks to an improved technological cooperation between member countries of a RIA the spread of ideas and information accelerates, and consequently technological differences decrease. Our indicator variables are: fixed subscribers and mobile phone per hundred people, internet user in percent, and paved roads in percent of total road kilometers. The last variable is an indicator for a workable transport network. An indicator for the quality of railway systems could be considered except that in some countries, transport by train is not common.

In Appendix C.II all selected indicator variables are summarized, separated by the categories outlined above, together with data sources and an artificial reference value or yardstick. We are certainly aware of the incompleteness, problems of measurement errors, etc. but recall that our proposal stresses the importance of practicability and international comparability and in particular to the availability and validity of data sources. An important note is how we handle potential entries or exits of countries within a RIA. In the context of this study we simply calculate the indices of a RIA independently of entries or exits of a (new) member. If these new or former members are included in (respectively excluded from) the calculation, the interpretation changes accordingly when comparing indices before and after this event. Though this is no problem for our indices (while it is for most of the indices discussed in Section 4.2), for the sake of presentation we give only numerical results calculated from a fixed country set in this study.

Even when only thinking of the performance of RIAs we come up with two, basically quite different ideas: convergence to equality, and convergence to some yardsticks. It is important to understand that we might not simply be interested in integration making all equal; we might just as much be interested in the developing progress of the member states of a RIA. This becomes even more obvious when we think of monitoring globalization or a specific development process, whether they are of economical, social, political, etc nature. Therefore we first introduce indices looking simply at whether the members of country group become increasingly similar in this multi-dimensional context. Afterwards, we look at the quality of convergence, i.e. the development. So the question arises as to whether coordination becomes more efficient and interdependencies stronger. That is, our indices measure not only pure integration achievements but also the results of integration. To guarantee this our indices are outcome-oriented. 
We start with a discussion of typical methodological problems. While it is generally accepted that normalization of the different indicators is necessary to bring them on comparable scales, it is often ignored that this normalization must not depend on years or country groups if later on it is planned to compare indices over time and / or space. This also holds true when determining the weights. Note that weighting and normalizing are intimately related; statistically speaking, normalization is actually nothing more than a particular case of weighting. Nonetheless, in practice people are more willing to accept this norm when choosing their weights than they are when it comes to normalizing. In order to respect this norm, both normalization factors and weights are determined from a representative world sample in a reference year (year 2000 in our study). This guarantees comparability over any group (e.g. RIA) and any time period. Also so-called yardsticks or reference values must not be calculated for each year or RIA separately, as the UNECA study does. Again, they have to be universal, at least for the underlying study, to make any comparison valid.

Next, accounting for multidimensionality can certainly be done via PCA (calculated from the world sample in a reference year, an unfortunately rarely respected rule). In PCA however, the variables with the largest variance get the largest weights irrespective of their economic or social relevance. In case of no preferences for any of our indicator variables we have basically two alternatives: either we only normalize to bring all indicators to the same scale, or we additionally account for the fact that some of the indicators are (strongly) correlated and therefore contain the same information. The necessary correction is to weight inversely with the correlation structure. In other words, if one includes three variables indicating the same economic fact (for example GDP per capita, mean income, mean expenditure) the sum of their weights would have to amount to the same as the single weight of an independent indicator. This is achieved by the Mahalanobis transformation of the data ${ }^{26}$, where the transformation again has to be defined by the world sample in a reference year in order to yield unique weights and thus comparable results. Statistically the Mahalanobis transform yields independent data on comparable scales such that, after transformation the weights can be chosen to be equal for all (transformed) indicator variables.

\footnotetext{
${ }^{26}$ The transformation is a multiplication of the data matrix by the inverse of the square root of the covariance matrix giving back a data matrix of uncorrelated, normalized variables. Note that in contrast to this general definition the covariance matrix is calculated from the world sample.
} 
Finally, multidimensionality has consequences not only for the required weighting, but also for the metric used when aggregating indicators. We agree with Dorrucci, Firpo, Fratscher, and Mongelli (2002) that graphically and intuitively people generally think in the Euclidian metric when discussing distances. Nonetheless, at the moment of constructing indices people stick to the non-intuitive $\mathrm{L}_{1}$ metric, i.e. aggregate by summing up absolute differences. The combination of Mahalanobis transformation and Euclidian distance is also known as Mahalanobis metric; it is by no means an exotic measure; it is a very common distance measure.

The first two indices we propose can be used to display integration of a country group in the sense of similarity. In order to do so we propose

(I.1) to calculate the average of the Euclidian distances between all country pairs inside each group after a normalization of each indicator variable by its standard deviation.

(I.2) to calculate the average of the Mahalanobis distances between all country pairs inside each group, i.e. calculate the Euclidian distances after a Mahalanobis transformation.

This is done for each year. As explained above, standard deviations and transformation matrix have to be calculated from a fixed world sample in a reference year.

For the sake of a better understanding of these new indices we will also calculate similarity measures that come closer to those in the standard literature: summing up the deviations from the mean and averaging over the $N_{\mathrm{k}}$ countries in group (RIA) $k$, i.e. calculating the $\mathrm{L}_{1}$ distance. For $\tilde{X}_{j, n}$ being the transformation of the $\mathrm{j}^{\text {th }}$ indicator variable of country $n$, calculate

$$
\frac{1}{N} \sum_{n=1}^{N} \sum_{j=1}^{J}\left|\widetilde{X}_{j, n}-\bar{X}_{j}\right|, \text { where } \bar{X}_{j}=\frac{1}{N_{k}} \sum_{n=1}^{N_{k}} \tilde{X}_{j, n}
$$

(I.3) after a normalization of each indicator variable by its standard deviation,

(I.4) after a Mahalanobis transformation.

Evidently, these indices mainly give information about the similarity of the considered country group (e.g. members of a RIA). One may question the information content of these indices. We have to accept, however, that an index is a single number such that, the more aspects we try to cope with and the more information we try to include, the less informative the outcome will be. The key is to retain a clear interpretability. In order to achieve this we prefer to clearly separate integration or globalization in the sense of similarity from 
development aspects. The reason why we have started with similarity is because it is possible there to construct a purely objective index. In the case of development we have goals, and so it matters whether an indicator increases or decreases. It also matters now whether there is an upper (or lower) bound because, without a yardstick, bounded and unbounded variables are not comparable, i.e. can not be aggregated sensibly. This will be the first point to be discussed, and unfortunately, it is subjective and thus debatable.

We now introduce two further indices that measure the quality of development processes rather than their similarity. It will be obvious that these indices can be applied to any country set, including the world sample or a single country. As mentioned above, reference values, or yardsticks, are necessary to make the included indicator variables comparable and thus enabling their aggregation. They mark the direction and goal of a process. In Appendix C.II we give a proposal for each of the selected variables. Note that, as for the weighting and normalization, also these reference values must be universal. If they are specific to a RIA, or year, the resulting indices may not be compared to those of other RIAs or years, respectively. While in some cases (think of the score-variables) the yardsticks are simply the natural limit, for others we are aware that these values are debatable and should be updated (like the reference year) after a certain period. For each indicator $X$, we now consider $\left|X-X^{r e f}\right|$ instead.

In a second step, we have to normalize these differences to bring them on a comparable scale. It is well known that the calculation of the standard deviations of these differences, $\sigma_{r e f}$, is quite unrobust when using the standard formula. We therefore propose a simple but robust measure of dispersion, namely the inter quartile range $(I Q R)$ of the differences divided by 1.34 which actually is equal to the standard deviation for normally distributed data. This gives a consistent estimator of the standard deviation under normality. To summarize, for each indicator variable we consider the transformed version

$$
\tilde{X}=\frac{\left|X-X^{r e f}\right|}{\sigma_{\text {ref }}}, \text { where } \sigma_{\text {ref }}=\operatorname{IQR}\left(\left|X_{\text {world }}-X^{\text {ref }}\right|\right) / 1.34 \text {. }
$$

The subindex 'world' of variable $X$ in the second formula emphasizes that this standard deviation has to be calculated from the world sample. We could have proceeded as before, doing first a Mahalanobis transformation and then calculating the Euclidian distance to the reference value. Unfortunately it is not clear what such a transformation means for the reference value. Further, in the context of development indices, we would like to consider the 
decomposition into sub-indices, say $L$; in particular the already discussed subdivision into economic, social, infrastructural, institutional and political aspects. The Mahalanobis transformation and the determination of Euclidian distances would then have to be carried out in two steps complicating the calculation and, to some extent, also the interpretation. We suspect that nobody would do that in practice. Instead, we propose the following weighted sum:

$I_{l}=\frac{1}{N_{k}} \sum_{n=1}^{N_{k}} \sum_{j=1}^{J_{l}} \omega_{j, l} \widetilde{X}_{j, l, n}$ for the $l^{\text {th }}$ sub-index, and $I=\sum_{l=1}^{L} \gamma_{l} I_{l}$ for the general index,

where $N_{k}$ indicates the number of countries in group $k$, and $J_{l}$ indicates the number of variables in sub-index $l$. The weight for each country is one over $N_{k}$, i.e. all countries are considered global players. Note that changing this interpretation would necessitate a different definition of $\sigma_{\text {ref }}$. Indices using different weights for each country e.g. proportional to the population size must normalize accordingly. This for example would cause serious problems in the Kearney index.

Our weights $\omega_{j, s, m}$ determine the importance of each variable inside its sub-index; the weights $\gamma_{s}$ determine the importance of each category inside the general index. Recall that these weights must not depend on the year or RIA if one wants to compare different indices over the years and RIAs, respectively. We recommend using a weighting $\omega_{j, s, m}$ that corrects for the correlation structure within the sub-indices; see our application in Section 4.4. For the determination of these weights $\omega_{j, s, m}$ in formula (3) we account of the correlation matrices of the standardized (i.e. transformed) variables inside each category, c.f. (2). These matrices are given in Appendix C.IV. However, we recommend always looking at both, the weighted version and the unweighted version of this index.

\subsection{Integration in North-North-, South-South-, and North-South-Agreements: A Comparison Study on Convergence to Equity and Development}

This section is dedicated to the comparison of North-North, South-South, and North-South RIAs with the aid of our monitoring tools. More specifically, we consider the ANZCERTA, EU-15, WAEMU, and NAFTA which are briefly presented in Appendix C.I. Although this comparison is interesting in itself, we hope this further helps to better understand the functioning and interpretation of the here newly introduced monitoring instruments. Based on 
the introductory discussion in Section 4.1, but also the review in Section 4.2, we concentrate only on two specific aspects of integration (recall also our discussion on the limitations of what indices can offer): development and equality or similarity. We will ignore here gaps between integration goals and their real implementation. Instead, we restrict our analysis to observable output monitoring resulting in the already mentioned list of indicator variables, see Appendix C.II for details. Also the discussion of the variable selection and categories in which they are separated to later create sub-indices is deferred to Appendix C.II.

In order to guarantee world wide applicability and comparability, we first created a representative world sample. Respecting the proportion of countries with different economic size in this sample, our sample contains 15 low income countries, 11 lower middle income countries, 10 upper middle income countries, and 14 high income countries (according the World Bank country classification). The reference year is always 2000. The resulting world sample is given in Appendix C.III.

The application and discussion of results follows the methodological order of Section 4.3. Accordingly we start with the findings when applying the first index approach, i.e. the distance measuring indices (DMI henceforth). As in Section 4.3, our discussion covers different methods of normalization and aggregation, specifically via Mahalanobis transformation (Table 4.1 and Appendix C.VI), or simply weighting by the inverse of the global standard deviation (Appendices C.V and C.VII), once computed with absolute difference from the mean, and indices computed from the distance matrix (recall details from Section 4.3). These indices are able to observe integration in the sense of similarity. In addition, we repeated the calculation of each index but without the variable internet user (given only in Appendices C), because exactly during our test period this variable showed discontinuities with time lags between neighbour countries and distorts the numerical results. For brevity, we concentrate on the findings under Mahalanobis transformation. Further results are deferred to the Appendices C.VI, C.VII and C.VIII. Table 4.1 show the DMI, I.2 (distance matrix based) and I.4 ( $\mathrm{L}_{1}$ norm based) for our four selected RIAs. As the NAFTA, EU-15 and WAEMU exist since 1994, ANZCER since 1983. Notice that therefore the first numbers given in Table 4.1 refer to a time point shortly before the foundation of each RIA.

The north-south area takes its largest values in 1990, right before the foundation of NAFTA. Then the index strongly decreases after the formation down to 0.51 (around 2000). After 2000 the index increases continuously back to the pre-NAFTA treaty-level (see Figure 4.1). At a first glance this would indicate the presence of only short run convergence but the lack of 
efforts to deepen the integration in the long run. However, the results of column 3 and 7 contradict indications that there may be only one variable that strongly diverges after 2000 .

Table 4.1: Distance indices I.4 and I.2; RIAs in alphabetic order

\begin{tabular}{|l|l|l|l|l|l|l|l|l|}
\hline & \multicolumn{4}{|c|}{ I.4 : $\mathrm{L}_{1}$ distance to mean } & \multicolumn{5}{c|}{ I.2 : Distance matrix } \\
\hline Col. & 1 & 2 & 3 & 4 & 5 & 6 & 7 & 8 \\
\hline & & & & & & & & \\
& ANZCER & EU-15 & NAFTA & WAEMU & ANZCER & EU-15 & NAFTA & WAEMU \\
\hline 1980 & 0.27 & --- & --- & --- & 0.09 & --- & --- & --- \\
\hline 1990 & 0.23 & 0.56 & 0.78 & 0.56 & 0.07 & 0.23 & 0.61 & 0.29 \\
\hline 1995 & 0.27 & 0.57 & 0.64 & 0.68 & 0.08 & 0.26 & 0.50 & 0.35 \\
\hline 2000 & 0.27 & 0.56 & 0.51 & 0.64 & 0.08 & 0.29 & 0.46 & 0.30 \\
\hline 2005 & 0.28 & 0.72 & 0.68 & 0.62 & 0.11 & 0.33 & 0.45 & 0.34 \\
\hline 2007 & 0.32 & 0.79 & 0.68 & 0.85 & 0.11 & 0.30 & 0.45 & 0.48 \\
\hline
\end{tabular}

Indeed the table in Appendix C.VI and the figures in Appendix C.VIII (in particular Figure C.A.2) demonstrate that it is simply the variable internet user which causes the divergence in I.4. The NAFTA does not show that divergence after 1998 when omitting this variable from index I.4. Instead, Figure C.A.2 shows a continuous trend to more similarity between the three NAFTA- countries. Altogether, this example illustrates that, when we think of a multidimensional, complex development, the Euclidian distance based indices I.1 and I.2 are much more reliable than the indices based on the $\mathrm{L}_{1}$ distances that are typically proposed and used in the literature.

Index I.2 (col. 7) shows a trend to more similarity within NAFTA until 2006, but after 1998 we observe stagnation (see Figure 4.2). This supports the statement of a lack of deeper integration in the NAFTA to reach long term integration. And indeed, the NAFTA is based on a pure free trade agreement; the main target is to remove tariff- and non-tariff trade barriers between the three states. There is no further cooperation; for example there are no ambitions for setting up supra-national governmental institutions. For this reason we observe a relatively high base level of dissimilarity, and a stagnating trend since 1998. 
Figure 4.1: RIAs in comparison along distance indicator I.4

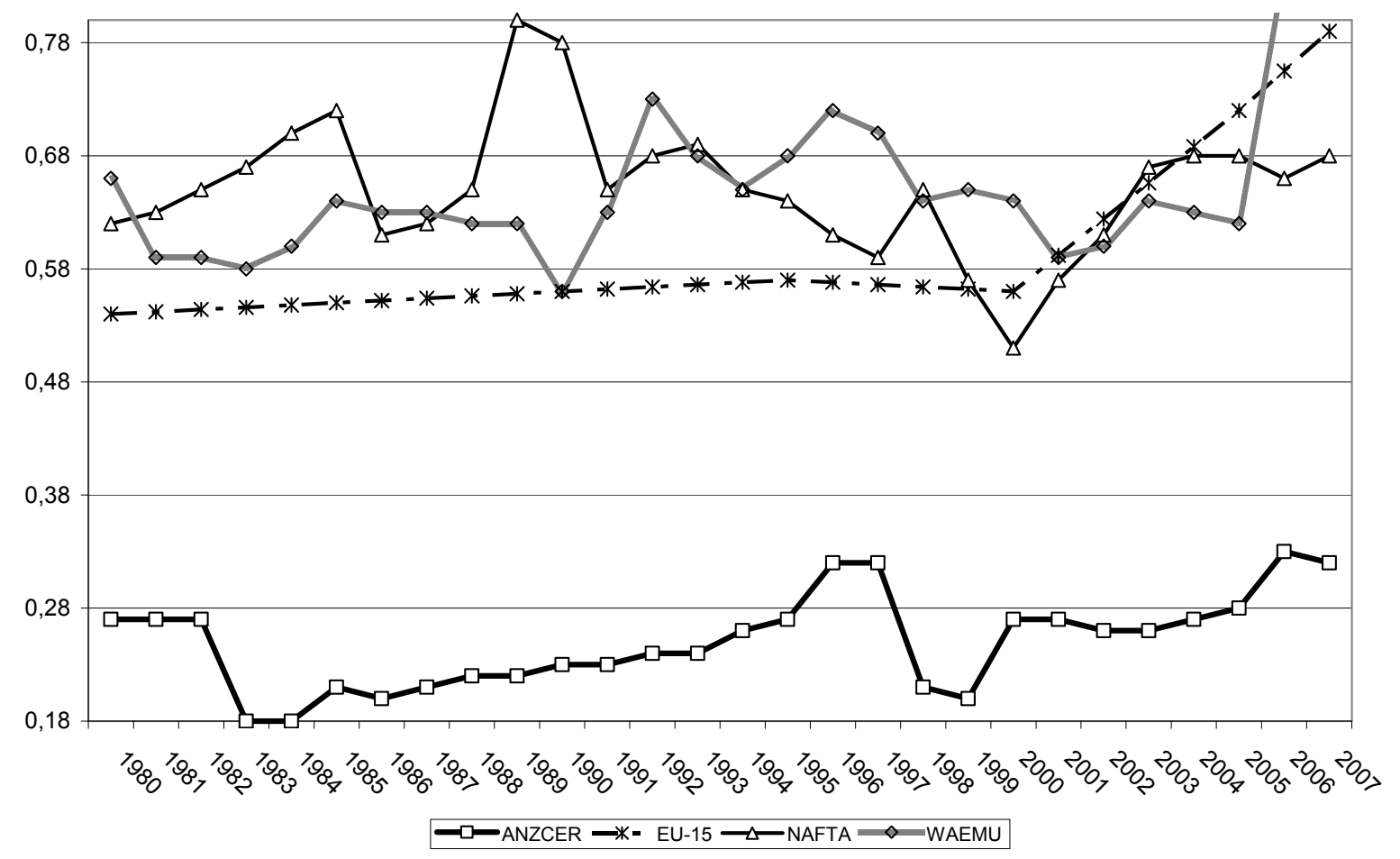

After the foundation of WAEMU 1994 we can observe a marginal decreasing of both indices (Table 4.1, cols. 4 and 8); from 1996 to 2000 even a decrease before they finally strongly increase. We can conclude that starting in 2002/03, and despite WAEMU-agreements, the differences between all eight countries increase see Figures 4.1 and 4.2. When we look at the data, we find increasing distances, for example in GDP per capita, life expectancy or the percentage of paved roads. Note that in the years 2005/06 the WAEMU even surpasses the NAFTA in dissimilarity although intuitively we would expect that South-South RIAs to be generally more similar than North-South RIAs are.

At a first glance it is surprising that the dissimilarity is even larger without internet user; see Appendices C.VI and C.VIII. Although all member countries can only slowly absorb the new technology of the internet, there are clear differences between the WAEMU countries. And these differences explain why, without the variable internet user, the members are more similar. 
Figure 4.2: RIAs in comparison along distance indicator I.2

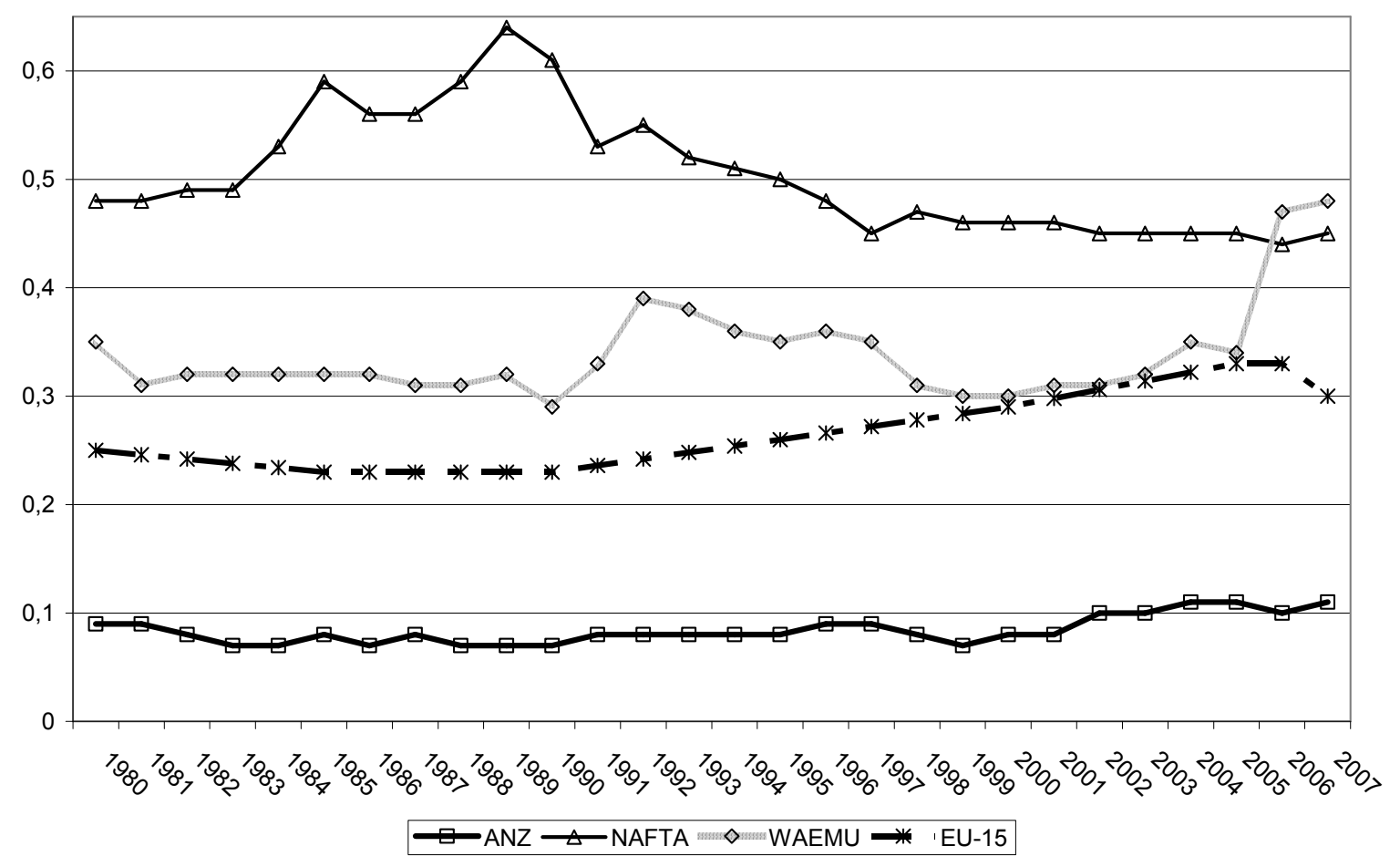

The selected North-North RIAs, EU-15 and ANZCERTA all show different trends. For the ANZCERTA both indices indicate a relatively high level of similarity. Both indices in Table 4.1 and Figures 4.1 and 4.2 reveal a stable similarity at an extremely high level (or dissimilarity at an extremely low level). They also show a marginal trend to dissimilarity. Removing the variable internet user does not change these findings significantly; both countries have absorbed the new technology relatively fast. However, looking at Figure C.A.1 we see that without internet user the general oscillation becomes smoother between 1996 and 2002.

When we look at the indices for the EU-15, we observe a rise of our indices (Table 4.1, cols. 2 and 6). Certainly, without the variable internet user (Appendices C.VI and C.VIII) we obtain a lower and flatter trend of these indices. Moreover, the members are more similar without the consideration of this variable. But besides the difference in internet technological absorption we find increasing distances in the development of GDPs per capita as well as corruption. Although the EU-15, as a North-North RIA, and the WAEMU, as an example for South-South RIA, have clearly strong differences in their economic, political, and social development, the members within both RIAs are equally similar during the period from 1999 to 2003 (see for example Figure 4.2). 
When we compare the results of all selected RIAs using our distance measuring indices (DMIs), we conclude that, not surprisingly, ANZCERTA is the RIA whose members are most similar; the EU-15 is in second place, and the WAEMU and NAFTA have the highest dissimilarity between their members.

Next we present the second approach to monitor integration and development. Recall that this offers a tool to monitor development overall and to subdivide total indices in sub-indices. We look at the results of indices with reference-value approach (IRV henceforth). In Tables 4.2, 4.4, 4.6 and 4.8 we show the sub- and main indices of the NAFTA, EU-15, WAEMU and ANCER un-weighted. In Tables 4.3, 4.5, 4.7 and 4.9 we see the findings of the correlationweighted indices of the selected RIAs.

Table 4.2: IRV for the NAFTA (reference method, unweighted)

\begin{tabular}{|l|l|l|l|l|l|l|}
\hline NAFTA & Index $_{\text {econ }}$ & Index $_{\text {social }}$ & Index $_{\text {polit }}$ & Index $_{\text {inf }}$ & Index $_{\text {instn }}$ & $\sum$ \\
\hline 1990 & 3.89 & 1.16 & 0.71 & 1.97 & 1.00 & 1.74 \\
\hline 1995 & 1.45 & 1.07 & 0.66 & 1.91 & 0.75 & 1.16 \\
\hline 2000 & 1.36 & 1.00 & 0.44 & 1.45 & 0.75 & 0.99 \\
\hline 2005 & 1.33 & 0.94 & 0.47 & 0.91 & 0.75 & 0.88 \\
\hline 2007 & 1.24 & 0.93 & 0.46 & 0.81 & 0.75 & 0.83 \\
\hline
\end{tabular}

Table 4.3: IRV for the NAFTA (reference method, weighted)

\begin{tabular}{|l|l|l|l|l|l|l|}
\hline NAFTA & Index $_{\text {econ }}$ & Index $_{\text {social }}$ & Index $_{\text {polit }}$ & Index $_{\text {inf }}$ & Index $_{\text {instn }}$ & $\sum$ \\
\hline 1990 & 4.25 & 1.21 & 0.67 & 1.74 & 1.00 & 1.77 \\
\hline 1995 & 1.55 & 1.12 & 0.63 & 1.69 & 0.75 & 1.15 \\
\hline 2000 & 1.46 & 1.05 & 0.28 & 1.35 & 0.75 & 0.98 \\
\hline 2005 & 1.44 & 1.00 & 0.40 & 0.93 & 0.75 & 0.91 \\
\hline 2007 & 1.35 & 0.99 & 0.39 & 0.85 & 0.75 & 0.86 \\
\hline
\end{tabular}

As before, we start with the North-South RIA; see Tables 4.2 and 4.3. The first striking fact is the enormous improvement in the sub-index economy from 1990 to 2007 . Index econ $_{\text {decreases }}$ more than 65 per cent in this period. As we can clearly see, the big step to progress took place immediately after the foundation of the NAFTA in 1995. As expected, the establishment of a 
North-South RIA is yield with an economic upturn due to technological transmission, increasing labour mobility and intra-regional trade.

In addition, the Mexican economy steadily stabilized in the period from 1991 to 1995 (e.g. inflation rate of $114.16 \%$ in 1990 decreased to $9.75 \%$ in 1995). Of course, the high inflation rate in Mexico is the main reason for the comparatively high initial value in 1990 (see also Figure 4.3). Also the sub-index for infrastructure exhibits a remarkable improvement, due to the categories communication and transport. In 1990 the index was 1.97; it decreased to 0.81 in 2007. It is well-known that at the beginning of the 90s the information- and communication sector boomed. This global technological progress (e.g. spread of internet access) affects our sub-index in the first years, but we can realize also a continuous upgrading after 2000. When we look at the sub-indices for social and political issues, we observe similarly large and steady development between 1990 and 2007. Since the NAFTA makes no effort to integrate politically, the fifth index stagnates after 1995. The total index of NAFTA decreases from 1.74 (respectively 1.77 ) in 1990 to 0.83 (respectively 0.86 ) in 2007 . Thus the index of the NAFTA declines at around 25 per cent after the establishment of this RIA, no matter whether we consider index I.5 or index I.6.

Table 4.4: IRV for the WAEMU (reference method, unweighted)

\begin{tabular}{|l|l|l|l|l|l|l|}
\hline WAEMU & Index $_{\text {econ }}$ & Index $_{\text {social }}$ & Index $_{\text {polit }}$ & Index $_{\text {inf }}$ & Index $_{\text {instn }}$ & $\sum$ \\
\hline 1990 & 2.61 & 2.75 & 2.04 & 2.29 & 0.75 & 2.09 \\
\hline 1995 & 2.80 & 2.72 & 1.59 & 2.28 & 0.50 & 1.98 \\
\hline 2000 & 2.13 & 2.65 & 1.54 & 2.26 & 0.25 & 1.77 \\
\hline 2005 & 2.02 & 2.58 & 1.51 & 2.19 & 0.25 & 1.71 \\
\hline 2007 & 2.30 & 2.56 & 1.41 & 2.15 & 0.25 & 1.73 \\
\hline
\end{tabular}

Table 4.5: IRV for the WAEMU (reference method, weighted)

\begin{tabular}{|l|l|l|l|l|l|l|}
\hline WAEMU & Index $_{\text {econ }}$ & Index $_{\text {social }}$ & Index $_{\text {polit }}$ & Index $_{\text {inf }}$ & Index $_{\text {instn }}$ & $\sum$ \\
\hline 1990 & 2.66 & 2.59 & 1.92 & 2.09 & 0.75 & 2.00 \\
\hline 1995 & 2.87 & 2.57 & 1.44 & 2.10 & 0.50 & 1.89 \\
\hline 2000 & 2.13 & 2.49 & 1.34 & 2.07 & 0.50 & 1.71 \\
\hline 2005 & 2.03 & 2.42 & 1.30 & 2.01 & 0.25 & 1.60 \\
\hline 2007 & 2.33 & 2.41 & 1.16 & 1.98 & 0.25 & 1.62 \\
\hline
\end{tabular}


In Tables 4.4 and 4.5 the numerical results for the WAEMU are given. An interesting point


(or 2.66) to 2.80 (or 2.87) between 1990 and 1995. This, however, is particularly due to the high inflation rates coming along with the currency devaluation in January 1994 (GuineaBissau in 1994 reaches $45.87 \%$ and in 1995 even 50.73\%). Thereafter we see a steadily gradual economic advancement until 2005 and a step backward from 2005 to 2007. The three

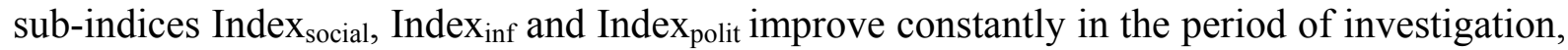
whereby the progress is greatest in the category politics. The categories political rights, civil liberty and democracy experience quantum jumps (the scoring of democracy for Niger was zero in 1990, and went up to 7 points in 2007).

Although we can observe an improvement in the sub-index for infrastructure, this progress is quite small and simply driven by the diffusion of communication technology all over the world. According to our data, the advancement concerning the expansion of paved road systems is also rather small. Since the WAEMU has undertaken numerous efforts to integrate institutionally (for example in 1998 the establishment of a common parliamentary committee and court of law), the fifth sub-index decreases here significantly to 0.25 in 2000 . Note however, that we can measure only the existence of supra-national institutions, not their practical functionality.

Table 4.6: IRV for the ANZCER (reference method, unweighted)

\begin{tabular}{|l|l|l|l|l|l|l|}
\hline ANZCER & Index $_{\text {econ }}$ & Index $_{\text {social }}$ & Index $_{\text {polit }}$ & Index $_{\text {inf }}$ & Index $_{\text {instn }}$ & $\sum$ \\
\hline 1980 & 2.19 & 0.86 & 0.42 & 1.96 & 1.00 & 1.28 \\
\hline 1985 & 1.91 & 0.83 & 0.29 & 1.94 & 0.75 & 1.14 \\
\hline 1990 & 1.54 & 0.79 & 0.18 & 1.90 & 0.75 & 1.03 \\
\hline 1995 & 1.28 & 0.73 & 0.09 & 1.74 & 0.75 & 0.91 \\
\hline 2000 & 1.31 & 0.66 & 0.08 & 0.88 & 0.75 & 0.73 \\
\hline 2005 & 1.61 & 0.59 & 0.07 & 0.41 & 0.75 & 0.68 \\
\hline 2007 & 1.40 & 0.58 & 0.06 & 0.36 & 0.75 & 0.63 \\
\hline
\end{tabular}


Table 4.7: IRV for the ANZCER (reference method, weighted)

\begin{tabular}{|l|l|l|l|l|l|l|}
\hline ANZCER & Index $_{\text {econ }}$ & Index $_{\text {social }}$ & Index $_{\text {polit }}$ & Index $_{\text {inf }}$ & Index $_{\text {instn }}$ & $\sum$ \\
\hline 1980 & 2.34 & 0.87 & 0.23 & 1.72 & 1.00 & 1.23 \\
\hline 1985 & 2.05 & 0.84 & 0.16 & 1.70 & 0.75 & 1.10 \\
\hline 1990 & 1.65 & 0.81 & 0.10 & 1.67 & 0.75 & 0.99 \\
\hline 1995 & 1.37 & 0.76 & 0.05 & 1.54 & 0.75 & 0.89 \\
\hline 2000 & 1.41 & 0.70 & 0.05 & 0.89 & 0.75 & 0.76 \\
\hline 2005 & 1.76 & 0.64 & 0.04 & 0.52 & 0.75 & 0.74 \\
\hline 2007 & 1.53 & 0.63 & 0.03 & 0.48 & 0.75 & 0.68 \\
\hline
\end{tabular}

The final RIAs to discuss are the two North-North agreements. As we expected, the member countries of ANZCER show a relatively high development in social and political categories (Tables 4.6 and 4.7). But also the category for infrastructure shows enormous progress. The sub-index $\mathrm{I}_{\text {econ }}$ presents economical development until 2000, but around 2005 we see a temporary decline, because of lower net investment inflow and a decrease of intra-regional trade. The ANZCER has hardly any intra-regional institutions such as common court of law or a common parliament. Since this RIA involves only two members with the main target of stimulation of economic growth, intra-regional and FDI net inflow, it can be assumed that no necessity exists for further common institutions. If other states would like to join this RIA, this situation would clearly change. Note that here the differences between the indices I.5 and I.6 highlight the correction of co-movement of most of the categories for which I.6 has been constructed. This does not necessarily always smooth the path of the index, but it mostly does. If we do not consider the naturally high correlation among the three variables, the results for this sub-index are dominated by this common driver.

Table 4.8: IRV for the EU-15 (reference method, unweighted)

\begin{tabular}{|l|l|l|l|l|l|l|}
\hline EU-15 & Index $_{\text {econ }}$ & Index $_{\text {social }}$ & Index $_{\text {polit }}$ & Index $_{\text {inf }}$ & Index $_{\text {instn }}$ & $\sum$ \\
\hline 1990 & 1.65 & 1.00 & 0.28 & 1.63 & 0.75 & 1.06 \\
\hline 1995 & 1.61 & 0.92 & 0.28 & 1.51 & 0.50 & 0.96 \\
\hline 2000 & 0.97 & 0.85 & 0.26 & 0.72 & 0.25 & 0.61 \\
\hline 2005 & 1.22 & 0.78 & 0.23 & 0.23 & 0.25 & 0.54 \\
\hline 2007 & 1.19 & 0.69 & 0.21 & 0.16 & 0.25 & 0.50 \\
\hline
\end{tabular}


Table 4.9: IRV for the EU-15 (reference method, weighted)

\begin{tabular}{|l|l|l|l|l|l|l|}
\hline EU-15 & Index $_{\text {econ }}$ & Index $_{\text {social }}$ & Index $_{\text {polit }}$ & Index $_{\text {inf }}$ & Index $_{\text {instn }}$ & $\sum$ \\
\hline 1990 & 1.60 & 1.09 & 0.12 & 0.85 & 0.75 & 0.88 \\
\hline 1995 & 1.57 & 1.01 & 0.11 & 0.78 & 0.50 & 0.79 \\
\hline 2000 & 0.94 & 0.95 & 0.10 & 0.38 & 0.25 & 0.52 \\
\hline 2005 & 1.20 & 0.88 & 0.09 & 0.13 & 0.25 & 0.51 \\
\hline 2007 & 1.18 & 0.79 & 0.07 & 0.10 & 0.25 & 0.48 \\
\hline
\end{tabular}

Another example is the sub-index for infrastructure in the EU-15; the un-weighted results lie well above the numbers resulting from the weighted index. There, the largest changes are in the variables telecommunication and internet access, but these are strongly related to each other, so the un-weighted results for Index $x_{\text {inf }}$ may overrate convergence and / or divergence processes. The sub-index Index $x_{\text {econ }}$ clearly shows the continual economic development of the 15 EU-members up to 2004. Since then a decline can be seen. The reasons for this decline are the temporary decrease of FDI net inflow and intra-regional trade. These effects are closely connected with the "eastward enlargement" in 2004 when 10 new states joined the EU.

Figure 4.3: IRV-Index (weighted) in comparsion

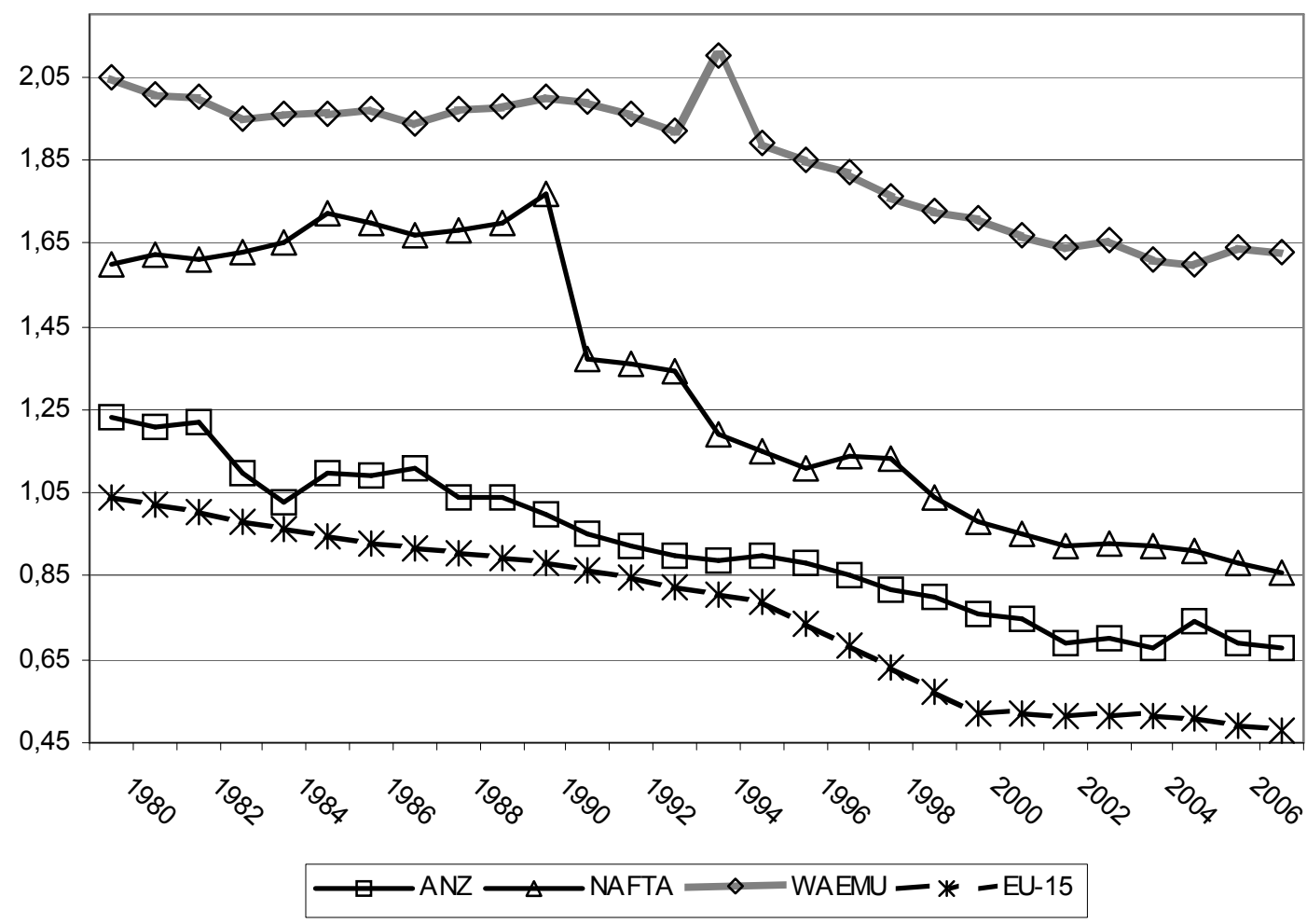


Figure 4.3 summarizes the findings in Tables 4.2-4.9. If we use the IRV-Index in order to monitor all selected RIAs, we can determine a clearly integrative tendency in the sense that, in all RIAs, the members converge towards some given development targets, i.e. the reference values. We note that the WAEMU starts with a high overall index level of 2.1, but, the progress of the last decades is visible. When we look at the NAFTA, they begin with initial large indices too, but particularly due to the economic and political changes in Mexico, this index falls strongly until 2005. The ANZCER-index shows a constant advancement between the two partner countries over the investigation period. In the case of EU-15 we find out three stages for the overall index; first a gradual decrease of the IRV; second, from 1995 to 2000, a rapid decline (i.e. progress) from 0.96 to 0.61 ; and third slow progress up to today. It is important to note that we can observe only the effects of eastward enlargement (in 2004) in the category "economics"; but not in the whole index trend nor in any other sub-index.

If we compare the sub-indices for economy of all selected RIAs in this study then, as expected, the EU-15 has been the most strongly economically integrated area since 2000. In addition, the EU-15 has rank 1 in the category infrastructure, whereby the largest progress has been made by the ANZCERTA. In the political and social categories ANZCER is in front. Concerning intra-regional institutions, the WAEMU and the EU-15 are equally positioned with 0.25 points. If, one day, the Lisbon contract (formally called constitution) comes into force, then the European Union will be politically fully-integrated. Recall again that we are not evaluating the functionality of institutions in this last category, but solely their existence.

\subsection{Conclusions and Final Remarks}

This article reviews first critically - though by no means comprehensively - indices constructed to monitor integration and / or development. Based on the discussed pros and cons of the existing indices we derive and propose a set of new indices - some of them based on concepts which are not really new in statistics but entirely new in this context. The intention is to design an indicator system that is easily implemented, has a clear and straightforward interpretation, and is universally applicable. For example, it should be generally applicable to North-North, North-South or South-South agreements. In brief, the objective is to achieve multidimensionality, feasibility, universality and comparability (both over time and space). We show that the indices offered in the literature are different in certain of these 
respects, especially the first and the last. We also emphasize replicability, an issue which is mostly violated because authors are often not willing to make their data available or to document their own calculations.

In Section 4.4 we test our indices by monitoring and comparing four integration areas which are used to represent South-South (in our case the WAEMU), North-South (the NAFTA), and North-North integration areas (ANZCERTA and the EU-15). We focus on the period 1980 (or $1990)$ to 2007 . This is possible as we possess indices comparable over time and space. To avoid bias caused by gaps between integration or development targets and real transformation, we limit the empirical study to a well-defined set of outcome variables. This study is mainly aimed at promoting a better understanding of the indices introduced here, but it may also serve as a contribution to the controversial discussion about the pros and cons of regional integration agreements.

One may be disappointed and question the information content, or even the sense, of these indices. What one really does then is put into question the significance or the sense of indices per se. This, however, is based on a fundamental misunderstanding of what indices can accomplish. One must not forget the following two principles: Indices are tools to explore empirical facts but they can hardly be compared with econometric tools like regression modeling or analysis, and not at all with computational experiments or experimental economics. We simply look at historical data, but we do not explore them, we have no model nor do we study any causality. The basic challenges here are to guarantee feasibility (in the sense of replicability), unambiguous interpretability, and comparability of the results. A good index should reflect empirical reality rather than what one wishes to see. Note that an index tries to compress all information into one single number. Unfortunately, the more aspects one tries to pack into an index the more diluted is the impact of each factor irrespective of the complexity of the construction of the index. 
Appendices:
A. Appendix chapter 1
B. Appendix chapter 2
C. Appendix chapter 4 


\section{Appendix A / Chapter 1 - Results for the split samples}

\section{A.A Solow-Model - unconditional}

Table A.A.1: Sample split Latin America - unconditional

\begin{tabular}{lllll}
\hline \hline & $\begin{array}{l}\text { Fixed-effects } \\
\text { (within) regression } \\
\text { MERCO=0 }\end{array}$ & $\begin{array}{l}\text { GSL-Regression } \\
\text { AR(1), heterosc. } \\
\text { MERCO=0 }\end{array}$ & $\begin{array}{l}\text { Fixed-effects } \\
\text { (within) regression } \\
\text { MERCO=1 }\end{array}$ & $\begin{array}{l}\text { GSL-Regression } \\
\text { AR(1), heterosc. } \\
\text { MERCO=1 }\end{array}$ \\
Initial income & $-.1027(.050)$ & $-.0048(.002)$ & $-.2250(.044)$ & $-.0156(.017)$ \\
Const. & $.8742(.410)$ & $.0666(.019)$ & $1.9813(.384)$ & $.1614(.150)$ \\
& & & & 25 \\
No. of observ. & 35 & 35 & 25 & 0.365 \\
Prob $>$ chi2 & 0.050 & 0.048 & 0.002 &
\end{tabular}

Table A.A.2: Sample split East Asia - unconditional (unfiltered)

\begin{tabular}{|c|c|c|c|c|}
\hline & $\begin{array}{l}\text { Fixed-effects } \\
\text { (within) regression } \\
\text { ASEAN=0 }\end{array}$ & $\begin{array}{l}\text { GSL-Regression } \\
\text { AR(1), heterosc. } \\
\text { ASEAN }=0\end{array}$ & $\begin{array}{l}\text { Fixed-effects } \\
\text { (within) regression } \\
\text { ASEAN=1 }\end{array}$ & $\begin{array}{l}\text { GSL-Regression } \\
\text { AR(1), heterosc. } \\
\text { ASEAN=1 }\end{array}$ \\
\hline Initial income & $-.0320(.006)$ & $-.0142(.000)$ & $-.0598(.009)$ & $-.0313(.007)$ \\
\hline Const. & $.3425(.050)$ & $.1923(.004)$ & $.5414(.071)$ & $.3024(.053)$ \\
\hline No. of observ. & 56 & 56 & 59 & 59 \\
\hline Prob $>$ chi 2 & 0.000 & 0.000 & 0.000 & 0.000 \\
\hline
\end{tabular}

Table A.A.3a: Sample split West Africa: ECOWAS - unconditional

\begin{tabular}{llrrr}
\hline \hline & $\begin{array}{l}\text { Fixed-effects } \\
\text { (within) regression } \\
\text { ECOWAS=0 }\end{array}$ & $\begin{array}{l}\text { GSL-Regression } \\
\text { AR(1), heterosc. } \\
\text { ECOWAS=0 }\end{array}$ & $\begin{array}{l}\text { Fixed-effects } \\
\text { (within) regression } \\
\text { ECOWAS=1 }\end{array}$ & $\begin{array}{l}\text { GSL-Regression } \\
\text { AR(1), heterosc. } \\
\text { ECOWAS=1 }\end{array}$ \\
Initial income & $.0016(.031)$ & $-.0242(.010)$ & $-.0642(.013)$ & $-.0239(.006)$ \\
Const. & $.0380(.224)$ & $.2133(.075)$ & $.4681(.092)$ & $.1984(.043)$ \\
& & & & \\
No. of observ. & 61 & 61 & 119 & 119 \\
Prob $>$ chi2 & 0.924 & 0.014 & 0.000 & 0.000 \\
\hline \hline
\end{tabular}

Table A.A.3b: Sample split West Africa: WAEMU - unconditional

\begin{tabular}{|c|c|c|c|c|}
\hline & $\begin{array}{l}\text { Fixed-effects } \\
\text { (within) regression } \\
\text { WAEMU }=0\end{array}$ & $\begin{array}{l}\text { GSL-Regression } \\
\text { AR(1), heterosc. } \\
\text { WAEMU }=0\end{array}$ & $\begin{array}{l}\text { Fixed-effects } \\
\text { (within) regression } \\
\text { WAEMU=1 }\end{array}$ & $\begin{array}{l}\text { GSL-Regression } \\
\text { AR(1), heterosc. } \\
\text { WAEMU }=1\end{array}$ \\
\hline Initial income & $-.0295(.017)$ & $-.0136(.003)$ & $-.1067(.098)$ & $-.0219(.007)$ \\
\hline Const. & $.2442(.120)$ & $.1344(.024)$ & $.7658(.683)$ & $.1807(.049)$ \\
\hline No. of observ. & 156 & 156 & 24 & 24 \\
\hline Prob $>$ chi 2 & 0.094 & 0.000 & 0.297 & 0.004 \\
\hline
\end{tabular}

Table A.A.3c: Sample split Central Africa: CEMAC - unconditional

\begin{tabular}{|c|c|c|c|c|}
\hline & $\begin{array}{l}\text { Fixed-effects } \\
\text { (within) regression } \\
\text { CEMAC }=0\end{array}$ & $\begin{array}{l}\text { GSL-Regression } \\
\text { AR(1), heterosc. } \\
\text { CEMAC }=0\end{array}$ & $\begin{array}{l}\text { Fixed-effects } \\
\text { (within) regression } \\
\text { CEMAC }^{3}=1\end{array}$ & $\begin{array}{l}\text { GSL-Regression } \\
\text { AR(1), heterosc. } \\
\text { CEMAC }=1\end{array}$ \\
\hline Initial income & $-.0814(.012)$ & $-.0210(.005)$ & $-.1044(.069)$ & $-.0079(.052)$ \\
\hline Const. & $.5885(.085)$ & $.1791(.035)$ & $.8645(.522)$ & $.0971(.370)$ \\
\hline No. of observ. & 159 & 159 & 21 & 21 \\
\hline Prob $>$ chi 2 & 0.000 & 0.000 & 0.159 & 0.879 \\
\hline
\end{tabular}


A.B Solow-Model - conditional

Table A.B. 4: Sample split Latin America - conditional

Fixed-effects GSL-Regression

(within) regression $\mathrm{AR}(1)$, heterosc.

MERCOSUR $=0 \quad$ MERCOSUR $=0$

Initial income
Investment
Schooling
$\mathrm{Ln}(\mathrm{n}+\mathrm{g}+\delta)$
Const.

$-.0946(.068)$ $.0806(.062)$ $.0303(.126)$

$.1355(.110)$ $.4534(.549)$

$$
\begin{aligned}
-.0119 & (.013) \\
.0071 & (.019) \\
-.0437 & (.013) \\
-.0363 & (.011) \\
.2066 & (.079)
\end{aligned}
$$

Fixed-effects

(within) regression

$\operatorname{MERCOSUR}=1$

$$
\begin{aligned}
-.3319 & (.107) \\
.1549 & (.104) \\
.9454 & (.568) \\
.0512 & (.155) \\
.7188 & (.107)
\end{aligned}
$$

GSL-Regression

AR(1), heterosc.

$\operatorname{MERCOSUR}=1$

$$
\begin{array}{rr}
-.0787 & (.029) \\
.0974 & (.023) \\
.0155 & (.018) \\
-.0279 & (.023) \\
.4276 & (.230)
\end{array}
$$

\begin{tabular}{|c|c|c|c|c|}
\hline & $\begin{array}{l}\text { Fixed-effects (within) } \\
\text { regression } \\
\text { ASEAN }=0\end{array}$ & $\begin{array}{l}\text { GSL-Regression } \\
\text { AR(1), heterosc. } \\
\text { ASEAN }=0\end{array}$ & $\begin{array}{l}\text { Fixed-effects (within) } \\
\text { regression } \\
\text { ASEAN=1 }\end{array}$ & $\begin{array}{l}\text { GSL-Regression } \\
\text { AR(1), heterosc. } \\
\text { ASEAN }=1\end{array}$ \\
\hline Initial income & $-.0552(.009)$ & $-.0444(.003)$ & $-.0878(.017)$ & $-.0529(.006)$ \\
\hline Investment & $.0129(.038)$ & $.0271(.004)$ & $.0688(.029)$ & $.0847(.008)$ \\
\hline Schooling & $.1189(.049)$ & $.0589(.002)$ & $.1490(.080)$ & .0117 (.009) \\
\hline $\operatorname{Ln}(\mathrm{n}+\mathrm{g}+\delta)$ & $.0079(.010)$ & $.0029(.006)$ & $.0145(.017)$ & $.0183(.008)$ \\
\hline Const. & $.2762(.087)$ & $.2540(.021)$ & $.3141(.113)$ & $.2006(.030)$ \\
\hline No. of observ. & 56 & 56 & 59 & 59 \\
\hline Prob $>$ chi2 & 0.000 & 0.000 & 0.000 & 0.000 \\
\hline
\end{tabular}

\begin{tabular}{|c|c|c|c|c|}
\hline & $\begin{array}{l}\text { Fixed-effects (within) } \\
\text { regression } \\
\text { ECOWAS }=0\end{array}$ & $\begin{array}{l}\text { GSL-Regression } \\
\text { AR(1), heterosc. } \\
\text { ECOWAS }=0\end{array}$ & $\begin{array}{l}\text { Fixed-effects (within) } \\
\text { regression } \\
\text { ECOWAS=1 }\end{array}$ & $\begin{array}{l}\text { GSL-Regression } \\
\text { AR(1), heterosc. } \\
\text { ECOWAS }=1\end{array}$ \\
\hline Initial income & $.0065 \quad(.036)$ & $-.0233(.016)$ & $-.0639(.021)$ & $-.0356(.010)$ \\
\hline Investment & $.0669 \quad(.023)$ & $.0240 \quad(.018)$ & $.0188(.010)$ & $.0168(.007)$ \\
\hline Schooling & $-.0604 \quad(.058)$ & $-.0021 \quad(.022)$ & $-.0015(.024)$ & $.0138(.008)$ \\
\hline $\operatorname{Ln}(n+g+\delta)$ & $.0133 \quad(.078)$ & $.0075 \quad(.036)$ & $-.0310(.027)$ & $-.0379(.012)$ \\
\hline Const. & $-.0888 \quad(.241)$ & $.1469 \quad(.109)$ & $.4611(.139)$ & $.2732(.069)$ \\
\hline No. of observ. & 61 & 61 & 119 & 119 \\
\hline Prob $>$ chi 2 & 0.035 & 0.365 & 0.000 & 0.000 \\
\hline
\end{tabular}

No. of obs.

$$
\begin{array}{r}
35 \\
0.077
\end{array}
$$

\begin{tabular}{|c|c|c|c|c|}
\hline & $\begin{array}{l}\text { Fixed-effects } \\
\text { (within) regression } \\
\text { WAEMU=0 }\end{array}$ & $\begin{array}{l}\text { GSL-Regression } \\
\text { AR(1), heterosc. } \\
\text { WAEMU }=0\end{array}$ & $\begin{array}{l}\text { Fixed-effects (within) } \\
\text { regression } \\
\text { WAEMU }=1\end{array}$ & $\begin{array}{l}\text { GSL-Regression } \\
\text { AR(1), heterosc. } \\
\text { WAEMU }=1\end{array}$ \\
\hline Initial income & $-.0117 \quad(.021)$ & $-.0273 \quad(.007)$ & $-.3619 \quad(.127)$ & $-.1106 \quad(.034)$ \\
\hline Investment & $.0476 \quad(.012)$ & $.0255 \quad(.007)$ & $.1042 \quad(.053)$ & $.0039 \quad(.007)$ \\
\hline Schooling & $-.0621 \quad(.030)$ & $.0119 \quad(.006)$ & $.5715 \quad(.240)$ & $.0593 \quad(.020)$ \\
\hline $\operatorname{Ln}(\mathrm{n}+\mathrm{g}+\delta)$ & $-.0089(.038)$ & $-.0237 \quad(.012)$ & $.0969 \quad(.107)$ & $-.0365 \quad(.027)$ \\
\hline Const. & $.0802 \quad(.139)$ & $.1874 \quad(.049)$ & $1.9412 \quad(.758)$ & $.7927 \quad(.201)$ \\
\hline No. of observ. & 156 & 156 & 24 & 24 \\
\hline Prob $>$ chi 2 & 0.000 & 0.000 & 0.123 & 0.000 \\
\hline
\end{tabular}

35

Note: Standard deviations for coefficient estimates are in parenthesis.

Table A.B. 5: Sample split East Asia - conditional (unfiltered)

Table A.B. 6a: Sample split West Africa: ECOWAS - conditional

Table A.B. 6b: Sample split West Africa: WAEMU - conditional 
Table A.B. 6c: Sample split Central Africa: CEMAC - conditional

\begin{tabular}{|c|c|c|c|c|c|c|c|}
\hline & \multicolumn{2}{|c|}{$\begin{array}{l}\text { Fixed-effects (within) } \\
\text { regression } \\
\text { CEMAC }=0\end{array}$} & $\begin{array}{l}\text { GSL-Regression } \\
\text { AR(1), heterosc. } \\
\text { CEMAC }=0\end{array}$ & \multicolumn{2}{|c|}{$\begin{array}{l}\text { Fixed-effects (within) } \\
\text { regression } \\
\text { CEMAC }=1\end{array}$} & \multicolumn{2}{|c|}{$\begin{array}{l}\text { GSL-Regression } \\
\text { AR(1), heterosc. } \\
\text { CEMAC }=1\end{array}$} \\
\hline Initial income & -.0731 & $(.019)$ & $-.0237(.006)$ & -.1211 & $(.073)$ & -.0878 & $(.013)$ \\
\hline Investment & .0144 & $(.009)$ & $.0196(.006)$ & .2859 & $(.192)$ & .2092 & $(.017)$ \\
\hline Schooling & -.0107 & $(.023)$ & $.0041(.005)$ & .3055 & $(.594)$ & .1440 & $(.019)$ \\
\hline $\operatorname{Ln}(\mathrm{n}+\mathrm{g}+\delta)$ & -.0307 & $(.025)$ & $-.0337(.010)$ & .1395 & $(.220)$ & -.0070 & $(.038)$ \\
\hline Const. & .5415 & $(.127)$ & $.1886(.043)$ & -.1466 & $(1.03)$ & .1274 & $(.105)$ \\
\hline No. of observ. & & 159 & 159 & & 21 & & 21 \\
\hline Prob > chi 2 & & 0.000 & 0.000 & & 0.392 & & 0.000 \\
\hline
\end{tabular}




\section{Appendix B/ Chapter 2}

Figure B 1.1: HP-filtered log income (pc) of the MERCOSUR plus associated members

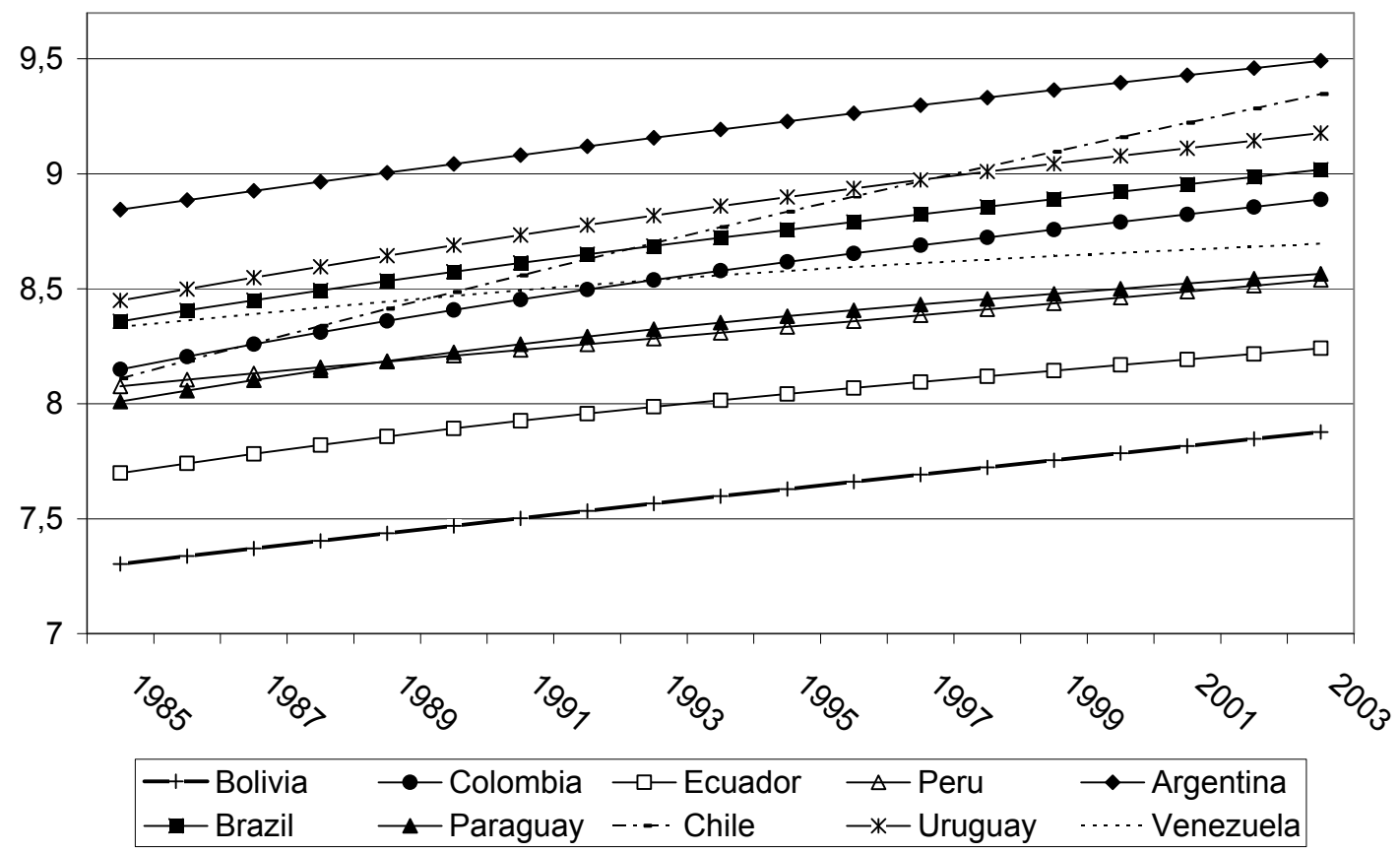

Figure B 1.2: HP-filtered log income (pc) of the 4 MERCOSUR founder

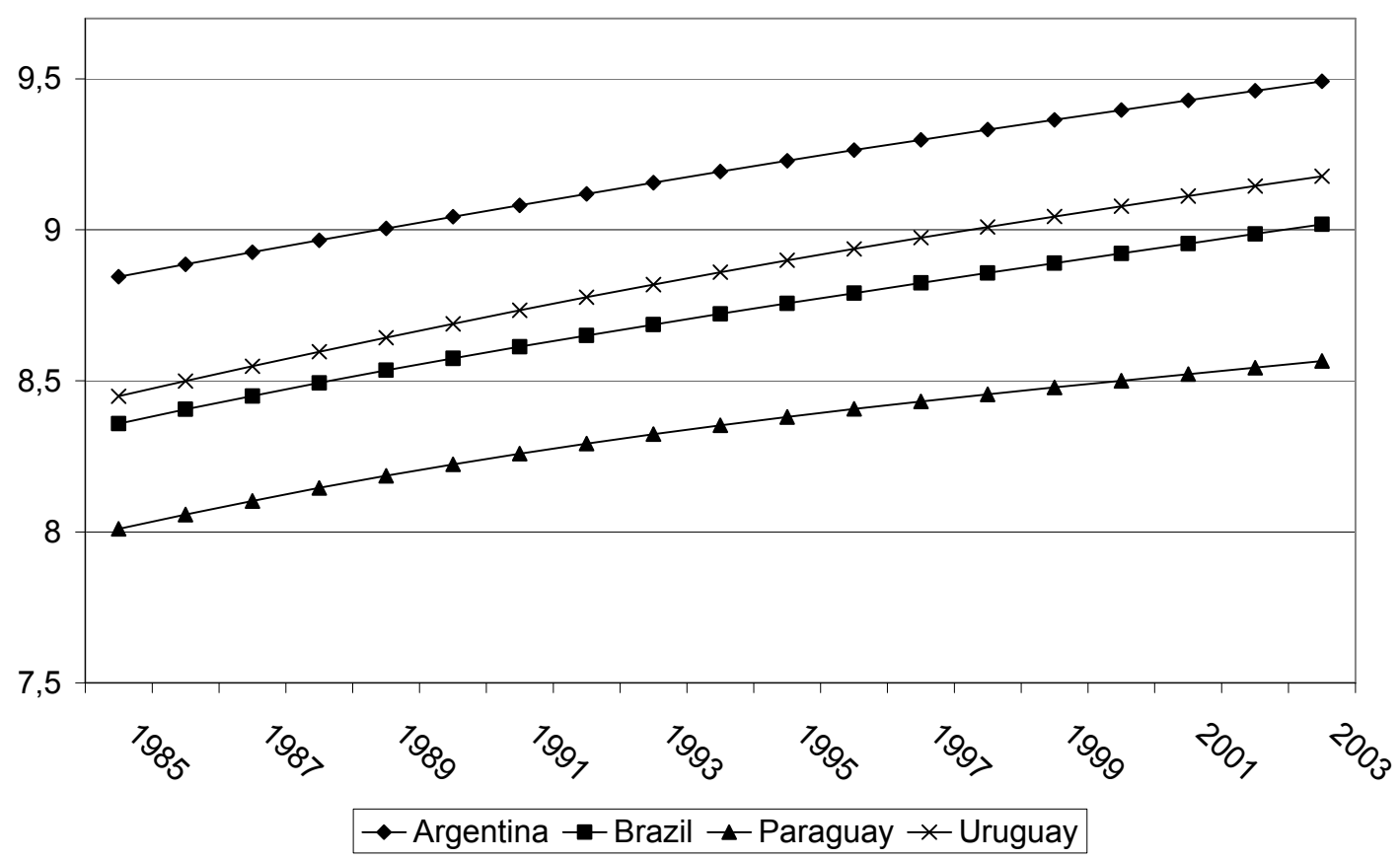


Figure B 1.3: HP-filtered log income (pc) of the ANDEAN countries



Figure B 1.4: Log per capita income of the MERCOSUR plus associated members

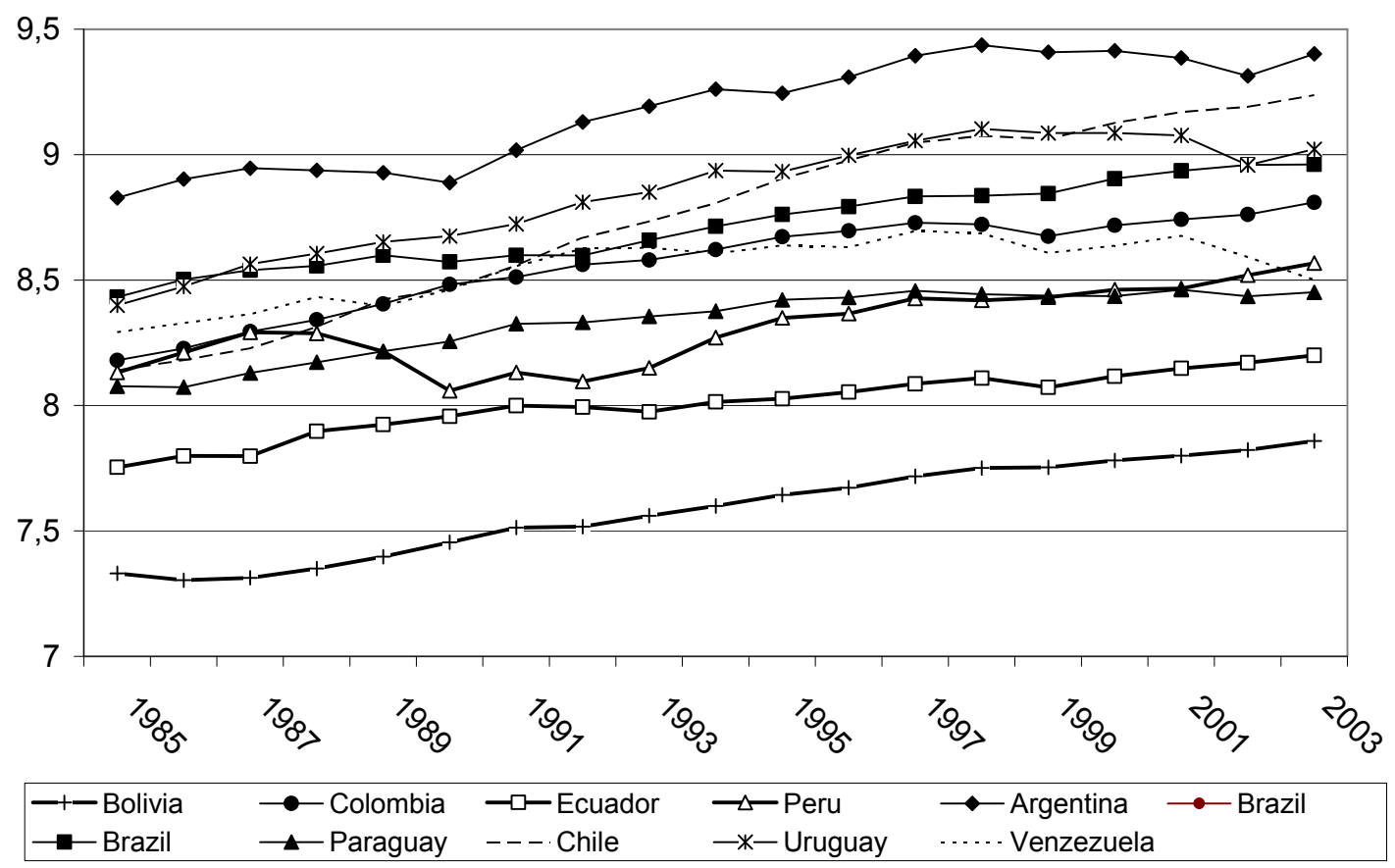


Figure B 1.5: Log per capita income MERCOSUR founder



Figure B 1.6: Log per capita income ANDEAN countries

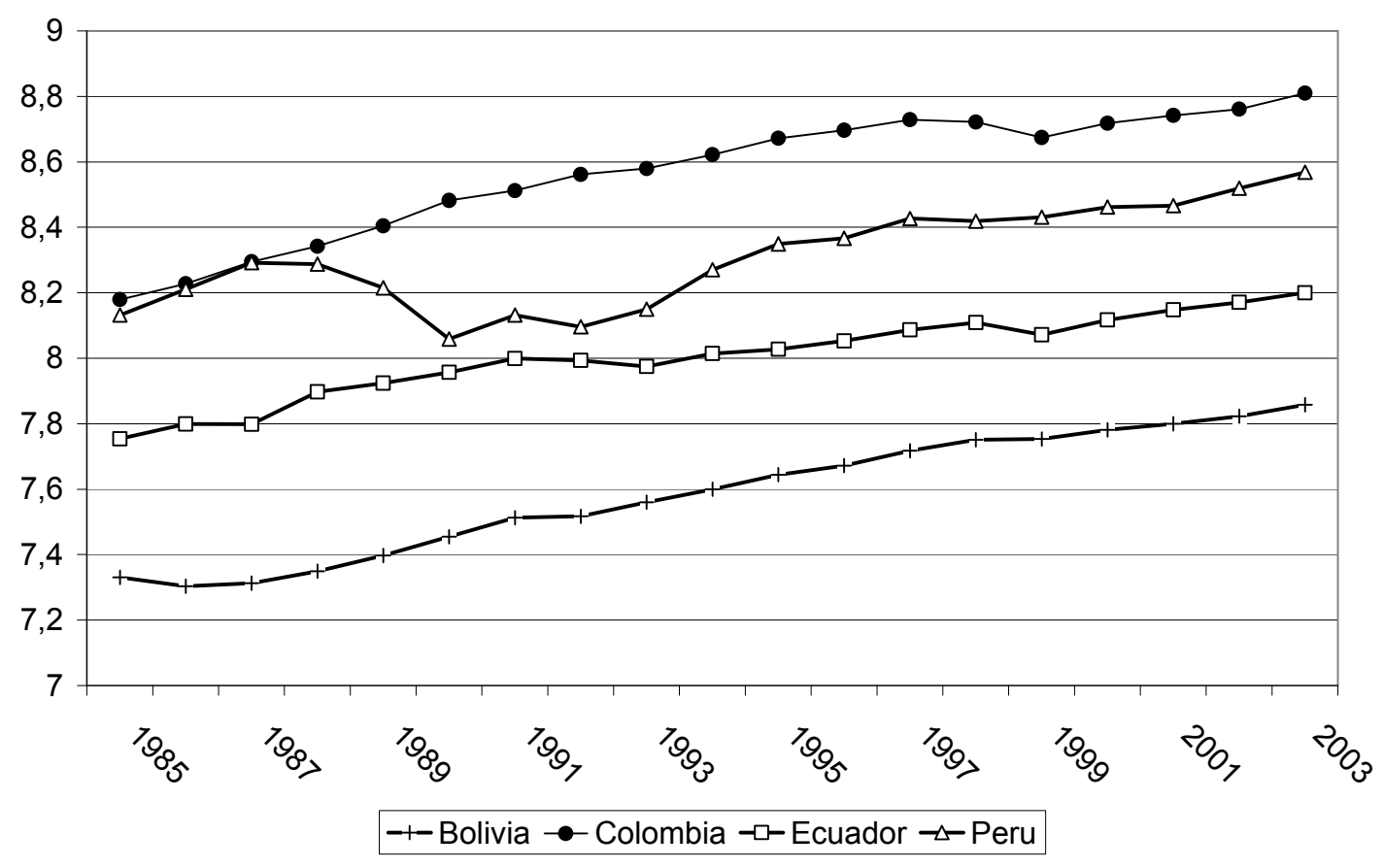


Figure B 1.7: Per capita income of the MERCOSUR plus associated members



Figure B 1.8: Per capita income of the MERCSOUR founder

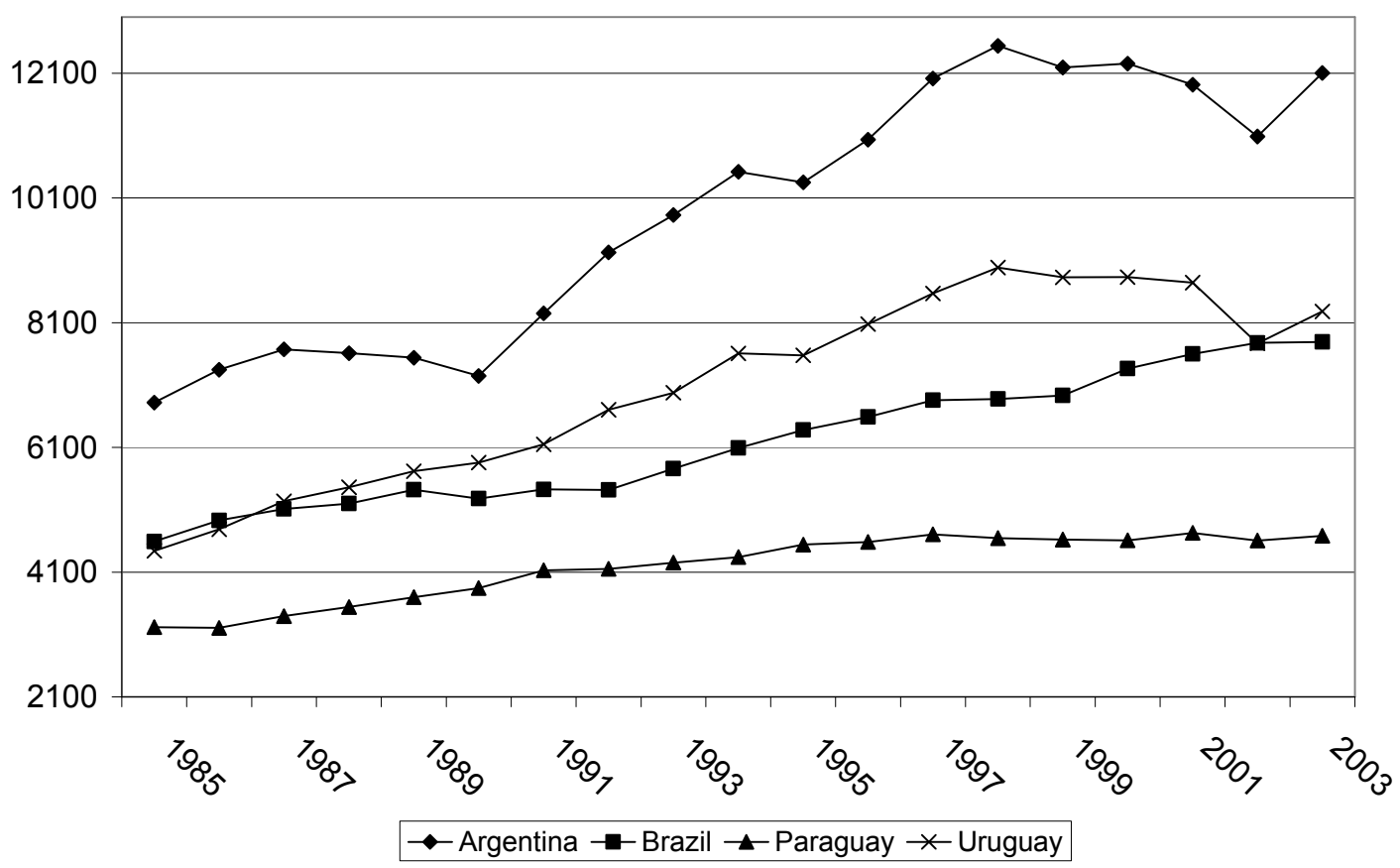

111 
Figure B 1.9: Per capita income of the ANDEAN countries

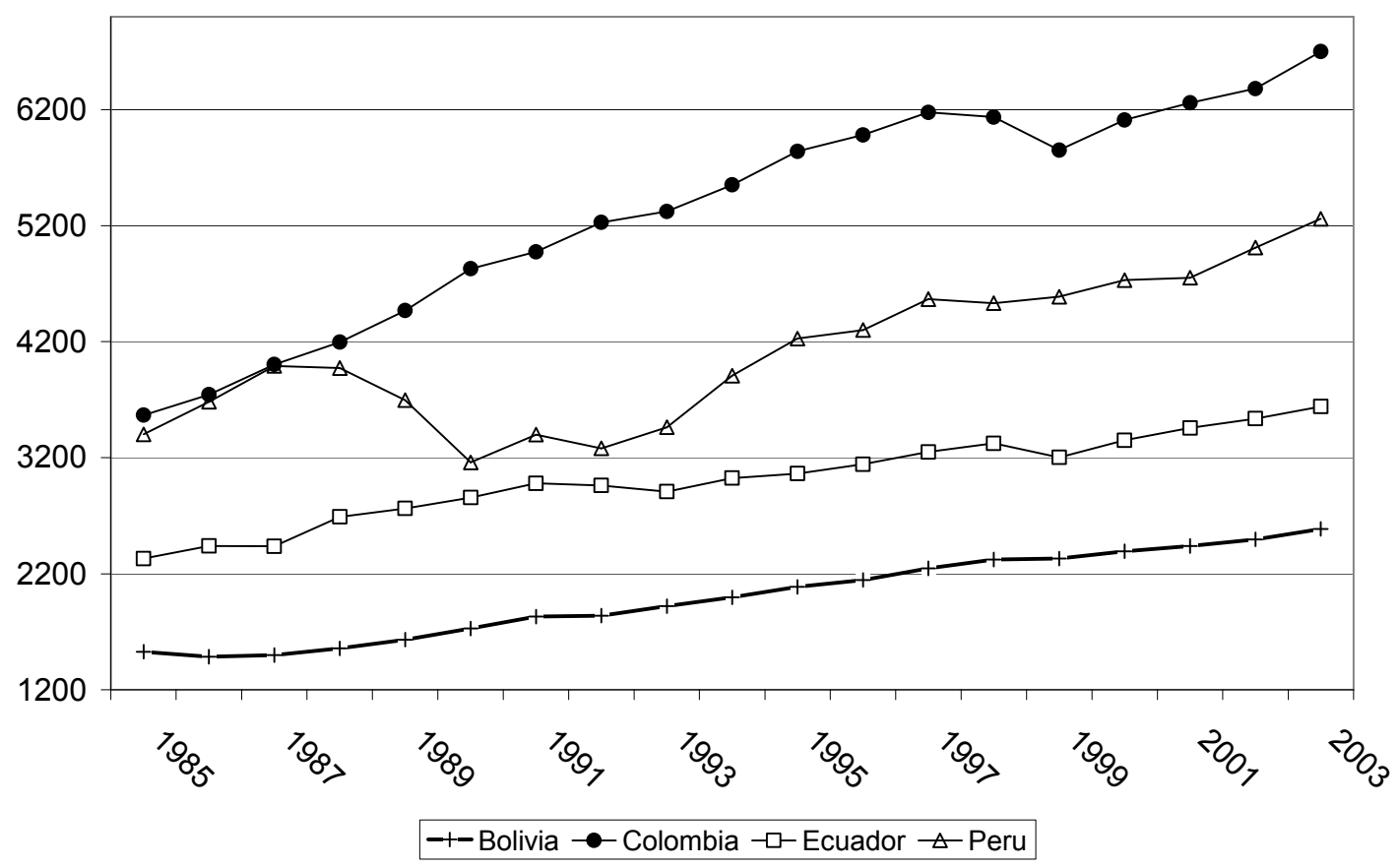

Figure B 2.1: HP-filtered log income (pc) of the ASEAN




Figure B 2.2: HP-filtered log income (pc) of the ASEAN founder

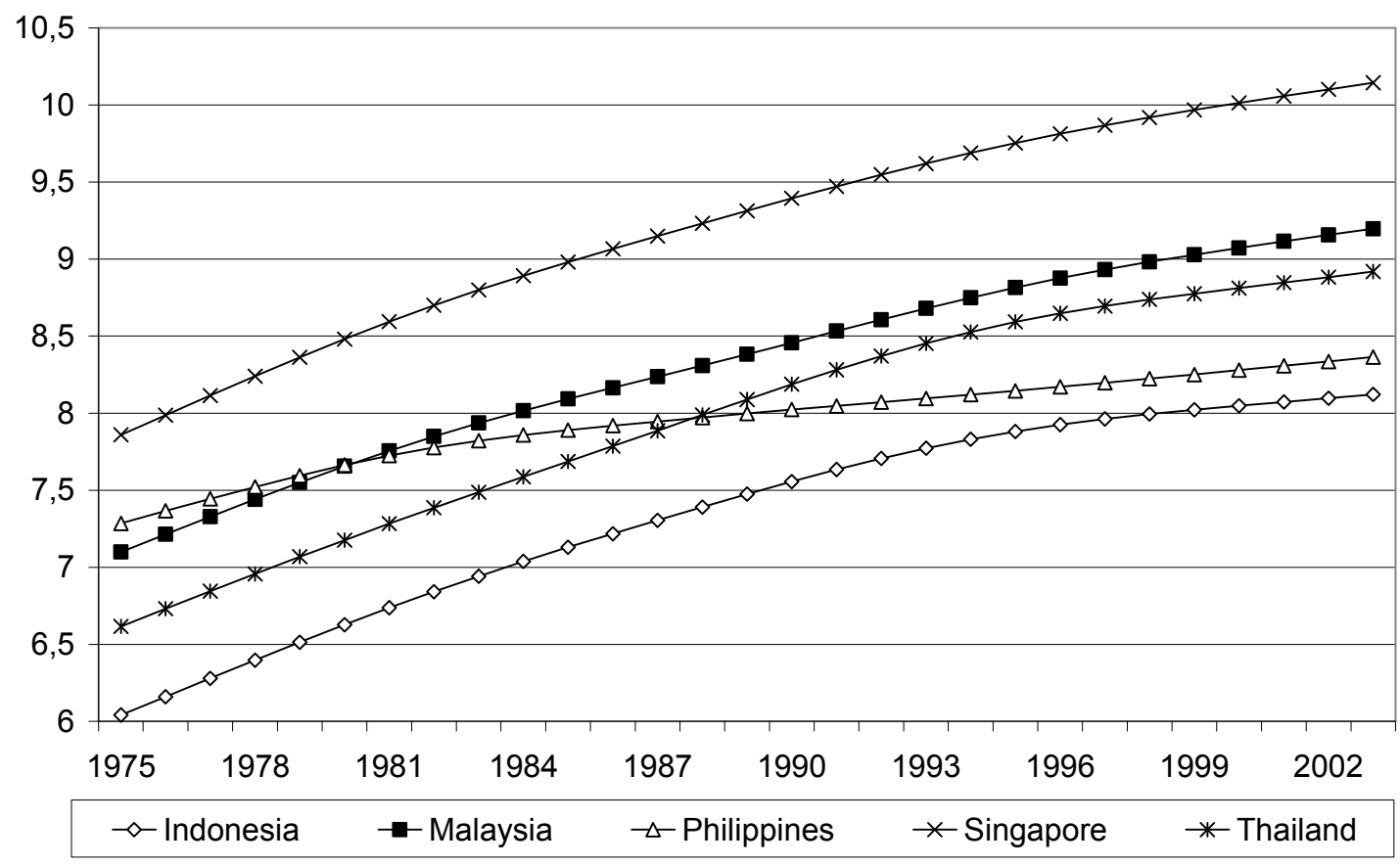

Figure B 2.3: HP-filtered log income (pc) of East Asia

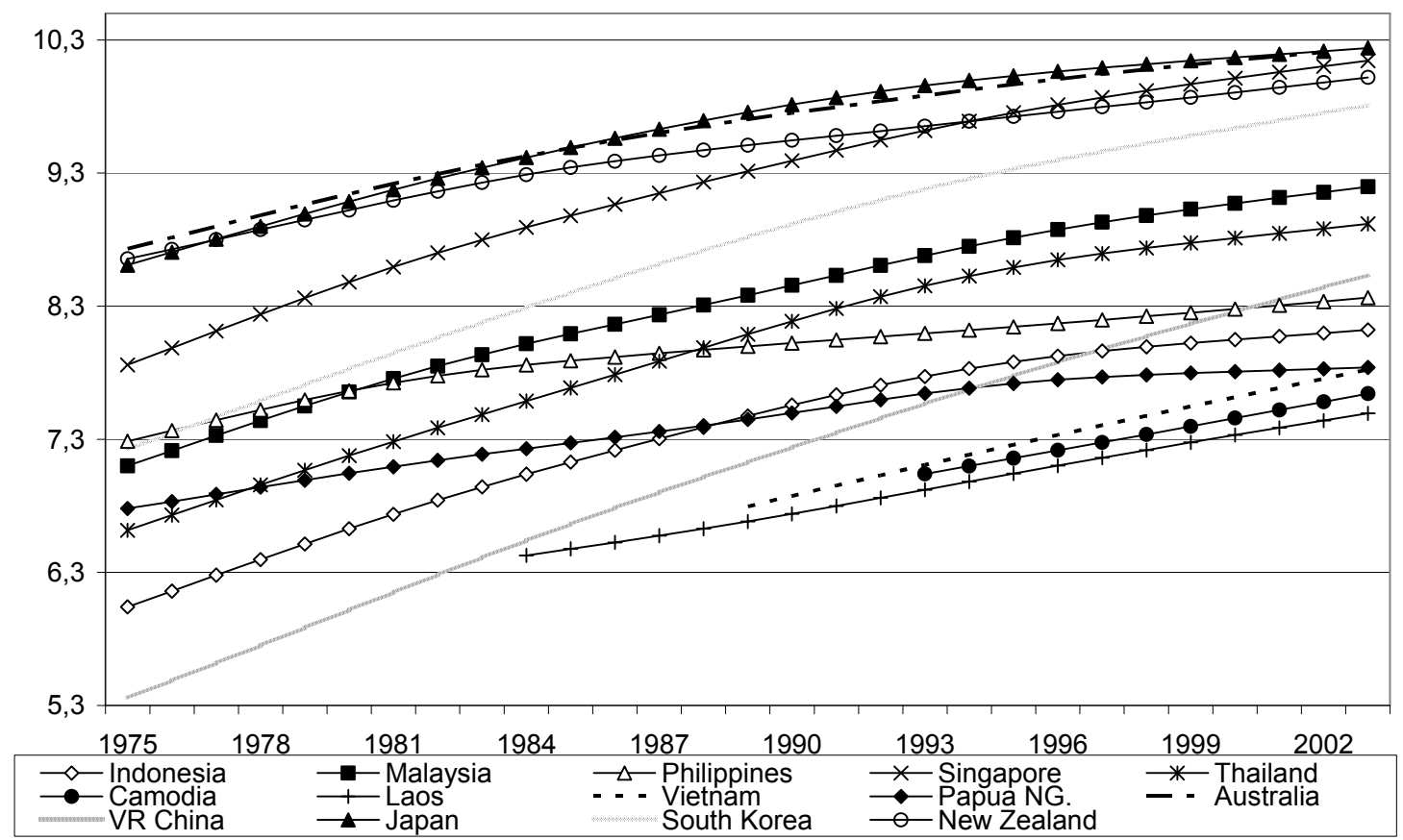


Figure B 2.4: Log per capita income of the ASEAN

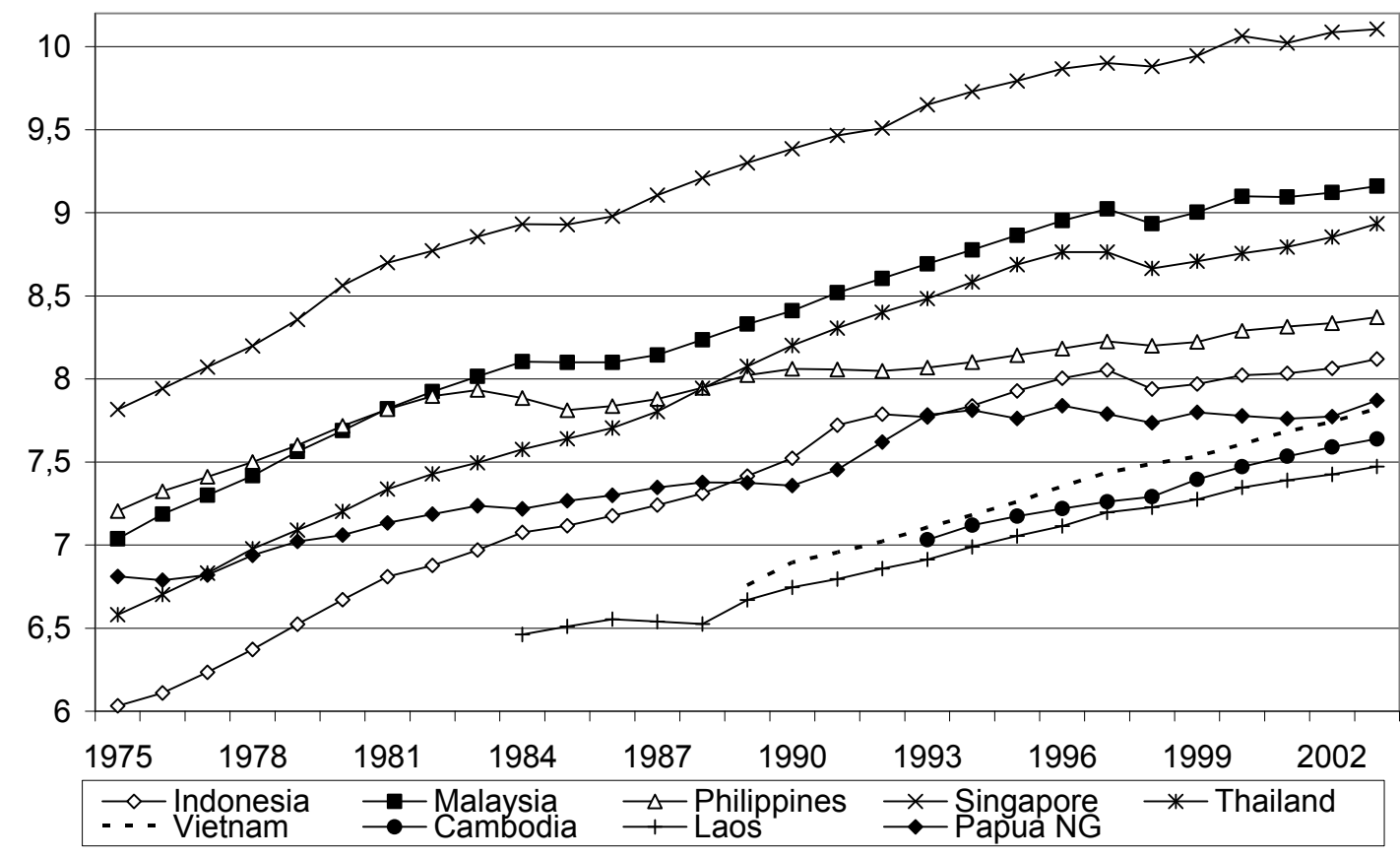

Figure B 2.5: Log per capita income of the ASEAN founder

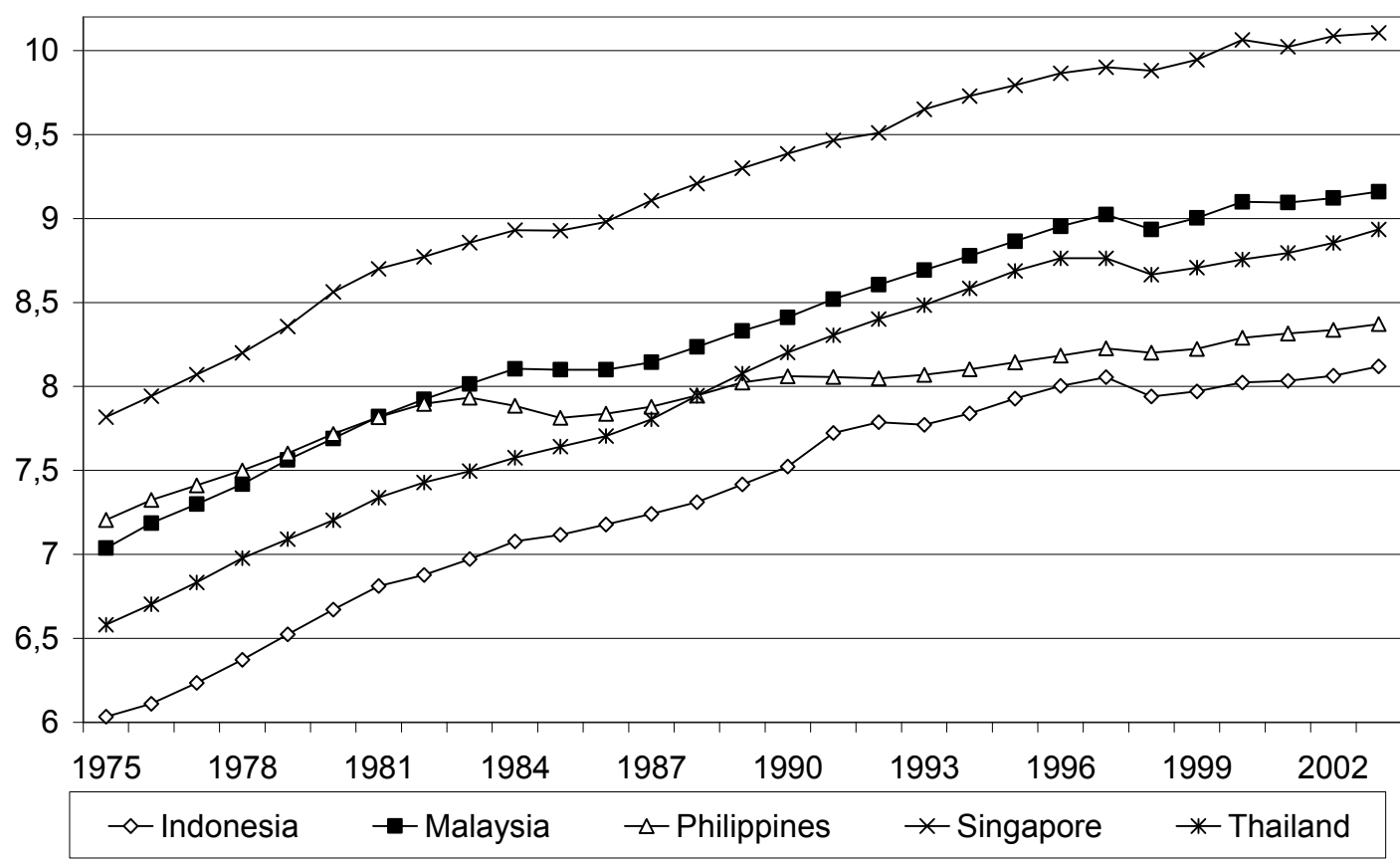


Figure B 2.6: Log per capita income of East Asia

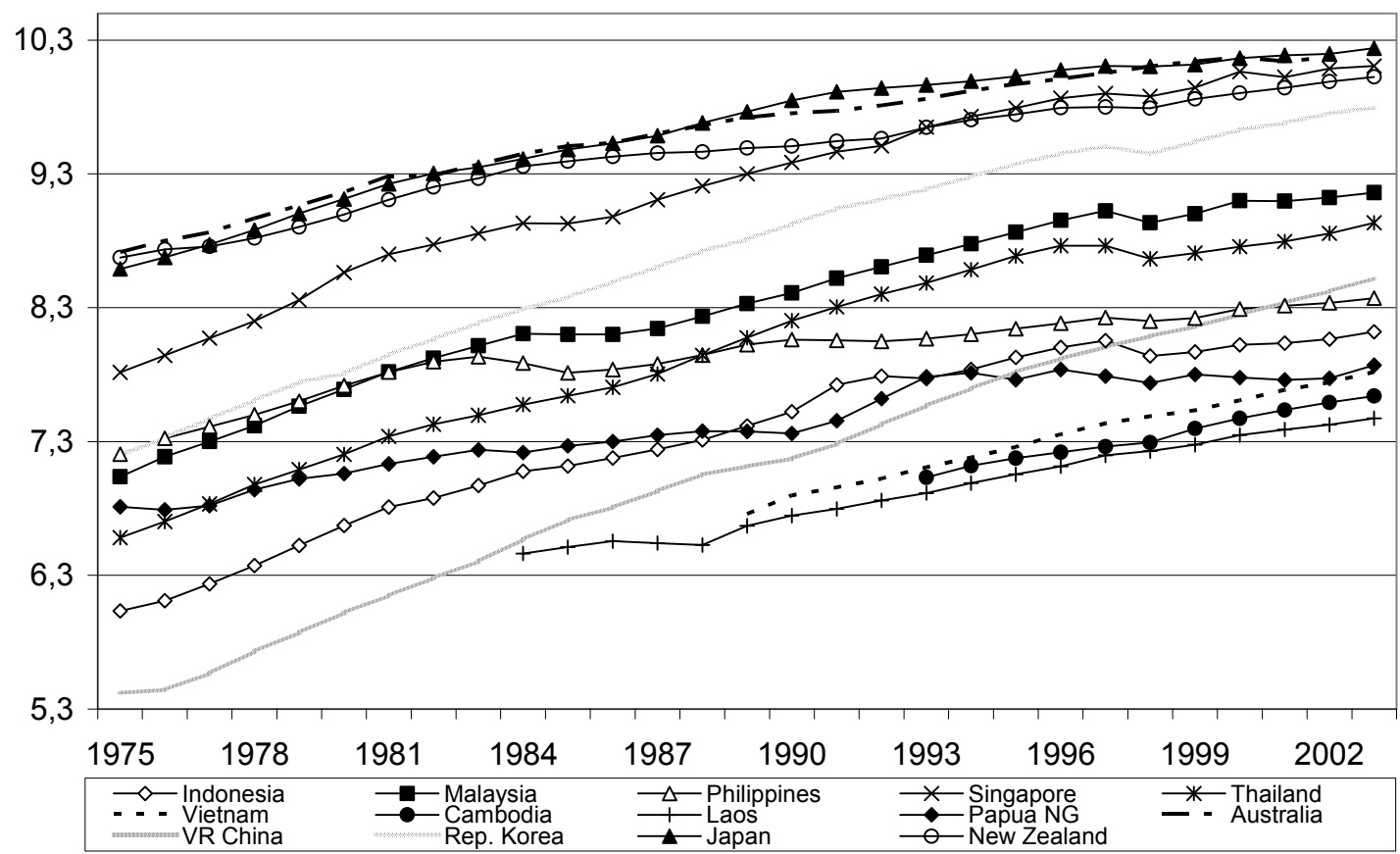

Figure B 2.7: Per capita income of the ASEAN




Figure B 2.8: Per capita income of the ASEAN Founder



Figure B 2.9: Per capita income of East Asia

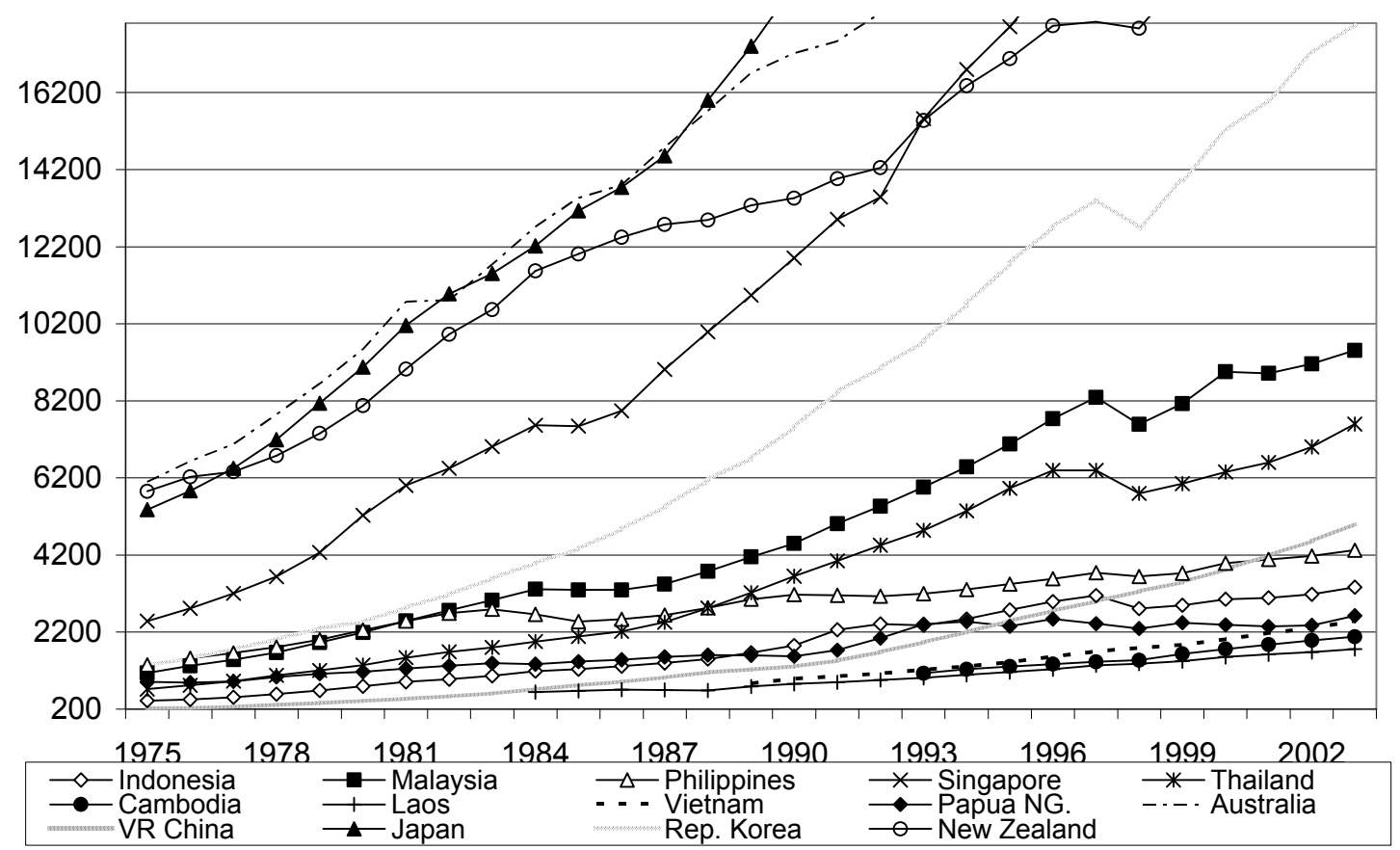


Figure B 3.1: HP-filtered log income (pc) of the ECOWAS/ West Africa

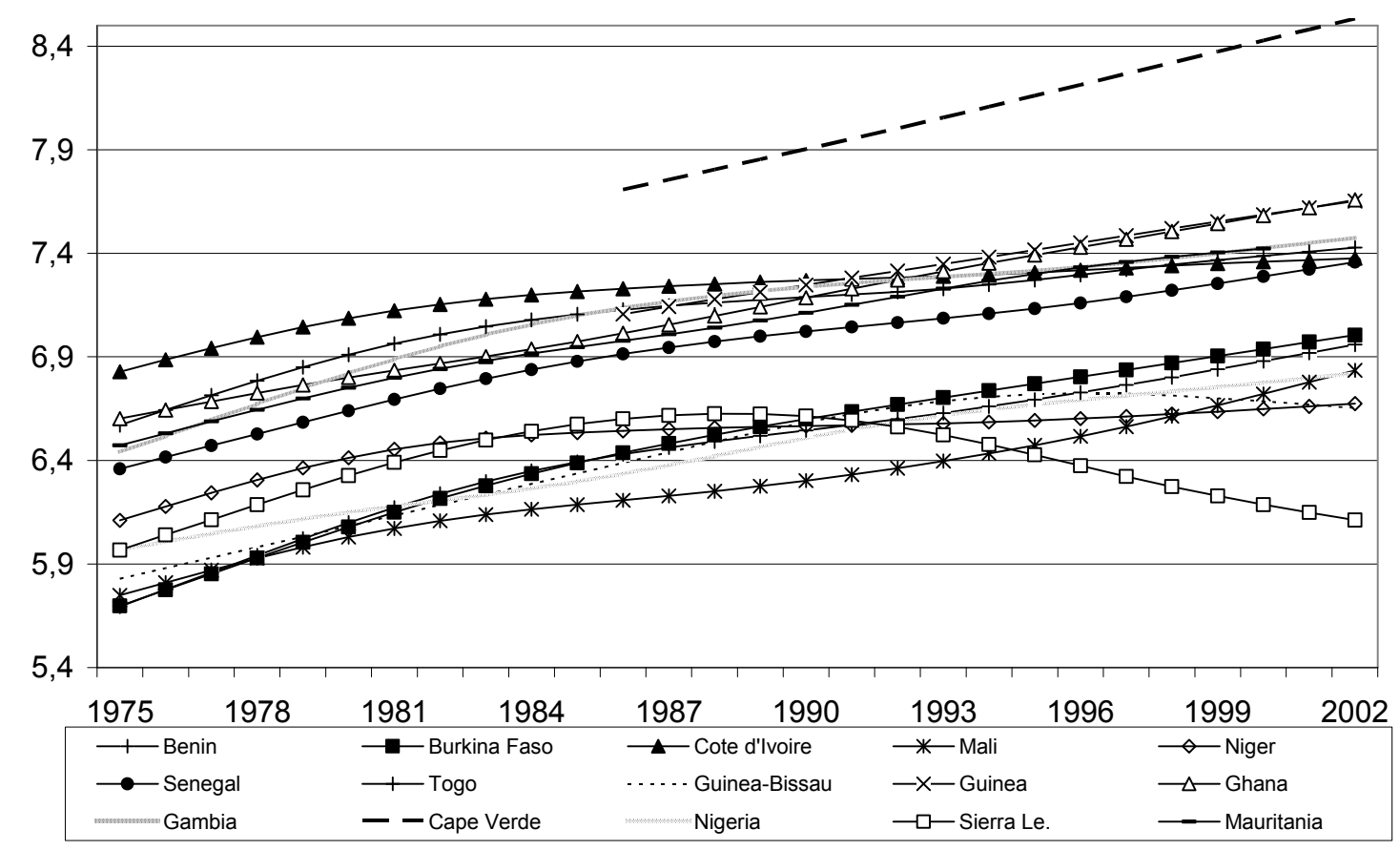

Figure B 3.2: HP-filtered log income (pc) of the WAEMU/ West Africa




Figure B 3.3: HP-filtered log income (pc) of the CEMAC/ Central Africa

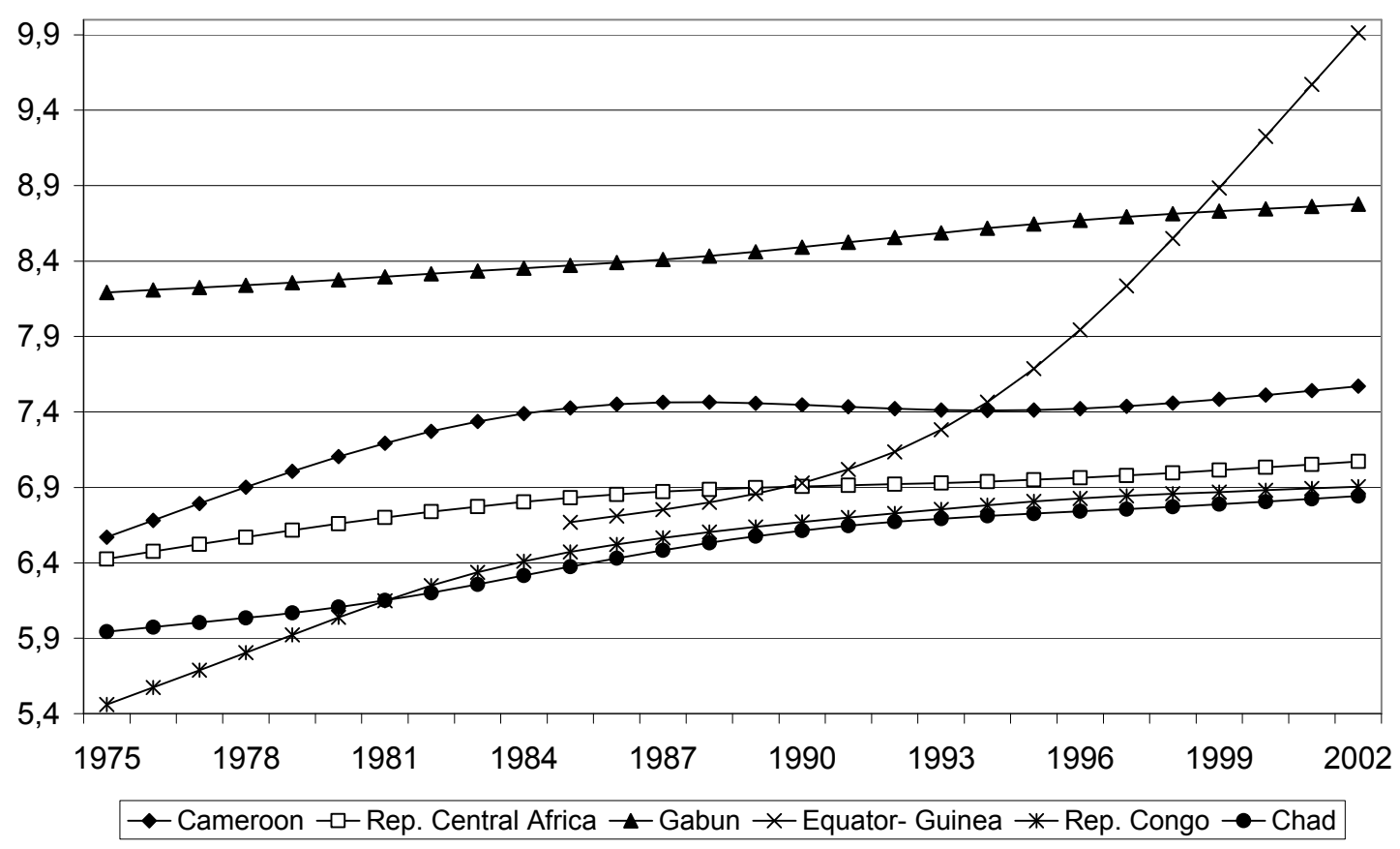

Figure B 3.4: HP-filtered log income (pc) of the CFA

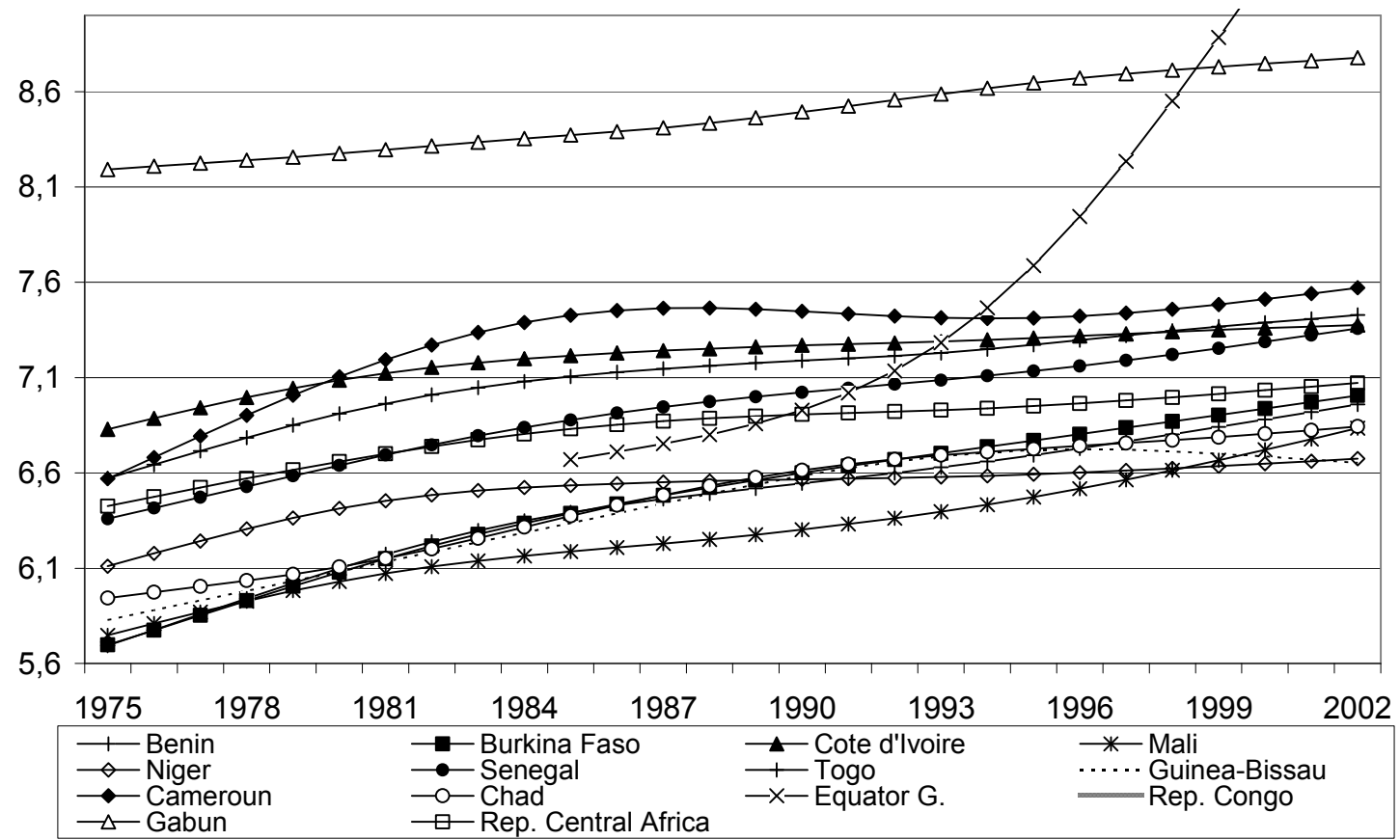


Figure B 3.5: HP-filtered log income (pc) of the whole region West- and Central Africa

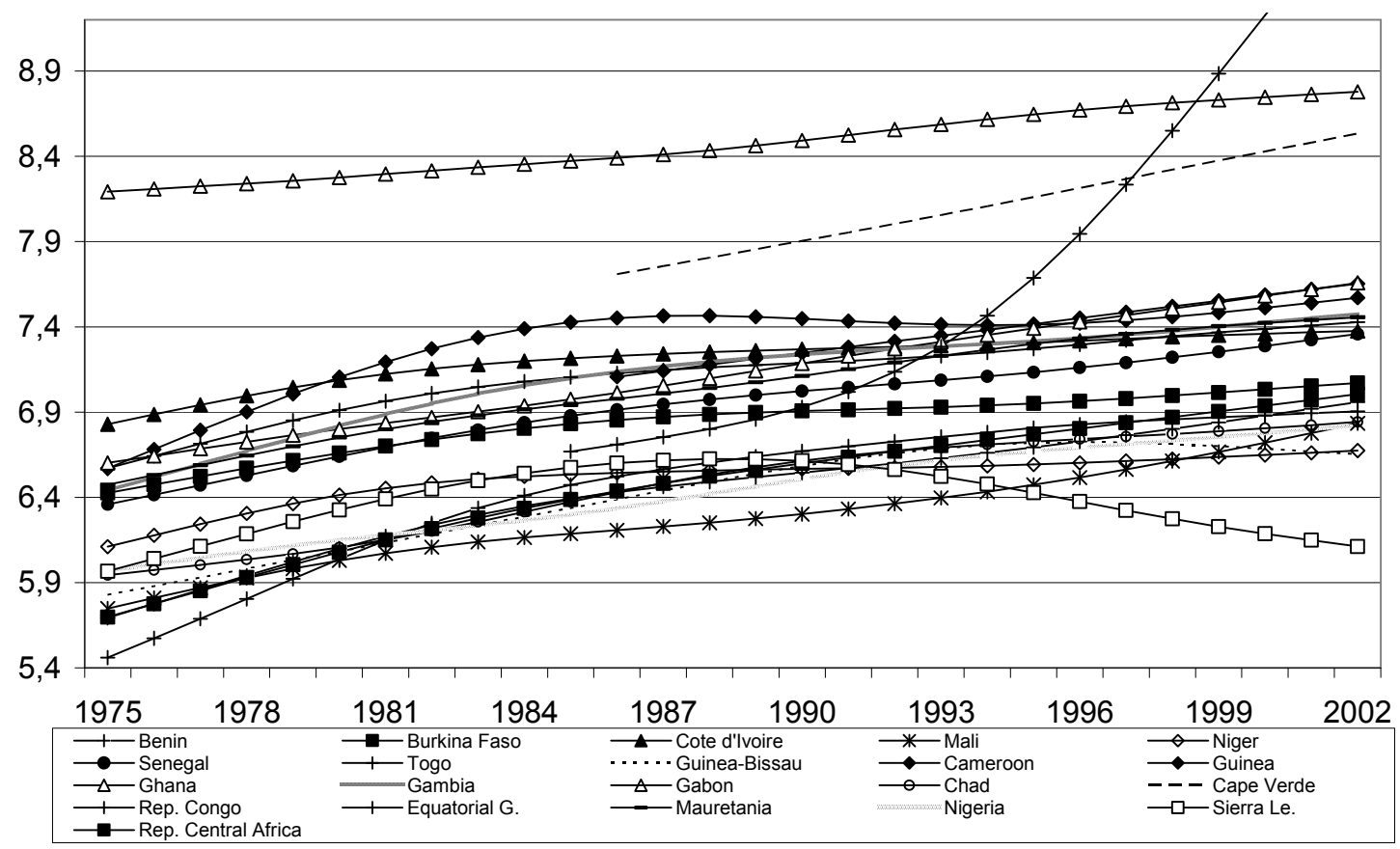

Figure B 3.6: Log per capita income of the ECOWAS/ West Africa

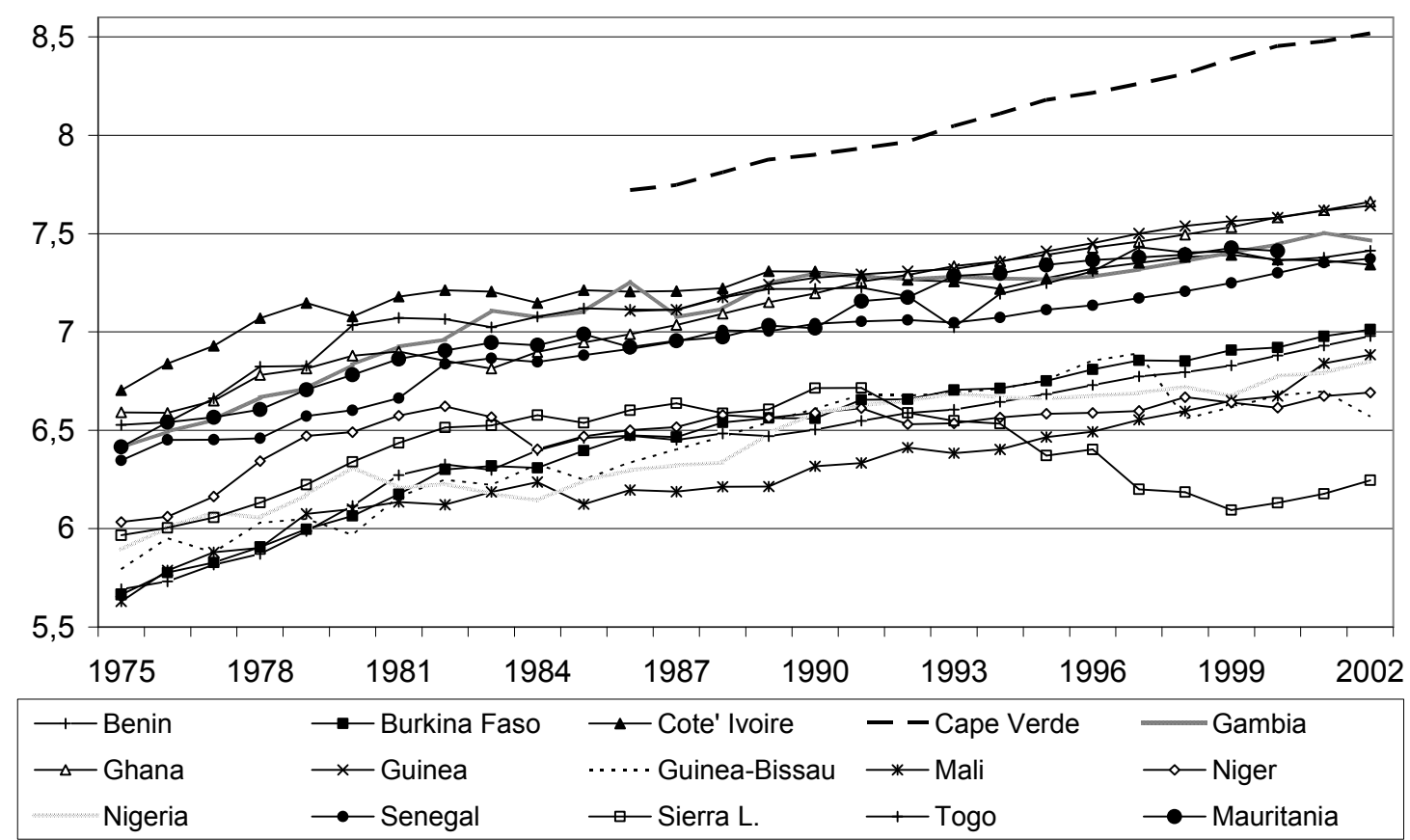


Figure B 3.7: Log per capita income of the WAEMU/ West Africa

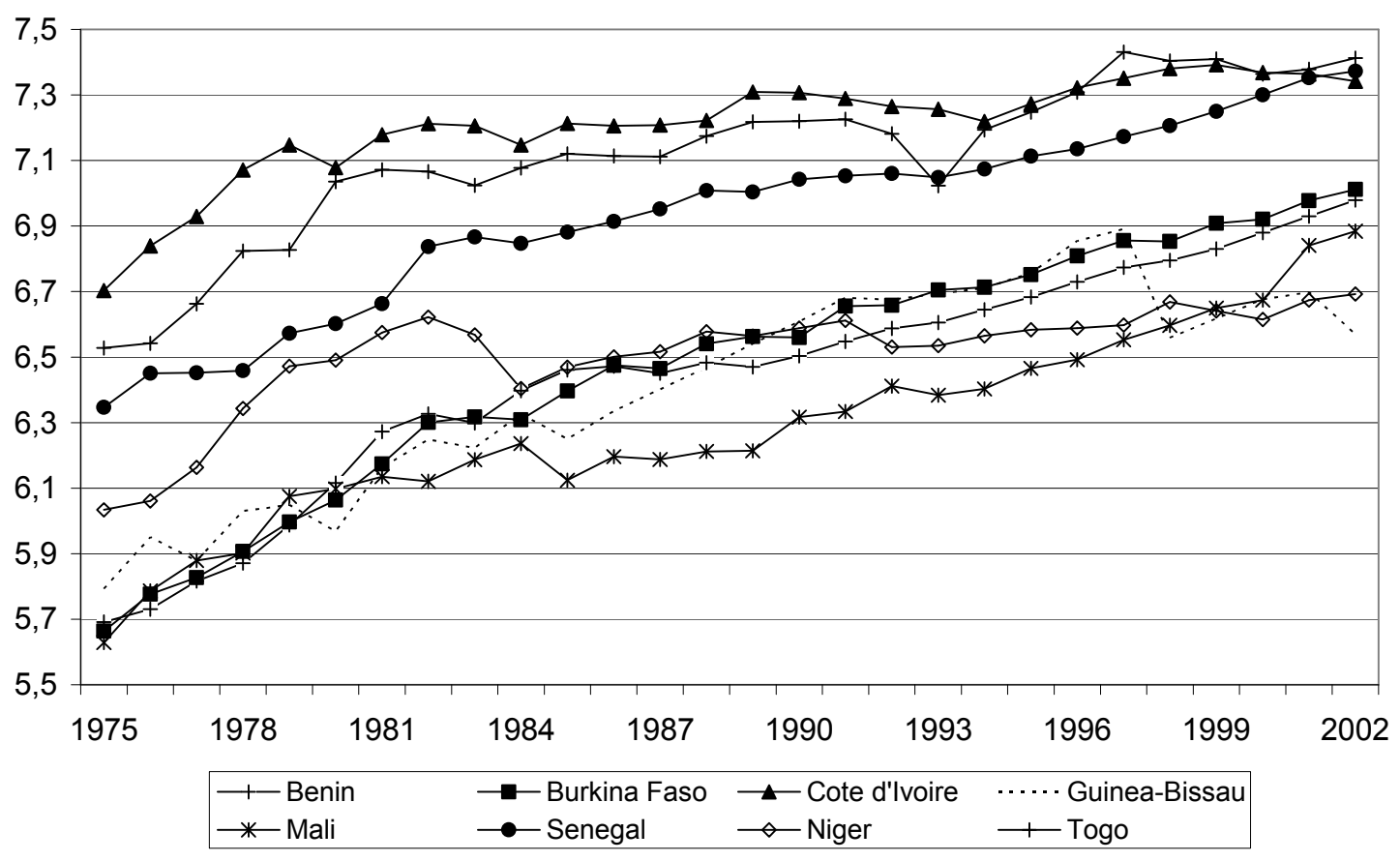

Figure B 3.8: Log per capita income of the CEMAC/ Central Africa

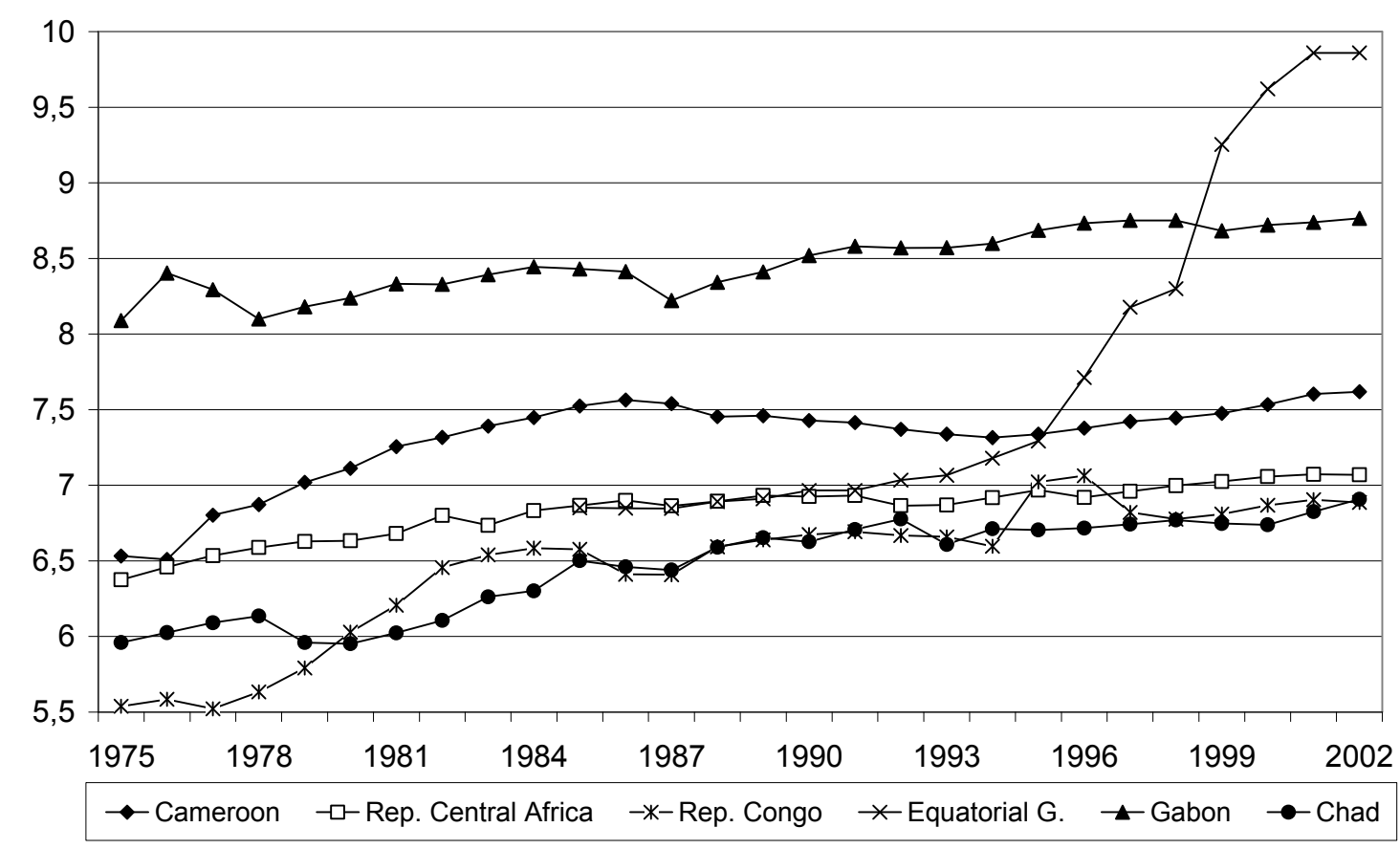


Figure B 3.9: Per capita income of the ECOWAS/ West Africa



Figure B 3.10: Per capita income of the WAEMU/ West Africa

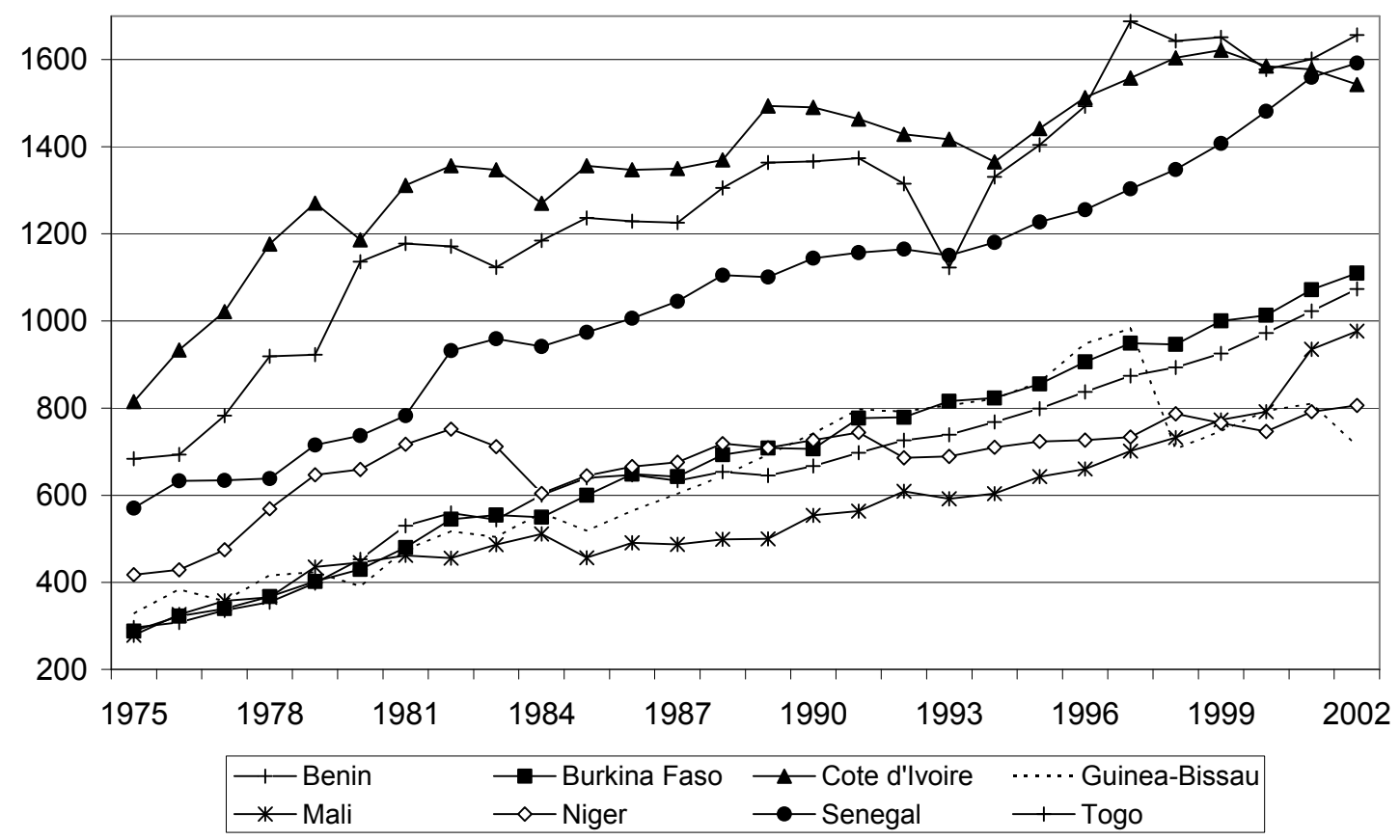


Figure B 3.11: Per capita income of the CEMAC/ Central Africa






\section{Appendix C/ Chapter 4}

Appendix C.I - List of the selected Regional integration Areas

ANZCERTA (Australia New Zealand Closer Economic Agreement) was founded in 1983. The main objectives are free trade of goods, services and capital between the partners.

EU-15 (European Union) was established by the treaty of Maastricht in November 1993. The EU foundation has its seeds in the Treaties of Rome 1957 and the formation of the European Economic Community with six founder members (Belgium, France, Italy, Luxembourg, Netherlands, and West-Germany). In 1995 a further nine members join (1973 Denmark, Ireland and United Kingdom as well as 1981 Greece, 1986 Spain and Portugal and 1995 Austria, Sweden and Finland). Starting from the year 1995 onwards all members were high income countries.

NAFTA (North America Free trade agreement) was founded in 1994. The members are the USA, Canada and Mexico. This RIA arose from the bilateral agreement between Canada and the USA from 1989. The target of NAFTA is to eliminate the barriers to trade, improve the conditions for investment opportunities, and to protect the intellectual property rights between the members.

WAEMU (West African Economic and Monetary Union27); the main targets are policy coordination and cooperation among the member states in several fields such as infrastructure, education, energy, and regional stability.

\footnotetext{
${ }^{27}$ WAEMU: Benin, Burkina Faso, Cote d’Ivoire, Guinea Bissau, Mali, Niger, Senegal, and Togo.
} 
$\underline{\text { Subindex }}$

Political

Economic
Democracy score shows the general openness of political institutions, $0=$ lowest, $10=$ highest.

Corruption is measured in units ranging approximately from about 2.5 to 2.5 , with higher values corresponding to better governance outcomes. The data are annually available from 1996 to 2007 (former or missing values are generated via linear interpolation).

Armed conflicts are measured by the sum of ethnic, civil or interstate conflicts in the neighbouring countries.

Political rights

The rates of political rights between 1 and 7 , where 1 represents the best protection.

Civil liberties The rates of civil liberties between 1 and 7 , where 1 represents the best protection.

Log real GDP per capita PPP (current prices international \$). Missing values are replaced by linear interpolations.

Intra-regional trade as a percentage share of the region's total trade (regional total imports plus regional total exports)

Inflation (harmonized index of consumer prices)

FDI in percent of GDP, net inflows (intra-regional)

National government budget (available since 1990 respectively 95; for previous years values are fixed to the first available number).
Kaufmann, Kraay and 2,5 Mastruzzi (2003)

www.systemicpeace.org 0 (2008)

Gastil; freedomhouse.org 1 (2008)

Gastil; freedomhouse.org 1 (2008)

WDI (2008) 10.73

$(=\log 46000)$

UN-COMTRADE (2008) 50

WDI (2008)

IFS (2009) 
Socio-

structural

Infra-

structure

Institutional
Average years of schooling in the total population (aged 15+) at 5-yr intervals (data available until 2000; annual data are calculated with linear interpolation; missing observations are calculated with data mapping).

Gini-Index (missing values are WDI (2008)

replaced by next available number).

Life expectancy at birth in years (missing values are replaced by linear interpolations).

Fixed subscribers and mobile phone per hundred people

Internet users in \%, people with access to worldwide network (values available since 1990; before this variable is set to null; further missing values are replaced by linear interpolations).

Paved roads in \% of total roads (available since 1990; for previous years values are fixed to the first available number; further missing values are replaced by linear interpolations)

Intra-regional institution index

Authors calculation

WDI (2008)

The index values are between 0 and 4, with 1: RIA secretary with arbitration board; 2: common central bank; 3: common parliament; court of justice; RIA commission; 4: a common constitution 
Appendix C.III - List of representative world sample

The selection of the world sample is based on the income groups (low income countries (15); lower middle income countries (11); upper middle income countries (10) and high income countries (14) in year 2000) proportionally (for country classification see World Bank 2000).

Albania LM

Algeria LM

Argentina UM

Armenia L

Australia $\mathrm{H}$

Austria $\mathrm{H}$

Azerbaijan L

Bangladesh L

Belarus LM

Belgium $\mathrm{H}$

Benin L

Bolivia LM

Botswana UM

Brazil UM

Bulgaria LM

Burkina Faso L

Burundi L

Cambodia L

Cameroon L

Canada $\mathrm{H}$

Central African Rep. L

Chile UM

Colombia LM

Cote d'Ivoire L

Denmark H
Egypt, Arab Rep. LM

France $\mathrm{H}$

Germany H

India $\mathrm{L}$

Indonesia L

Iran, Islamic Rep. LM

Israel $\mathrm{H}$

Korea, Rep. UM

Malaysia UM

Mali L

Mexico UM

Norway $\mathrm{H}$

Paraguay LM

Peru LM

Senegal L

Singapore H

South Africa UM

Spain $\mathrm{H}$

Switzerland H

Thailand LM

Trinidad and Tobago UM

Turkey UM

United Kingdom H

United States H

Zambia L 
$\underline{\text { Appendix C.IV - Determining of }} \varpi_{j, s, m}$ via correlation matrices

\begin{tabular}{llll}
\hline Index $_{\text {social }}$ & life & gini & school \\
life & 1.00 & & \\
gini & -0.46 & 1.00 & \\
school & 0.77 & -0.41 & 1.00 \\
\hline
\end{tabular}

Note: Gini has a weight of 1.5.

\begin{tabular}{llll}
\hline Index $_{\text {inf }}$ & tele & road & net \\
tele & 1.00 & & \\
road & 0.66 & 1.00 & 1.00 \\
net & 0.90 & 0.50 & \\
\hline
\end{tabular}

Note: net and tele have weights 0.5 .

\begin{tabular}{llllll}
\hline Index $_{\text {polit }}$ & confl & democ & $\mathrm{cl}$ & pr & corr \\
confl & 1.00 & & & & \\
democ & -0.35 & 1.00 & & & \\
cl & 0.32 & -0.64 & 1.00 & & \\
pr & 0.30 & -0.71 & 0.92 & 1.00 & 1.00 \\
corr & -0.37 & 0.64 & -0.91 & -0.90 & \\
\hline
\end{tabular}

Note: corr, pr and cl have weights 0.33 .

\begin{tabular}{llllll}
\hline Index $_{\text {econ }}$ & gdp & infl & fdi & budget & trade \\
gdp & 1.00 & & & & \\
infl & -0.15 & 1.00 & & & \\
fdi & 0.39 & -0.09 & 1.00 & & \\
budget & 0.44 & 0.01 & 0.07 & 1.00 & 1.00 \\
trade & -0.09 & 0.14 & 0.10 & 0.05 & \\
\hline
\end{tabular}

Note: gdp has the weight 0.5 . 


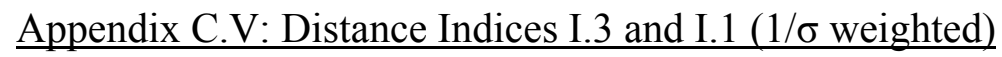

\begin{tabular}{|l|l|l|l|l|l|l|l|l|}
\hline & \multicolumn{3}{|c|}{ I.3 : $\mathrm{L}_{1}$ distance to mean } & \multicolumn{5}{c|}{ I.1 : Distance matrix } \\
\hline & & & & & & & & \\
& ANZCER & EU-15 & NAFTA & WAEMU & ANZCER & EU-15 & NAFTA & WAEMU \\
\hline 1980 & 2.95 & --- & --- & --- & 1.02 & --- & --- & --- \\
\hline 1990 & 2.56 & 4.67 & 6.46 & 4.65 & 0.87 & 1.93 & 5.02 & 2.42 \\
\hline 1995 & 3.10 & 4.66 & 5.82 & 5.91 & 0.93 & 2.28 & 3.90 & 2.67 \\
\hline 2000 & 2.75 & 4.67 & 4.58 & 5.47 & 0.92 & 2.50 & 3.60 & 2.53 \\
\hline 2005 & 2.89 & 6.67 & 6.29 & 5.30 & 1.23 & 3.59 & 3.82 & 2.74 \\
\hline 2007 & 3.34 & 7.11 & 7.00 & 7.03 & 1.29 & 3.25 & 3.99 & 4.35 \\
\hline
\end{tabular}

Appendix C.VI: Distance Indices I.4 and I.2 without variable internet

\begin{tabular}{|l|l|l|l|l|l|l|l|l|}
\hline & \multicolumn{4}{|c|}{ I.4 : $\mathrm{L}_{1}$ distance to mean } & \multicolumn{5}{c|}{ I.2 : Distance matrix } \\
\hline & & & & & & & & \\
& ANZCER & EU-15 & NAFTA & WAEMU & ANZCER & EU-15 & NAFTA & WAEMU \\
\hline 1980 & 0.28 & -- & -- & -- & 0.10 & --- & --- & --- \\
\hline 1990 & 0.23 & 0.53 & 0.71 & 0.58 & 0.08 & 0.25 & 0.66 & 0.31 \\
\hline 1995 & 0.26 & 0.56 & 0.54 & 0.69 & 0.08 & 0.27 & 0.53 & 0.37 \\
\hline 2000 & 0.21 & 0.52 & 0.51 & 0.65 & 0.07 & 0.26 & 0.43 & 0.32 \\
\hline 2005 & 0.29 & 0.59 & 0.64 & 0.62 & 0.11 & 0.30 & 0.38 & 0.35 \\
\hline 2007 & 0.27 & 0.56 & 0.61 & 0.85 & 0.10 & 0.25 & 0.37 & 0.50 \\
\hline
\end{tabular}


Appendix C.VII: Distance Indices I.3 and I.1 without variable internet

\begin{tabular}{|l|l|l|l|l|l|l|l|l|}
\hline & \multicolumn{3}{|c|}{ I.3 : $\mathrm{L}_{1}$ distance to mean } & \multicolumn{5}{c|}{ I.1 : Distance matrix } \\
\hline & & & & & & & & \\
& ANZCER & EU-15 & NAFTA & WAEMU & ANZCER & EU-15 & NAFTA & WAEMU \\
\hline 1980 & 2.90 & --- & --- & --- & 1.02 & --- & --- & --- \\
\hline 1990 & 2.55 & 4.31 & 5.72 & 4.54 & 0.87 & 1.93 & 5.02 & 2.42 \\
\hline 1995 & 3.06 & 4.44 & 4.76 & 5.64 & 0.92 & 2.25 & 3.90 & 2.67 \\
\hline 2000 & 2.28 & 4.21 & 4.37 & 5.32 & 0.86 & 2.22 & 3.32 & 2.53 \\
\hline 2005 & 2.88 & 5.32 & 5.85 & 5.13 & 1.21 & 3.10 & 3.09 & 2.73 \\
\hline 2007 & 2.92 & 4.88 & 6.07 & 6.76 & 1.15 & 2.52 & 3.06 & 4.34 \\
\hline
\end{tabular}

$\underline{\text { Appendix C.VIII: Figures of distance indices in comparison }}$

Figure C.A.1: Distance index I.4 with and without (*) variable internet

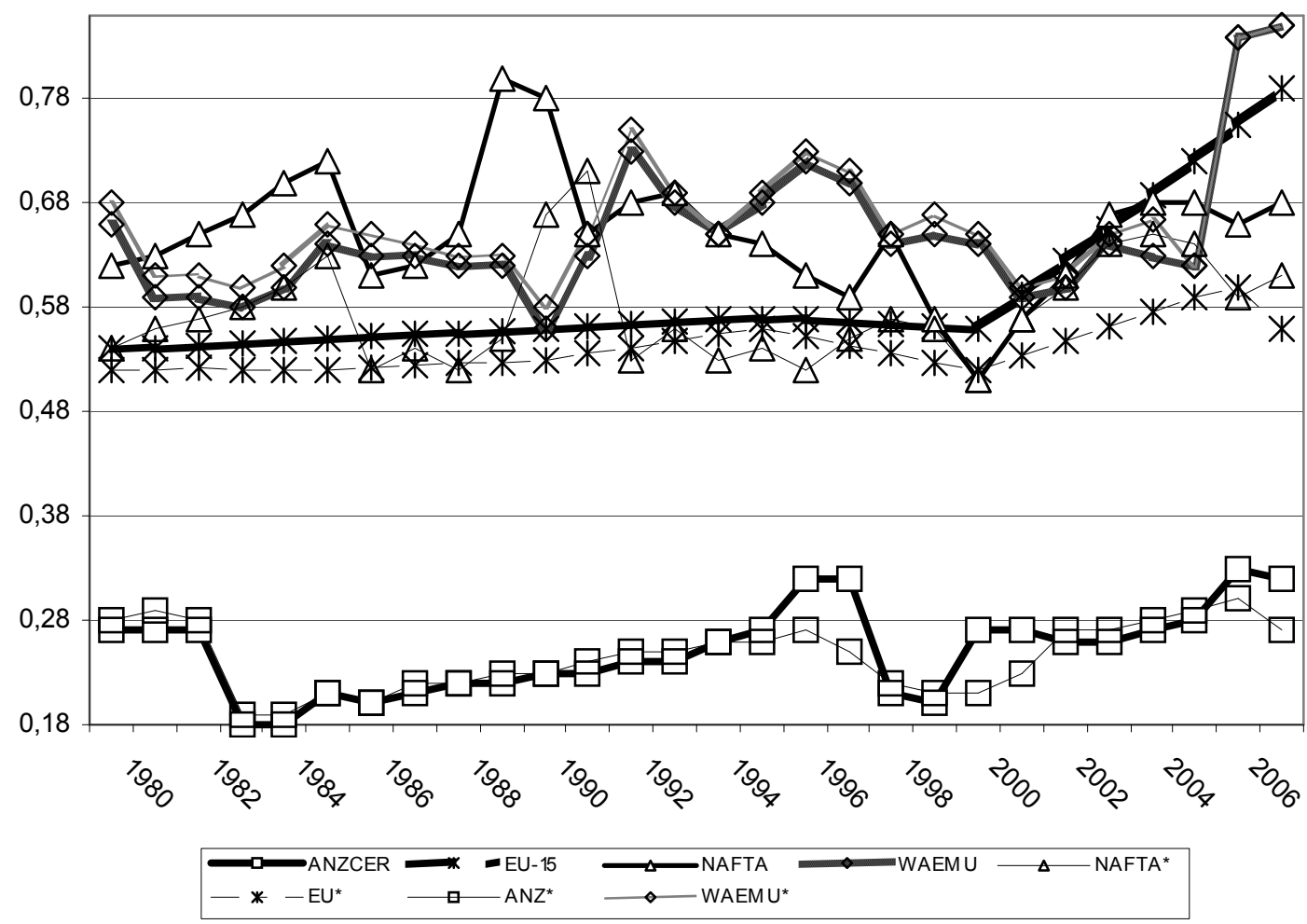


Figure C.A.2: Distance index I.2 with and without $\left({ }^{*}\right)$ variable internet

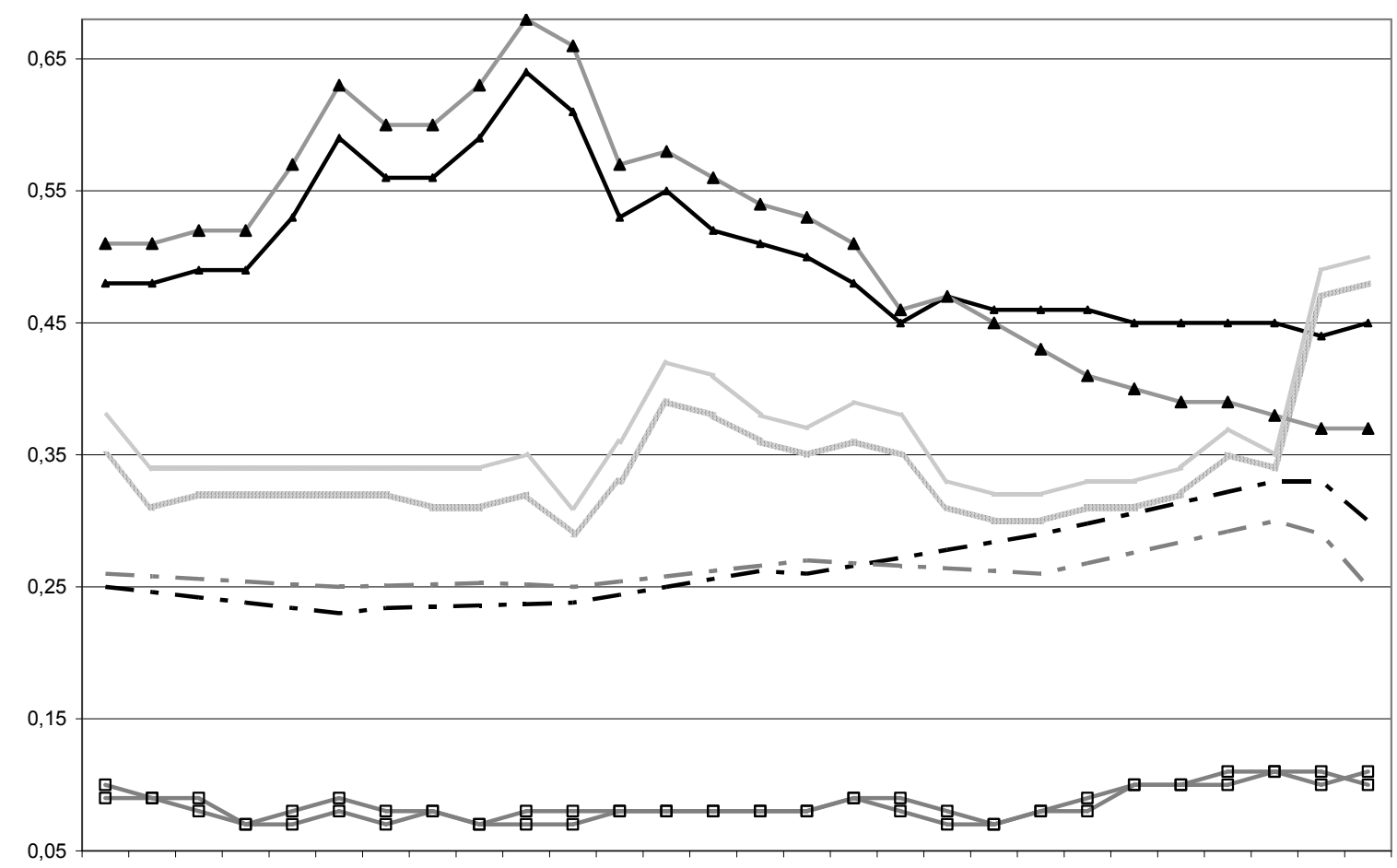

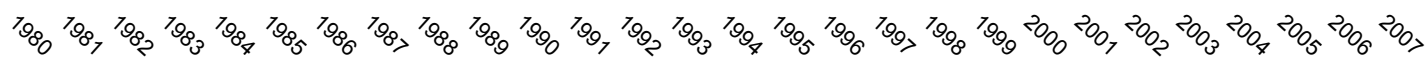



Figure C.A.3a: Distance index I.3 with and without (*) variable internet

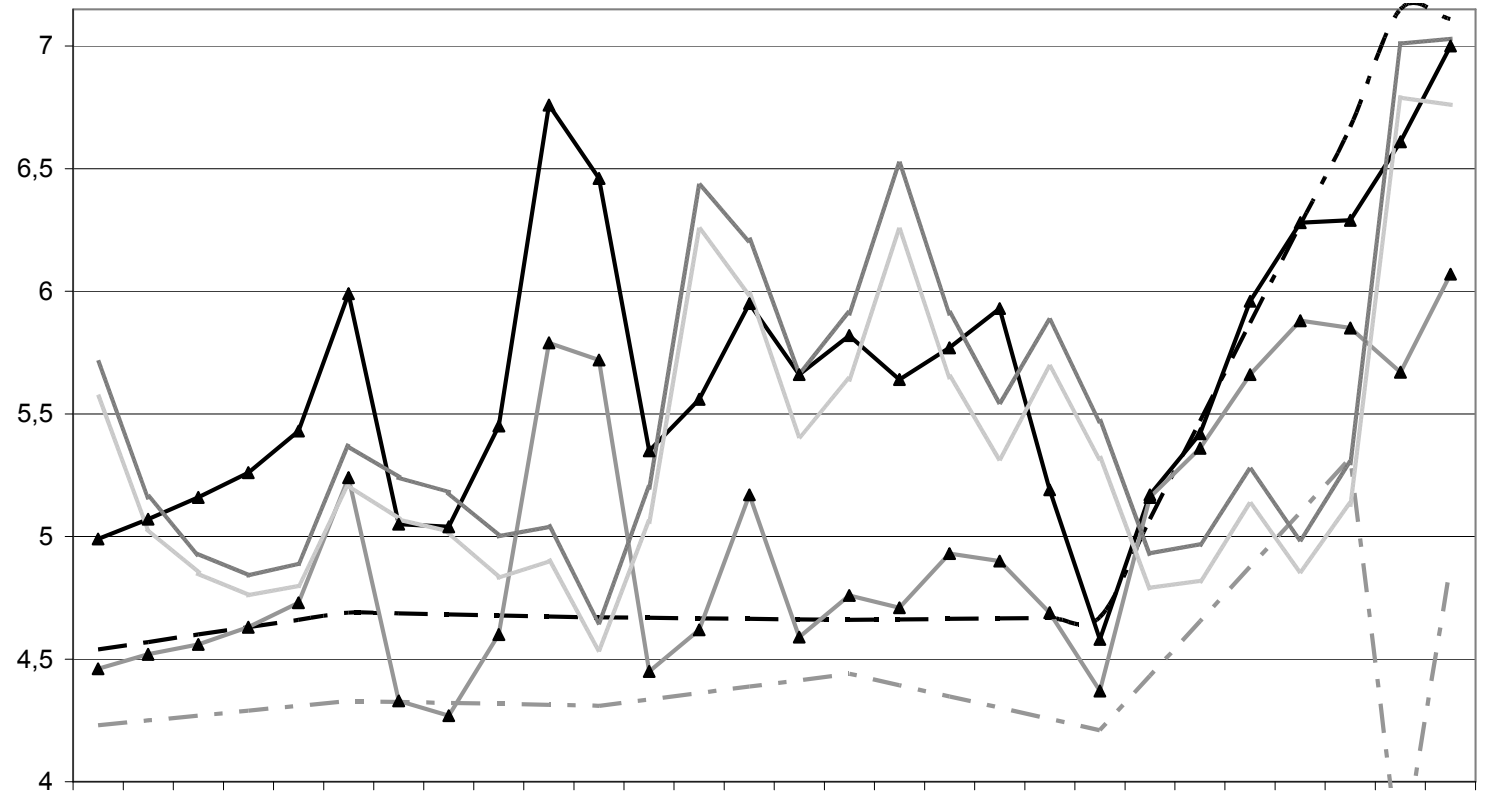

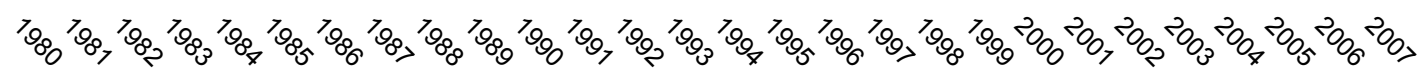

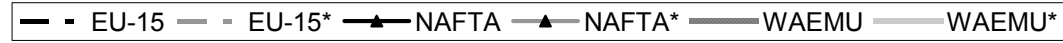


Figure C.A.3b: Distance index I.3 with and without (*) variable internet

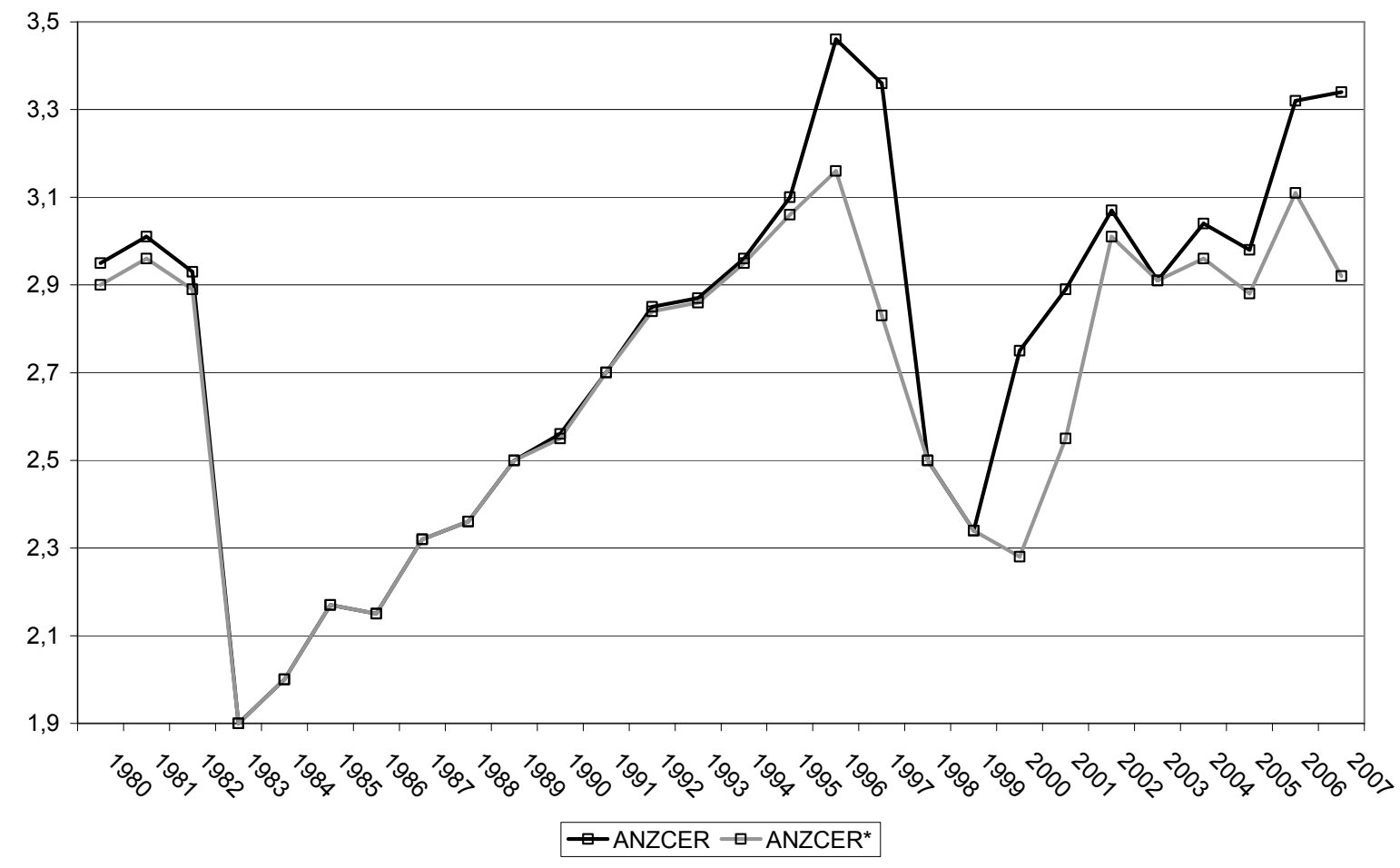

Figure C.A.4: Distance index I.1 with and without (*) variable internet

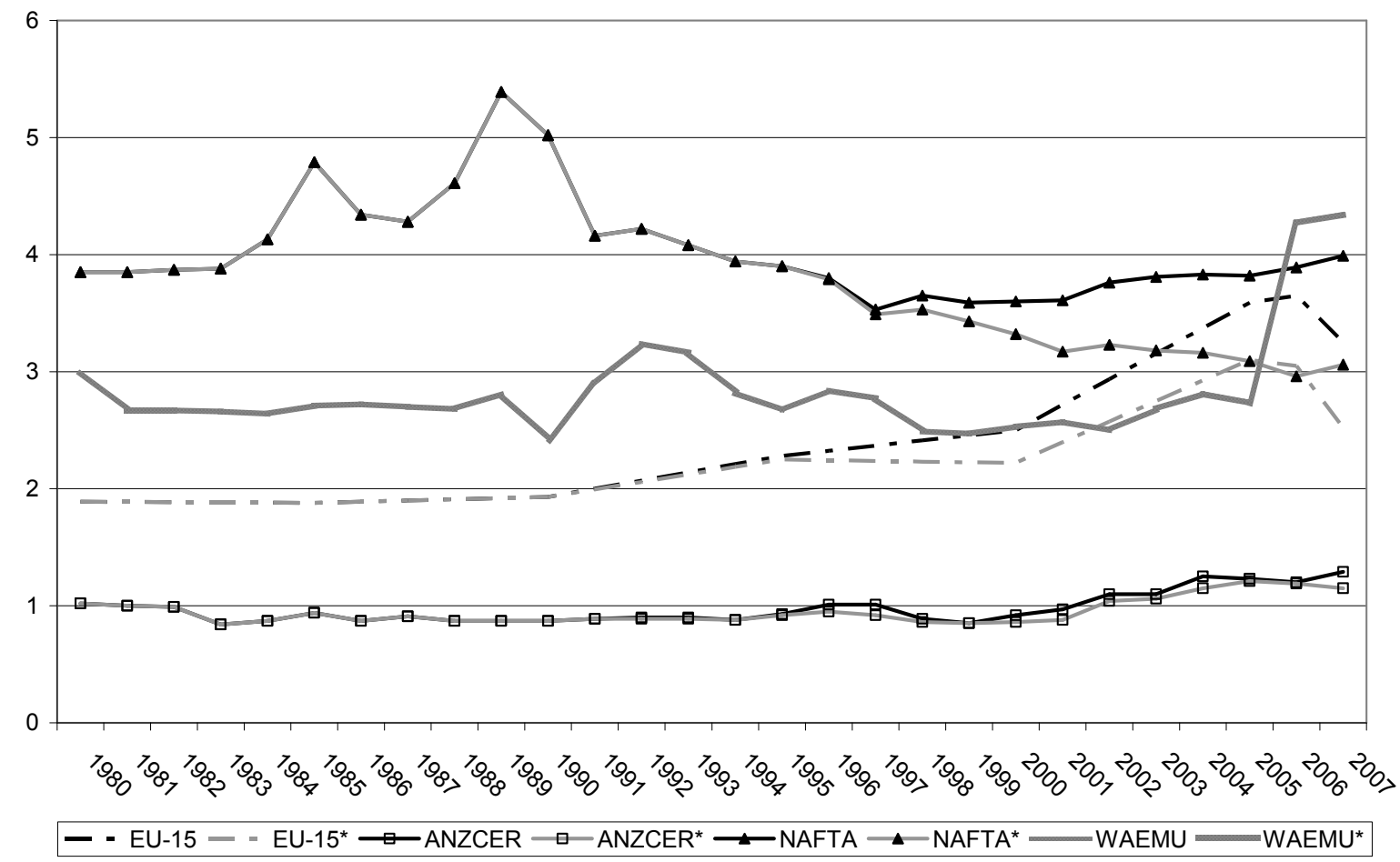




\section{Bibliography}

[1] Arellano, M. (2003): Panel Econometrics; Oxford University Press Inc., New York.

[2] Balassa, B. (1961): The theory of economic integration; R. Irwin, Homewood Illinois.

[3] Baldwin, R. E. (2004): Stepping stones or building blocs? Regional and multilateral integration; Graduate Institute of International Studies, Geneva.

[4] Baldwin, R. E., P. Martin and G. I. P. Ottaviano (2001): Global income divergence, trade, and industrialization: The geography of growth take-offs, Journal of Economic Growth; Vol. 6, pp. 5-37.

[5] Barro, R. J. (1991): Economic growth in a cross section of countries; The Quarterly Journal of Economics; Vol. 106:2, pp. 407-443.

[6] Barro, R. J. and J. W. Lee (1994): Losers and winners in economic growth; NBER working paper series, No. 4341.

[7] Barro, R. J. and K. Lee (2002): Education panel data set for 138 countries, NBER and http://www.cid.harvard.edu/ciddata/ciddata.html.

[8] Barro, R. J. and X. Sala-i-Martin (1992): Convergence; The Journal of Political Economy, Vol. 100-2: pp. 223-251.

[9] Barro, R. J. and X. Sala-i-Martin (1995): Capital mobility in neoclassical models of growth; American Economic Review; Vol. 85, pp. 103-115.

[10] Baumol, W. J. (1986): Productivity growth, convergence and welfare: What the longrun data show; The American Economic Review, Vol. 76-5: pp. 1072-1085.

[11] Belassa, B. (1961): The theory of economic integration; R. Irwin, Homewood Illinois.

[12] Ben-David, D. (1994): Convergence clubs and diverging economies; CEPR Discussion Paper No. 922, London.

[13] Bernard, A. B. and S. N. Durlauf (1995): Convergence in international output; Journal of Applied Econometrics, Vol. 10-2: pp. 97-108.

[14] Bhagwati, J., D. Greenaway and A. Panagariya (1998): Trading preferentially theory and policy; The Economic Journal; Vol. 108, pp. 1128-1148.

[15] Binder, M, C. Hsiao and M. H. Pesaran (2005): Estimation and inference in short panel vector autoregressions with unit roots and cointegration; Econometric Theory, Vol. 21: pp. 79.

[16] Blyde, J. S. (2005): Convergence in MERCOSUR, Working paper: Inter-American Development Bank. 
[17] Borrmann, Axel (1997): Interregionale Integration von Industrie- und Entwicklungsländern - Erfolgsbedingungen und Perspektiven; Working paper 45, HWWA Hamburg.

[18] Bulmer-Thomas, V. (2003): The economic history of Latin America since independence; University of Cambridge, Cambridge Latin America Studies, 2. Edition, pp. 5837.

[19] Camarero, M., R. G. Flôres and C. Tamarit (2003): Output convergence in MERCOSUR: Multivariate time series evidence; Economics Working Papers No. 510 (Ensaios Economicos da EPGE) from Graduate School of Economics, Getulio Vargas Foundation (Brazil).

[20] Caselli, F. , G. Esquivel and F. Lefort (1996): Reopening the convergence debate: A new look at cross-country growth empirics; Journal of Economic Growth, Vol. 1: pp. 363389.

[21] Cass, D. (1965): Optimum growth in an aggregative model of human capital; The Review of Economic Studies, Vol. 32-3: pp. 233-240.

[22] De la Fuente, A. and R. Domenech (2001): Schooling data, technological diffusion, and the neoclassical model; The American Economic Review, Vol. 91-2: pp. 323-327.

[23] De Lombaerde, P., G. Pietrangeli and C. Weeratunge (2006): System of indicators for monitoring regional integration processes: Where so we stand? United Nation University, CRIS Brugge.

[24] De Long, B. (1988): Productivity growth, convergence and welfare: Comment; The American Economic Review, Vol. 78-9: pp. 1138-1154.

[25] Dennis, D. J. and Z. A. Yusof (2003): Developing indicators of the ASEAN integration - A preliminary survey for a road map, REPSF-publications.

[26] Dreher, A. (2006): Does globalization affect growth? Evidence from a new index of globalization; Applied Economics; Vol. 38:10, pp. 1091-1110.

[27] Dorrucci E. S. Firpo, M. Fratscher and F. P. Mongelli (2002): European integration: What are lessons for other regions? A case of Latin America?, ECB Working Paper, No. 185. [28] Durlauf, S. N. (1996): Controversy on the convergence and divergence of growth rates; The Economic Journal, Vol. 106-437: pp. 1016-1018.

[29] Durlauf, S. N. and D. T. Quah (1999): The new empirics of growth; in: J. B. Taylor \& M. Woodford (ed.), Handbook of Macroeconomics, 1. Edition, Vol. 1: pp. 235-308.

[30] Durlauf, S.N.; P.A. Johnson and J. Temple (2005): Growth econometrics; in: O. Aghion \& S. Durlauf (eds.), Handbook of economic growth (pp. 555-677), Elsevier. 
[31] Duro, J. A. (2004): Regional income inequalities in Europe: An updated measurement and some decomposition results; preprint Universidad Autonoma de Barcelona.

[32] Ethier, W. J. (1998): The new regionalism; Economic Journal, Vol. 108, pp. 11491161.

[33] Feng, Y. and G. M. Genna (2003): Regional integration and domestic institutional homogeneity: A comparative analysis of regional integration in the Americas, Pacific Asia and Western Europe; Review of International Political Economy, Vol. 10/2, 278-309.

[34] Fielding, D. and K. Shields (2003): Economic integration in West Africa: Does the CFA make a difference?; Economica, Vol. 72: pp. 683-704.

[35] Galor, O. (1996): Convergence? Inferences from theoretical Models, The Economic Journal, Vol. 106: pp. 1056-1069.

[36] Genna, G. M. (2005): Measuring regional economic integration: The Integration achievement score; University of South Florida.

[37] Giannetti, M. (2002): The effects of integration on regional disparities: Convergence, divergence or both?; European Economic Review; Vol. 46-3: pp. 539-567.

[38] Goodfriend, M. and J. McDermott (1998): Industrial development and the convergence question, American Economic Review, Vol. 88: 5, pp. 1277-1289.

[39] Goretti, M. and H. Weisfeld (2008): Trade in the WAEMU: Development and trade opportunities; IMF Working Paper No. 68.

[40] Hammouda, H. B., S. N. Karingi, A. E. Njuguna, M. S. Jallab (2007): Why doesn't regional integration improve income convergence in Africa? Discussion Paper UNECA.

[41] Hodrick, R. J. and E. C. Prescott (1997): Post-war U.S. Business cycles: An empirical investigation; Journal of Money, Credit and Banking, Vol. 29:1 pp. 1-16-

[42] Hufbauer, G. C. and J. J. Schott (1994): Western hemisphere economic integration, Institute for International Economics, Washington.

[43] Islam, N. (1995): Growth empirics: A panel data approach; The Quarterly Journal of Economics, Vol. 110-4: pp. 1127-1170.

[44] Jones, B. (2002): Economic integration and convergence of per capita income in West Africa; African Development Bank.

[45] Khan, Sarah A. (1994): Nigeria: The political economy of oil; Oxford University Press.

[46] Kearney, A. T. (2002): The Carnegie endowment for international peace 2002,

Globalizations last hurrah; Foreign Policy; Januar/Februar, pp. 38-51. 
[47] Kearney, A. T. (2003): The Carnegie endowment for international peace 2003; Measuring globalization; Who's up; who's down?; Foreign Policy; Januar/Februar, pp. 6072.

[48] Khan, Sarah A. (1994): Nigeria: The political economy of oil; Oxford University Press. [49] Knight M., N. Loayza and D. Villanueva (1993): Testing the neoclassical theory of economic growth: A panel approach; IMF staff paper, Vol. 40:3, pp. 512-541.

[50] Koopmans, T. C. (1965): On the concept of optimal economic growth; Cowles Foundation for Research in Economics, Paper 238 - Yale University.

[51] Krugman, P. (1991a): Increasing returns and economic geography, Journal of Political Economy, Vol. 99, pp. 483-499.

[52] Krugman, P. (1991b): Geography and trade; Cambridge (Mass.) MIT Press.

[53] Krugman, P. and A. J. Venables (1996): Integration, specification and adjustment, European Economic Review Vol. 40, pp. 959-967.

[54] Lee, K. and M. H. Pesaran (1997): Growth and convergence in a multi-country empirical stochastic Solow model; Journal of Applied Econometrics, Vol. 12-4: pp. 357-392.

[55] Lee, K. M., H. Persaran and R. P. Smith (1997): Growth and convergence in a multicountry empirical stochastic Solow model; Journal of Applied Econometrics 12:4, pp. 357392.

[56] Lee, K., M. H. Pesaran and R. Smith (1998): Growth empirics: A panel data approach - A comment; The Quarterly Journal of Econometric, Vol. CXIII: pp. 319-323.

[57] Lim L. K. and M. McAleer (2004): Convergence and catching up in ASEAN: A comparative analysis; Applied Economics, Vol. 36: pp. 137-153.

[58] Loayza, N. V. (1994): A test of the international convergence hypothesis using panel data; World Bank Policy Research Working Paper 1333.

[59] Madariaga, N., S. Montout and P. Ollivaud (2003): Regional convergence, trade liberalization and agglomeration of activities: An analysis of NAFTA and MERCOSUR cases; Maison des Science Economiques, Paris.

[60] Mankiw, N. G., D. Romer and D. N. Weil (1992): A contribution to the empirics of economic growth; The Quarterly Journal of Economics, Vol. 107-2: pp. 407-437.

[61] McKinnon, R. I. (1963) Optimum currency areas; American Economic Review; Vol. 53, 717-725.

[62] Minot, N. and F. Goletti (1998): Export liberalization and household welfare: The case of rice in Vietnam; American Journal of Agricultural Economics, Vol. 80: 4, pp. 738-749. 
[63] Mundell, R.A. (1961) A Theory of optimal currency areas; American Economic Review; Vol. 51, 105-146.

[64] Nye, J. S. (1968): Comparative regional integration: Concept and measurement; International Organization; Vol. 22:4, pp. 855-880.

[65] Park, D. (2000): Is the Asia - Australasia region a convergence club? Asian Economic Journal, Vol. 14: pp. 421-443.

[66] Pritchett, L. (2001): Where has all the education gone?; The World Bank Economic Review, Vol. 15-3: pp. 367-391.

[67] Quah, D. T. (1993a): Empirical cross-section dynamics in economic growth; European Economic Review, Vol. 37, pp. 426-34.

[68] Quah, D. T. (1993b): Galton's fallacy and tests of the convergence hypothesis; The Scandinavian Journal of Economics; Vol. 95:4, pp. 427-443.

[69] Quah, D. T. (1995): Empirics of economic growth and convergence; LSE Economic Department London, Discussion Paper No. 253.

[70] Quah, D. T. (1996a): Twin peaks: growth and convergence in models of distribution dynamics, Economic Journal, Vol. 106:437, pp. 1045-55.

[71] Quah, D. T. (1996b): Empirics for economic growth and convergence, European Economic Review, Vol. 40:6, pp. 1353-75.

[72] Quah, D. T. (1996c): Convergence empirics across economies with (some) capital mobility, Journal of Economic Growth, Vol. 1:1, pp. 95-124.

[73] Quah, D. T. (1997): Empirics of growth and distribution: Stratification, polarization and convergence clubs; Journal of Economic Growth: Vol. 106, pp. 1045-1055.

[74] Rey, S. J. and M. V. Janikas (2005): Regional convergence, inequality and space; Journal of Economic Geography, Vol. 5, pp. 155-176.

[75] Ruiz Estrada, M. A. (2004): Global dimension of regional integration (GDRI) Model; FEA Working Paper No. 7.

[76] Sala-i-Martin, X. (1996a): The classical approach to convergence analysis; The Economic Journal, Vol. 106-437: pp. 1019-1036.

[77] Sala-i-Martin, X. (1996b): Regional cohesion: Evidence and theories of regional growth and convergence; European Economic Review Vol. 40, pp. 1325-1352.

[78] Scott, A. J. (2006a): Geography and Economy, Oxford University Press.

[79] Scott, A.J. (2006b): Entrepreneurship, innovation and industrial development: Geography and the creative field revisited; Small Business Economics, Vol. 26, pp. 1-26. 
[80] Shin, K. and Y. Wang (2003): Trade integration and business cycle synchronization in East Asia; KIEP Discussion Paper 574.

[81] Smulders, S. and T. van de Klundert (1996): North-South knowledge spillovers and competition: Convergence versus divergence; Journal of Development Economics; Vol. 50, pp. 213-232.

[82] Solow, R. M. (1956): A contribution to the theory of economic growth; The Quarterly Journal of Economics, Vol. 70:1, pp. 65-94.

[83] Solow, R. M. (1957): Technical change and the aggregate production function; The Review of Economics and Statistics, Vol. 39:3, pp. 312-320.

[84] Swan, T.W. (1956): Economic growth and capital accumulation; Economic Record, Vol. 32:2; pp. 334-361.

[85] Temple, J. R. W. (1998): Robustness tests of the augmented Solow model; Journal of Applied Econometrics; Vol. 13, pp. 361-375.

[86] Thorp, R. (1998): Progress, poverty and exclusion: An economic history of Latin America in the 20th century, Inter-American Development Bank Washington.

[87] Tsangaride, C. G. (2005): Growth empirics under model uncertainty: Is Africa different?; IMF Working Paper 05/18.

[88] UNECA 2004: Assessing regional integration in Africa; ECA Policy Research Report UN-ECA, Addis Ababa.

[89] Van Hoa T. (2003): Growth of Asian regional trade and income convergence: Evidence from ASEAN+3 based on Helpman-Krugman Hypothesis and flexible modelling approach; Economics Working Paper, University of Wollongong.

[90] Venables, A. J. (2003): Winners and losers from regional integration agreements; The Economic Journal; Vol. 113:490, pp. 747-767.

[91] Viner, J. (1950): The customs union issue, New York: Carnegie Endowment for International Peace Press, No. 10.

[92] Wane, A. A. (2004): Growth and convergence in WAEMU countries; IMF Working Paper 04/198.

[93] Young, A. T., M. J. Higgins and D. Levy (2007): Sigma convergence versus beta convergence: Evidence from U.S. county-level data; preprint University of Mississippi.

[94] Ziltener, Patrick (2003): Gibt es einen regionalen Integrationsprozess in Ostasien? MPIFG Diskussion Paper 02/3. 


\section{Versicherung an Eides Statt (\$14, Promotionsordung)}

Ich, Yvonne Sperlich, versichere an Eides Statt, dass ich die eingereichte Dissertation (Regional integration processes: Four studies about convergence, growth and monitoring tools) selbständig verfasst habe. Anderer als der von mir angegebenen Hilfsmittel und Schriften habe ich mich nicht bedient. Alle wörtlich oder sinngemäss den Schriften anderer Authorinnen und Authoren entnommenen Stellen habe ich kenntlich gemacht.

Göttingen, den 20.04.2010

gez. Yvonne Sperlich 
Dateiname: $\quad$ EbookSUB_Sperlich.doc

Verzeichnis: $\quad$ F: $\backslash$ Yvonne_trade

Vorlage:

Vorlagen $\backslash$ Normal.dot

C: $\mid$ Profile $\backslash$ ssperli.WSO_SSL.000\Anwendungsdaten $\backslash$ Microsoft $\backslash$

Titel:

Extended Abstract: Konvergenz Paper

Thema:

Autor:

Universität Göttingen

Stichwörter:

Kommentar:

Erstelldatum: $\quad 20.07 .20109: 43$

Änderung Nummer: 2

Letztes Speicherdatum: $\quad$ 20.07.2010 9:43

Zuletzt gespeichert von: ssperli

Letztes Druckdatum: 20.07.2010 9:44

Nach letztem vollständigen Druck

Anzahl Seiten: 138

Anzahl Wörter: 35.316 (ca.)

Anzahl Zeichen: 222.498 (ca.) 